\title{
Piezoelectric Materials for Controlling Electro-Chemical Processes
}

Cite as

Nano-Micro Lett.

(2020) 12:149

Received: 14 April 2020

Accepted: 15 June 2020

Published online: 14 July 2020

(C) The Author(s) 2020

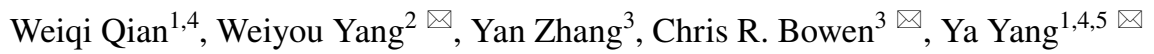 \\ $\triangle$ Weiyou Yang, weiyouyang@tsinghua.org.cn; Chris R. Bowen, C.R.Bowen@bath.ac.uk; Ya Yang, \\ yayang@binn.cas.cn \\ 1 CAS Center for Excellence in Nanoscience, Beijing Key Laboratory of Micro-nano Energy and Sensor, \\ Beijing Institute of Nanoenergy and Nanosystems, Chinese Academy of Sciences, Beijing 100083, \\ People's Republic of China \\ 2 Institute of Materials, Ningbo University of Technology, Ningbo 315211, People's Republic of China \\ 3 Department of Mechanical Engineering, University of Bath, Bath BA2 7AK, UK \\ 4 School of Nanoscience and Technology, University of Chinese Academy of Sciences, Beijing 100049, \\ People's Republic of China \\ 5 Center on Nanoenergy Research, School of Physical Science and Technology, Guangxi University, \\ Nanning 530004, People's Republic of China
}

\section{HIGHLIGHTS}

- This review focuses on recent development of the piezo-electro-chemical coupling multiple systems based on various piezoelectric materials.

- Comparison of operating conditions and their electro-chemical performance is provided.

- Challenges, potential future directions, and applications for the development of piezo-electro-chemical hybrid systems are described.

\begin{abstract}
Piezoelectric materials have been analyzed for over 100 years, due to their ability to convert mechanical vibrations into electric charge or electric fields into a mechanical strain for sensor, energy harvesting, and actuator applications. A more recent development is the coupling of piezoelectricity and electro-chemistry, termed piezo-electro-chemistry, whereby the piezoelectrically induced electric charge or voltage under a mechanical stress can influence electro-chemical reactions. There is growing interest in such coupled systems, with a corresponding growth in the number of associated publications and patents. This review focuses on recent development of the piezo-electro-chemical coupling multiple systems based on various piezoelectric materials. It provides an overview of the basic characteristics of piezoelectric materials and comparison of operating conditions and their overall electro-chemical performance. The reported piezo-electro-chemical mechanisms are examined in detail. Comparisons are made between the ranges of material morphologies employed, and typical operating conditions are discussed. In addition, potential

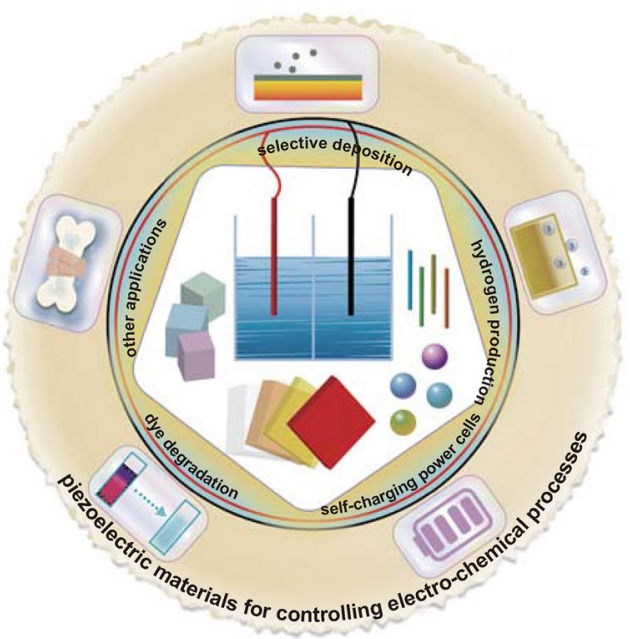
future directions and applications for the development of piezo-electro-chemical hybrid systems are described. This review provides a comprehensive overview of recent studies on how piezoelectric materials and devices have been applied to control electro-chemical processes, with an aim to inspire and direct future efforts in this emerging research field.
\end{abstract}

KEYWORDS Piezoelectric materials; Piezoelectric effect; Electro-chemistry; Piezo-electro-chemistry 


\section{Introduction}

Piezoelectricity was first discovered by P. Cure and J. Curie in 1880 based on their observations of the production of an electrical charge when specific materials were subjected to a mechanical force [1]. The term 'piezoelectricity' originates from 'piezo' and 'electricity,' where 'piezo' represents the application of a pressure and 'electricity' corresponds to moving electrons [2]. Materials that exhibit piezoelectricity are termed piezoelectric materials, which generate an electric charge in response to applied stress (the direct piezoelectric effect), and develop a mechanical strain when subjected to an applied electric field (the converse piezoelectric effect) [3-7].

The origin of piezoelectricity is related to a non-centrosymmetric distribution of positive and negative electric charges in the unit cell of a material $[8,9]$. When a piezoelectric material is subjected to an applied stress or mechanical vibration, the induced displacement of ions results in a net electric charge due to a change in the dipole moment of the unit cell, which builds a piezoelectric potential across the material [10,11]. Generally, among the 21 crystal point groups of non-centrosymmetric crystals, there are 20 point groups of crystals possessing piezoelectricity, where 10 point groups belong to nonpolar crystals which show piezoelectricity and the other 10 point groups of polar crystals exhibit piezoelectricity and ferroelectricity $[8,9]$. Piezoelectric materials belonging to nonpolar crystals which are non-ferroelectric can have no electric net dipole in the zero-stress state and only generate an electric dipole under stress due to the separation of electric charge centers and a resulting induced piezoelectric potential; a good example of such a material is quartz [12-18]. There are also piezoelectric materials belonging to polar crystals that exhibit a spontaneous polarization in the zero-stress state or no electric field state since there is a separation between positive and negative charges [19, 20]. A good example of such a material is zinc oxide. A subclass of piezoelectric materials are ferroelectric materials belonging to polar crystals, whose spontaneous polarization can be changed permanently and switched when exposed to an external strong electric field, for example, in barium titanate [21, 22]. Since the polarization of a ferroelectric changes with stress, all ferroelectric materials exhibit piezoelectricity by default $[11,23,24]$.

Irrespective of the mechanism by which polarization is induced, whether spontaneously or mechanically, the induced electric field across material affects its electrical properties dramatically on the interior and the exterior regions of the material, where the built-in electric field can disrupt electronic energy states, and electric charges are rearranged $[25,26]$. If the outside surface of the material is in contact with a medium, the rearrangement of electric charges can alter the electric conductivity, which is highly dependent on the density of electric charge as well as the continuity of the occupiable electronic energy states between the material and the medium [27]. We will see in the review that this process can have a particularly strong influence on electro-chemistry.

Typically, an electro-chemical reaction is driven by an external power source [28-30], and the coupling of power generation with electro-chemical process remains a vibrant topic. Large-scale renewable and clean power generation approaches are being considered that store solar and wind energy and subsequently convert it into electrical power for driving electro-chemistry [31-34]. However, smaller-scale and more local energy, such as mechanical energy in the range of microwatt to milliwatt, can be harvested and utilized by systems based on piezoelectric materials [19, 35]. In recent decades, piezoelectrically induced electric fields have been used to control catalytic rates in chemical solutions [36-38], the corrosion rate of metals in etchant solutions [39-43], self-charging systems [44-50], and a variety of other electro-chemical processes [51-53]. The coupling of piezoelectricity and electro-chemistry is termed piezoelectro-chemistry, where a piezoelectrically induced electric charge or potential difference generated by a mechanical stress can influence electro-chemical reaction systems [54-56].

There are a variety of excellent reviews on electrochemistry $[19,57-64]$, but those that specifically focus on piezoelectrically influenced electro-chemical reactions have received limited attention to date. This review places a focus on the range of piezoelectric materials used for 
controlling electro-chemical processes. It will provide an overview of the basic characteristics of piezoelectric materials and comparison of the operating conditions and electro-chemical performance. The reported piezoelectro-chemical mechanisms will then be examined in detail. Within this review, we have collected virtually all published research work to date on the use of piezoelectric materials for controlling electro-chemistry; this body of work is summarized in Table 1 which contains detailed information regarding the specific piezoelectric materials, along with the electro-chemical processes and performance. In addition, the piezo-electro-chemical reaction systems to be covered within this review include materials that are in bulk [65, 66], fiber [67-69], sheet [70, 71], flower [37, 72, 73], particle [74, 75], and irregular [32, 76] form. The piezoelectric materials include ferroelectric perovskites [77, 78], wurtzite zinc oxide [79, 80], twodimensional layered transition metal dichalcogenide-based materials [81, 82], organic piezoelectric materials [44, 83, 84], and biological materials [85] that are used for a variety of applications such as selective deposition [38, 77, 86], hydrogen production [32, 65, 69], dye degradation [73, 76, 87-89], self-charging power cells [44, 45, 49, 83], and others $[47,90]$. The above-mentioned piezo-electrochemical reactions are shown schematically in Fig. 1, and the intention of this review is to overview recent studies on piezoelectric materials and devices that have been applied to control electro-chemical processes and inspire increasing efforts in this new and emerging research field.

\section{Mechanism of Piezoelectric Controlled Electro-chemistry}

\subsection{Fundamental Electro-chemical Mechanism}

The piezo-electro-chemical processes, which involve the coupling of piezoelectricity and electro-chemistry, are chemical reactions driven by piezoelectrically induced electric charge and voltage. The fundamental quantitative relationships in electro-chemistry can be concluded as the well-known law of 'Faraday's laws of electrolysis,' published by Faraday in 1834 [91]. During a typical electrochemical reaction, the mass of produced material $(m)$ is related to the total transferred electric charge $(Q)$, which can be summarized by:
$m=\frac{Q M}{F z}$

where $M$ and $z$, related to specific materials, represent the molar mass of the substance in grams per mol and the valence number of ions of the substance (individual electric charges transferred per ion), respectively. In addition, $F$ is known as the Faraday constant with a fixed value of $96,485.3 \mathrm{C} \mathrm{mol}^{-1}$. For a specific electro-chemical reaction system, it can be seen that $M, F$, and $z$ are constant, so that the larger the value of $Q$ the larger the mass of produced material, $m$.

For piezo-electro-chemistry, the magnitude of $Q$ is primarily a response to the charge output of the specific piezoelectric materials as a result of a change in polarization under a mechanical load. The material factors for output will be discussed in the following section.

\subsection{Piezoelectric Material Factors}

Piezoelectric material factors that influence the value of $Q$ can be firstly related to aspects of the most suitable structure, since materials of the same nature and different structures have a far-reaching effect on the transfer of electric charges or ions. A range of structures have been suggested as a piezo-separator for self-charging power cells. For example, the migration rate of lithium ions can be evaluated by an important parameter, the ionic conductivity, and this materials parameter in the solid state refers to the ease of ion motion in a crystal lattice. Porous nanostructured PVDF films have shown higher ionic conductivity compared to a quasi-bulk film, and the reported explanation of this phenomenon is that the pores can act as a pathway for $\mathrm{Li}$ ions to move across the piezo-separator solid [83, 84]. Additionally, porous structures are beneficial for a higher intake of electrolyte solution to facilitate the migration of lithium ions. Therefore, the design of piezoelectric material structures should take account of the influence in the transfer of ions and electric charges.

In addition, in order to ensure efficient ion or electric charge transfer to surrounding atoms/molecules that participate in electro-chemical oxidation-reduction processes, the selected material requires an enhancement of the specific surface area and reactivity [91]. On varying the shape and size, especially at the smaller scale, Li et al. observed a peak shift and an intensity change of the peaks for Raman spectra of ferroelectric BFO materials due to 


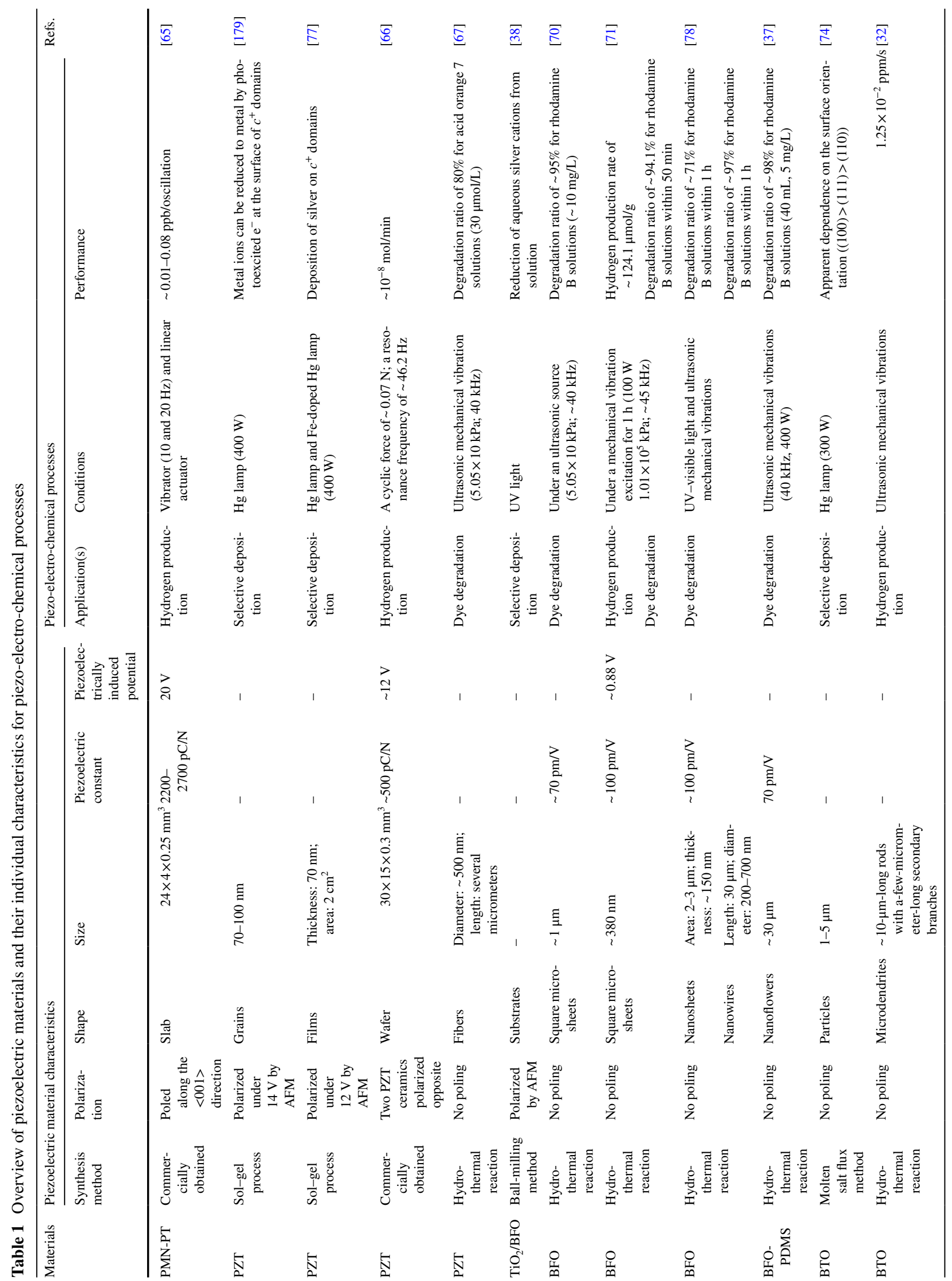




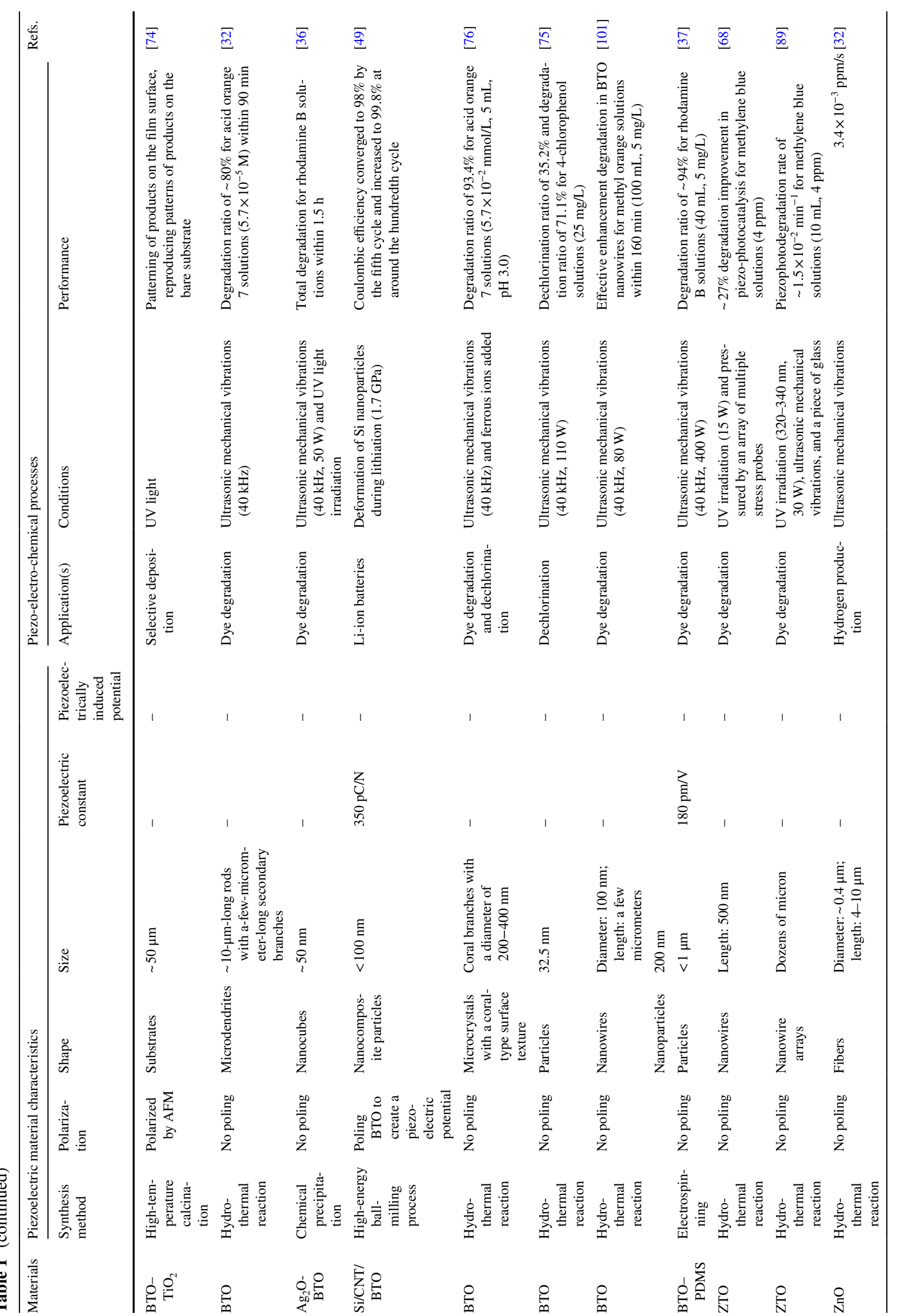




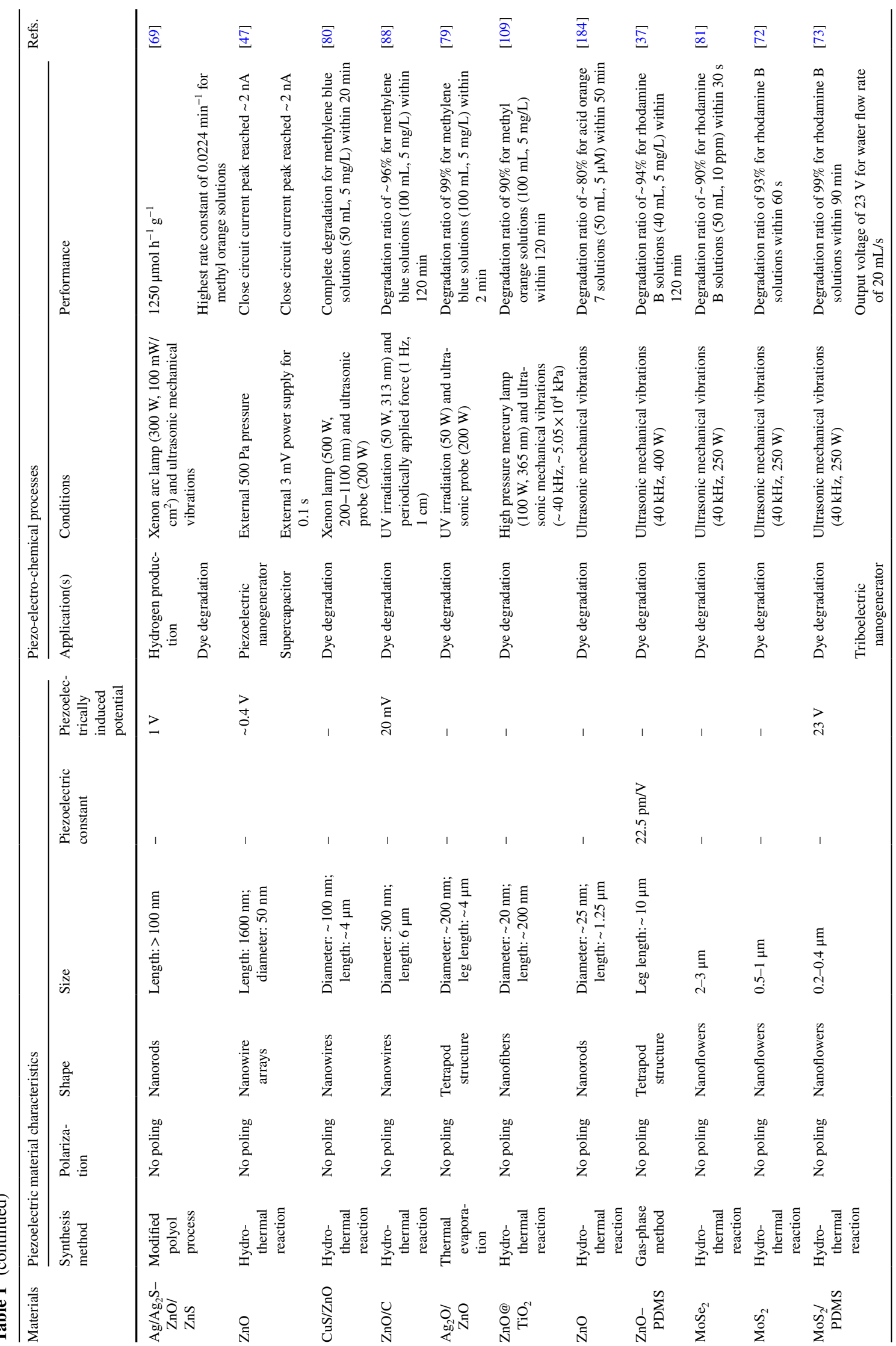




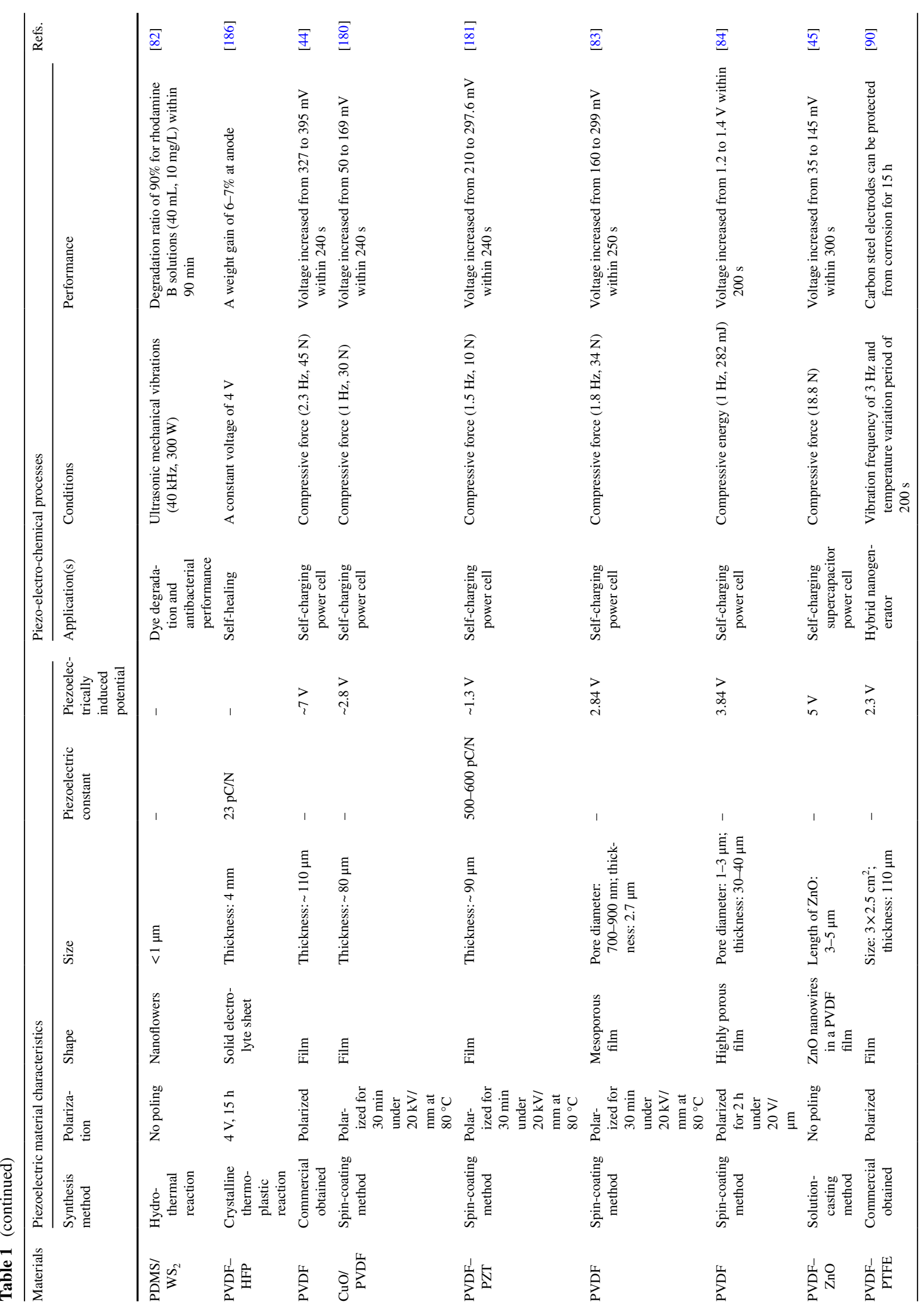




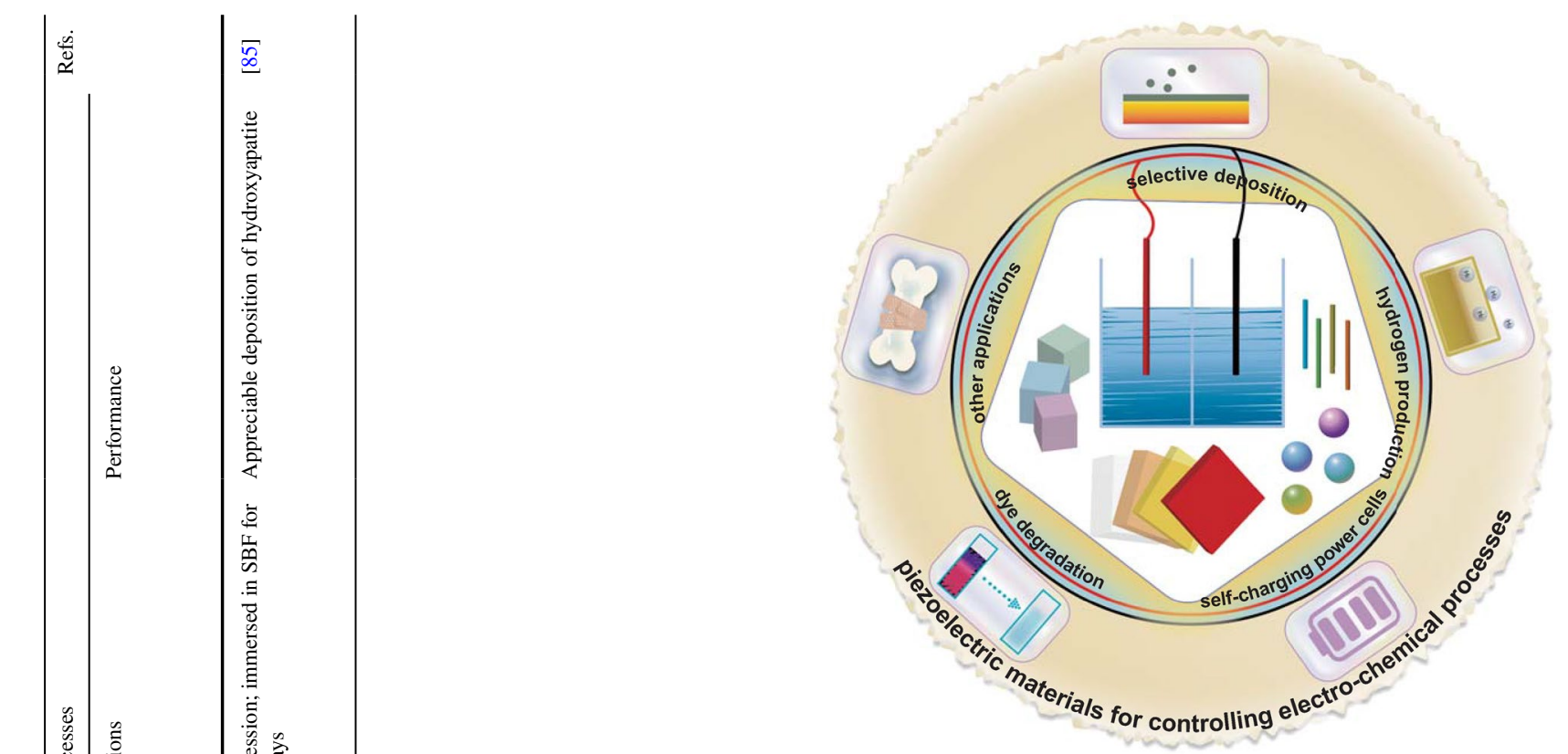

Fig. 1 Piezo-electro-chemical reaction systems to be covered in the review with various materials and practical applications

changed spin-phonon coupling and lattice distortions [92], and a shift in absorption edge for UV-Vis absorption spectra of differing BFO samples which depended on varying crystal field intensity [93]. Thus, the optical absorption properties of materials can be strongly influenced by variations in the crystal structure including shape and size and play a significant role in electro-chemical reactions affected by light illumination; the influence of illumination on a piezo-electro-chemical reaction system will be discussed in the following section. In all, there are a variety of shape- and size-controlled physical/chemical factors that are related to mass transfer, contact area, bonding interactions as well as local crystal structure change, where factors mentioned here are generally issues of morphology, and more piezoelectric-related details will be described in the following paragraphs.

The practical output performance of piezoelectric materials closely relates to piezoelectricity, a linear electromechanical coupling, which can be considered as the following equation:

$P_{i}=d_{i j k} \sigma_{j k}$

where $P_{i}, d_{i j k}$, and $\sigma_{j k}$ represent the polarization vector, the piezoelectric third-rank tensor, and the stress tensor, 
respectively [94]. The piezoelectric third-rank tensor $d_{i j k}$ comprises a piezoelectric matrix with typical values dependent on the specific crystalline structure. During a typical piezo-electro-chemical process, the piezoelectrically induced open-circuit voltage $\left(V_{i}\right)$ follows the rule of piezoelectricity [27]:

$V i=\frac{d_{i j k} \sigma_{j k} w}{\varepsilon_{0} \varepsilon_{r}}$

where $w$ is the material size, $\varepsilon_{0}$-is the vacuum permittivity, and $\varepsilon_{\mathrm{r}}$ is the relative permittivity. In addition, $d_{i j k}$ is always considered as the piezoelectric charge sensitivity coefficient or piezoelectric constant in the $\mathrm{pC} / \mathrm{N}$ or $\mathrm{pm} / \mathrm{V}$ range $[95$, 96]. On the basis of Eqs. (2) and (3), the piezoelectrically induced output depends on the piezoelectric constant, the permittivity, the size, and the applied stress for a typical material.

The loading stress for a specific material can be related to the shape of the material [78, 97-99]. A larger and easier level of deformation can be achieved in piezoelectric materials with a higher aspect ratio, which induces a higher electrical charge generation [100]. Therefore, the piezoelectric output of materials in one or two dimensions such as nanofibers (nanowires or nanorods) and nanoflowers is often larger than the equal-size spherical particles', because of the nature of its large and easy deformation [67, 97]. Taking issues of material shape and size into consideration, the piezoelectric potential distribution of nanowires and nanoparticles was simulated via a finite element method with COMSOL multiphysics software, as shown in Fig. 2 [101]. Individual BTO nanowires oriented along the $z$-axis are strained by a point-applied lateral force, faceapplied axial compression, and face-applied lateral pressure in Fig. 2a-c. For contrast, a BTO nanoparticle with a quadrilateral shape indicates the piezoelectric potential is proportional to the applied pressure and the size of nanoparticle, as in Eq. (3). When the applied pressure is $10^{8} \mathrm{~Pa}$, BTO nanowire and nanoparticle of the same size of $100 \mathrm{~nm}$ exhibit distinctly different voltage outputs: $11.2 \mathrm{~V}$ for the nanowire and only $1.1 \mathrm{~V}$ for a nanoparticle due to higher and easier deformation of the nanowire. These simulation results are consistent with the actual phenomena of observations, where the practical degradation rate constant $k$ is in the order: $k_{\text {nanowire }}>k_{\text {nanoparticle }}$ [101].
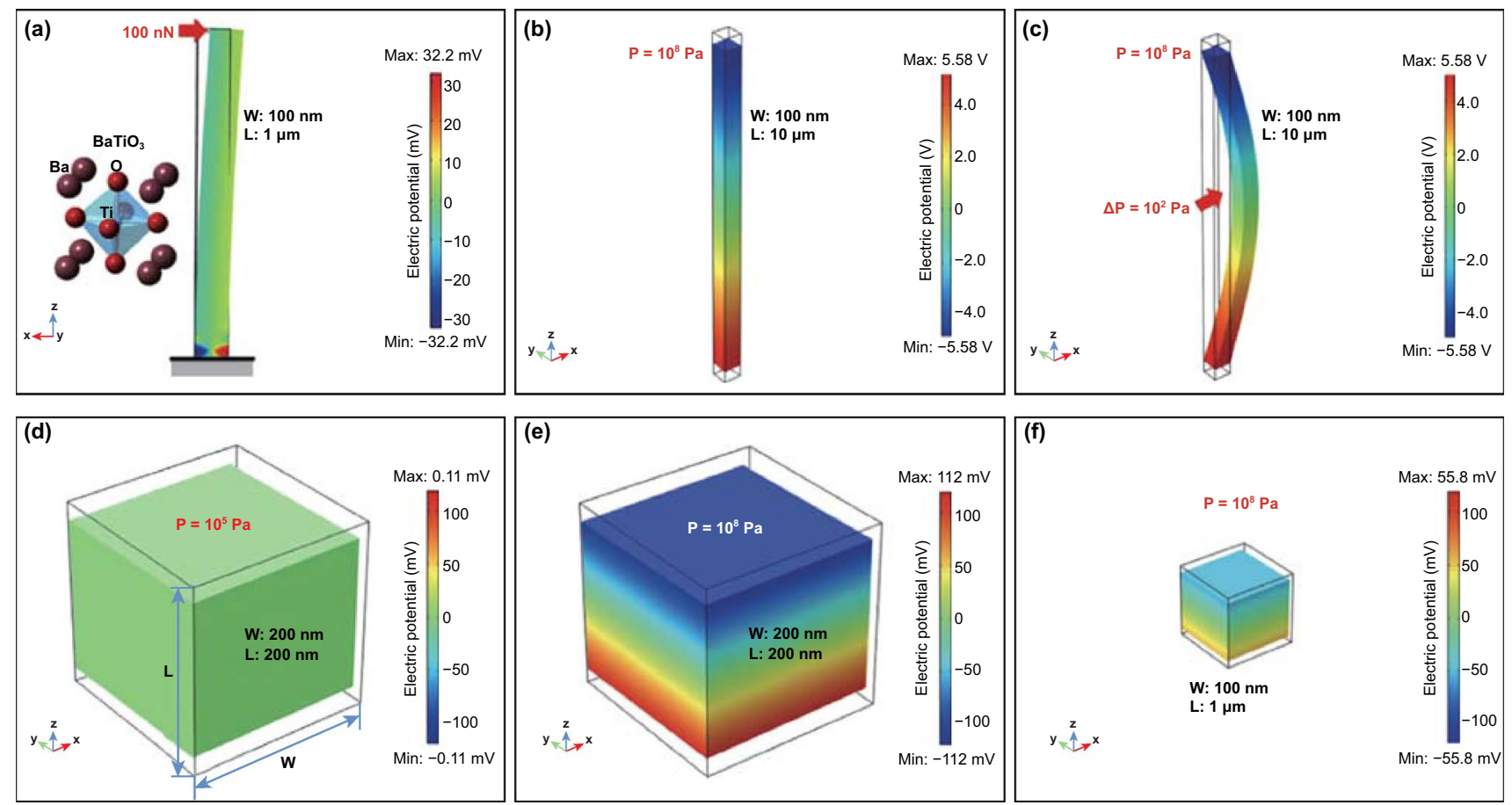

Fig. 2 a A BTO nanowire with a diameter of $100 \mathrm{~nm}$ and a length of $1 \mu \mathrm{m}$ stressed on the top by a lateral force with $100 \mathrm{nN}$ where the bottom side is grounded and fixed. b A BTO nanowire under an axial compression with the pressure of $10^{8} \mathrm{~Pa}$. c A BTO nanowire stressed at middle part under a lateral deformation with the pressure of $10^{8} \mathrm{~Pa}$. A BTO nanoparticle with a size of $200 \mathrm{~nm}$ under the pressure of $\mathbf{d} 10^{5} \mathrm{~Pa}$ and $\mathbf{e}$ $10^{8} \mathrm{~Pa}$. f A BTO nanoparticle with a size of $100 \mathrm{~nm}$ under the pressure of $10^{8} \mathrm{~Pa}$. Reproduced with permission [101]. Copyright 2018, Elsevier 
In addition, the loading stress created by external forces or mechanical vibrations can induce a forced oscillation of the material. When an oscillating force is applied at the resonant frequency of a material/structure, it will oscillate at a higher amplitude compared to non-resonant frequencies, where a resonant frequency is in harmonic proportion to a natural frequency of material. Therefore, a larger deformation can be achieved in materials forced at its resonant frequency. A variation in the geometry, size, crystalline structure, and atomic composition can influence the fundamental mechanical properties of materials. Here, we consider materials under an elastic deformation, which obey the rule of resonance, as follows [102]:

$f^{r}=\frac{x}{2 l} \sqrt{\frac{E}{\rho}}$.

Equation (4) describes the resonance frequency $\left(f^{r}\right)$ of a typical rod vibrated longitudinally, where $l, E$, and $\rho$ are the length, Young's modulus, and density of the rod material, respectively. In addition, $E$ is one of mechanical properties that define the relationship between stress and strain.

$f^{r}=\frac{11.2 x^{2}}{\pi l^{2}} \sqrt{\frac{E I}{\rho S}}$.

Equation (5) is based on the same rod material vibrated by a lateral oscillation, where $I$ and $S$ represent the axial moment of inertia and cross-sectional area, respectively.

$f^{r}=\frac{\pi H}{2}\left[\left(\frac{x}{a}\right)^{2}+\left(\frac{y}{b}\right)^{2}\right] \sqrt{\frac{E}{12 \rho\left(1-\sigma^{2}\right)}}$.

Equation (6) provides the value of $f^{r}$ that is dependent on a rectangular sheet with a thickness of $H$ and an area size of $a \times b$, where $\sigma$ is Poisson's ratio that equals to the negative of the ratio of transverse strain to axial strain. For the resonance equations above, when the values of both $x=y=1$, the resonance frequency $f^{r}$ is the first-order resonance frequency, which can be considered as the natural frequency of the material.

According to Eqs. (4)-(6), the dependence of the resonant frequency on its vibration mode, geometry, size, and fundamental mechanical properties can be determined. A variety of piezoelectric materials show a different response to an applied mechanical force or vibration, ranging from low frequency to high frequency, so that the selection and design of piezoelectric materials or related hybrid systems can be optimized to match practical applications with a specific frequency band spectrum. As reported, the use of hydrothermally synthesized BFO square sheets for piezoelectro-chemical hydrogen production exhibits an enhanced production rate when subjected to mechanical vibrations at a frequency near their natural frequency $(\sim 45 \mathrm{kHz})$ compared to other frequencies [71]. For further practical applications, oceans provide a wide range of vibration energy sources with a frequency band ranging in 10 to $500 \mathrm{~Hz}$ for seismic exploration and commercial shipping, $500 \mathrm{~Hz}$ to $500 \mathrm{kHz}$ for small vessel sonar, and sea-surface agitation, and $>25 \mathrm{kHz}$ for thermal noise [103-107].

In this section, we have discussed the dependence of piezoelectric materials characteristics on the output performance, where the shape, size, and mechanical properties have been taken into detailed consideration. We now discuss the charge transfer mechanism for piezo-electro-chemical and piezo-photo-electro-chemical processes.

\subsection{Charge Carrier Separation and Transfer}

In addition to the geometry, size, and mechanical properties of the piezoelectric materials affecting the piezoelectric output, the applied experimental conditions are also of importance for piezo-electro-chemical processes. To induce piezoelectricity, mechanical vibrations with a specific orientation and amplitude can affect the emergence of electric carriers $[19,108]$. In addition, illumination by light leads to excited photo-electro-chemical reactions in piezoelectric materials that are affected by the built-in piezoelectric potential of the material [38, 109].

During a typical piezo-electro-chemical reaction, the charge transfer mechanism can be described by the following. When there is no externally applied mechanical force on the piezoelectric material, it remains at equilibrium, with occupiable electronic states and the surface energy bands in quasi-static states. When subjected to only mechanical vibrations, piezoelectricity leads to a change of polarization, which can develop a piezoelectrically induced electric field across the piezoelectric, thereby leading to electric charge carriers reorienting across different ends of the material. Consequently, both the occupiable electronic states and the surface energy bands are affected by the accumulation of these electric charges on the different sides of the material 
$[110,111]$. Of particular note is that the temperature of the reaction system must be over $0 \mathrm{~K}$; as a result, separated electron-hole pairs in such a piezoelectric semiconductor can be thermally activated. The above-mentioned occupiable electronic states and bending energy bands guide the thermally activated separated electron-hole pairs to the surface of the material, which can participate in oxidation and reduction reaction to generate active species for electro-chemical processes [37]. When the accumulated electric charges on the material surface counteract the built-in electric field, the system returns to an equilibrium level. The reverse change

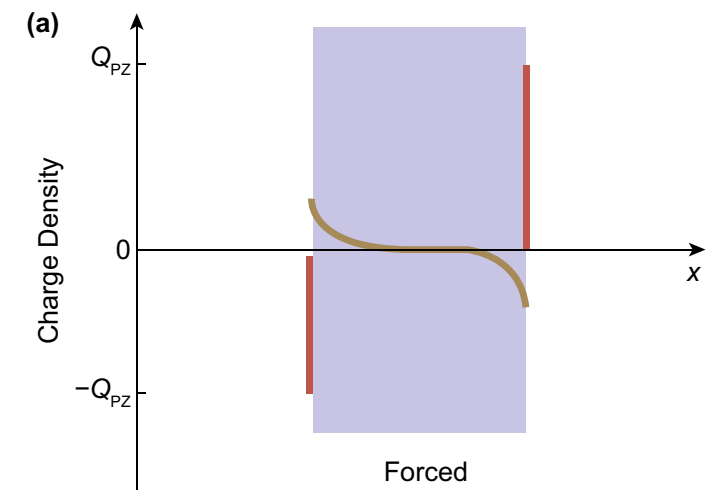

(b)

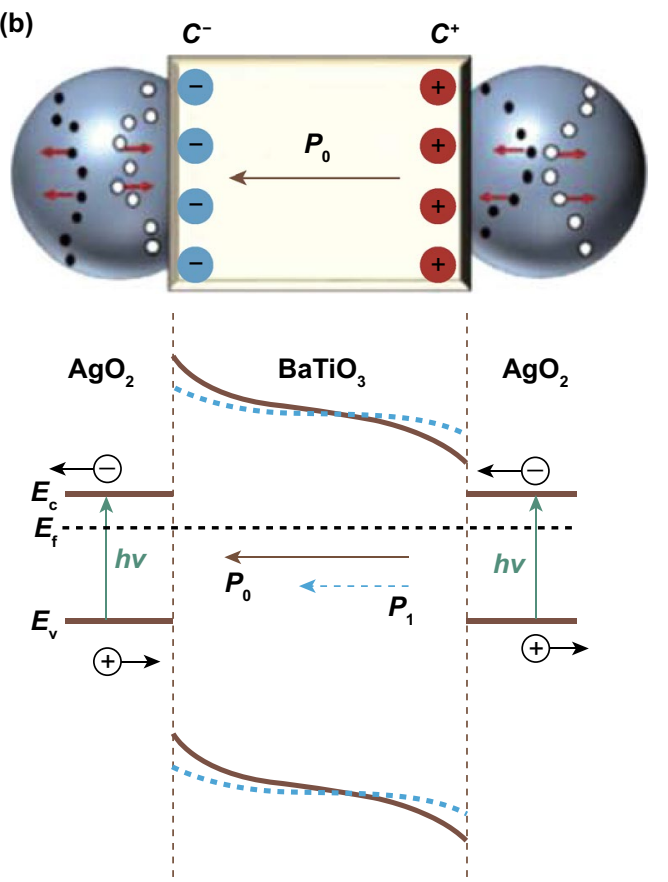

of polarization results in reverse accumulation of electric charges and reverse transfer of electron-hole pairs.

A schematic of this piezoelectrically induced charge transfer mechanism is shown in Fig. 3a, which is a system that is stimulated by mechanical vibration only [37]. The variation of the orientation and magnitude of polarization electric field across the material depends on the material type (ferroelectric or piezoelectric), and the force as a function of time since both varying the direction of vibration and mechanical intensity can influence the polarization field. Starr and Wang have pointed out the difference between the

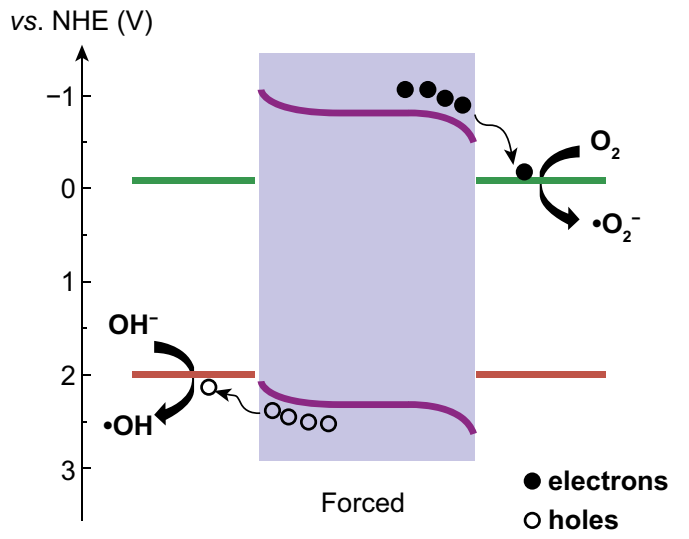

(c) Applied Bias $=0$

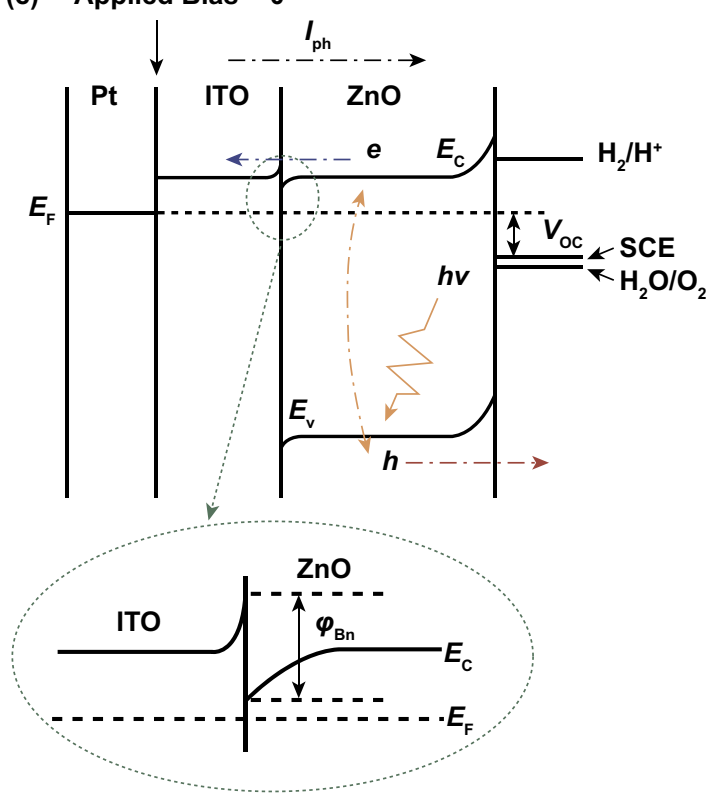

Fig. 3 a Schematic of the piezo-catalytic effect in BTO-PDMS. Reproduced with permission [37]. Copyright 2019, American Chemical Society. b Schematic of charge carrier separation and transfer in $\mathrm{Ag}_{2} \mathrm{O}$ nanoparticles attached to two opposite surfaces of a BTO nanocube. Reproduced with permission [36]. Copyright 2015, American Chemical Society. c Schematic illustration of the band lineup of the entire PEC system. Reproduced with permission [116]. Copyright 2011, American Chemical Society 
three subcategories of materials in terms of their polarization and electric dipoles [3]. In the absence of strain, ferroelectric materials exhibit a spontaneous polarization, where positive and negative electric charge centers exhibit no superposition, giving rise to resultant electric dipoles along the material, while piezoelectric materials without ferroelectricity such as quartz exhibit a zero internal dipole. However, upon the application of a strain both polarization orientation and magnitude can be varied for piezoelectric materials, since there is a separation between the positive and negative electric charge centers, where the polarization orientation is related to the direction of applied force in general.

For individual photo-electro-chemical process in a semiconductor, as is well known, the absorption activity is determined by the band gap, which is relevant to the electronic energy states [112]. For a typical semiconductor with a direct band gap which is suitable for the separation of electron-hole pairs, the general absorption coefficient near the band edge obeys the Tauc equation [93, 113]:

$\alpha h v=A\left(h v-E_{\mathrm{g}}\right)^{1 / 2}$

where $\alpha, h, \nu, A$, and $E_{\mathrm{g}}$ are the absorption coefficient, Planck's constant, irradiation frequency, proportionality constant, and energy band gap, respectively. According to Eq. (7), the adsorption activity is relevant to irradiated light and the material's $E_{\mathrm{g}}$. Generally, irradiated light sources with a different wavelength and intensity throughout the reaction can be controlled precisely; however, the value of $E_{\mathrm{g}}$ is also related to changing spin-phonon coupling and lattice distortions which is influenced by shape and size. A high absorption coefficient is preferred for optical absorption during the photo-electro-chemical reaction and demands that the optical absorption of a material's characteristic wavelength corresponds to the value of $E_{\mathrm{g}}$ within in the solar spectrum. In addition, the selection of material's $E_{\mathrm{g}}$ should also take the challenge of charge separation into consideration.

In order to achieve efficient photo-electro-chemical reactions, research effort has been focused on impurity doping, increasing the reaction temperature, and the construction of heterojunction structures to restrain the recombination of photo-generated electron-hole pairs [114, 115]. When piezoelectric materials participate in photo-electro-chemical reactions, the piezoelectric polarization acts as an adjustment for the barrier height of the semiconductor at the interface, where electronic energy states can be influenced strongly. Two examples of electric charge transfer mechanism for the hybrid piezo-photo-electro-chemistry system are now described. One example is based on $\mathrm{Ag}_{2} \mathrm{O}-\mathrm{BTO}$ hybrid nanostructures, where a schematic of the charge carrier transfer mechanism is shown in Fig. 3b [36]. To summarize the $\mathrm{Ag}_{2} \mathrm{O}-\mathrm{BTO}$ hybrid system in brief, the $\mathrm{Ag}_{2} \mathrm{O}$ acts as a semiconductor to produce photo-generated carriers, while the ferroelectric polarization of BTO accelerates the separation of electron-hole pairs. Under dark conditions, there are limited electron and hole electric carriers in the $\mathrm{Ag}_{2} \mathrm{O}$. When excited by photons, charge carriers generated in the $\mathrm{Ag}_{2} \mathrm{O}$ nanoparticles are attached on two sides of the BTO nanocube; however, electrons and holes often exhibit high rates of recombination. An electric field is built across BTO along its spontaneous polarization orientation, which provides a driving force for attracting electrons and holes moving to opposite sides, thereby reducing recombination. The separation of electron-hole pairs continues until all of the piezoelectric polarization charges are fully screened. When subjected to a compressive stress, the polarization potential is diminished, indicating the screened charges can be released, which is a fast discharge process. Subsequently, the recovery of deformation reconstructs the balance between the screened charges and the built-in field, which is a recharging process.

Another example is based on a ITO/ZnO heterojunction structure, where both ITO and $\mathrm{ZnO}$ are n-type semiconductors, but the free charge carrier concentration of $\mathrm{ZnO}$ is much lower [116]. Figure $3 c$ demonstrates the band lineup of the photo-electro-chemical reaction system under no illumination or external bias. At the interface between ITO and $\mathrm{ZnO}$, a Schottky barrier-like $\mathrm{n}-\mathrm{n}$ junction is formed with a small barrier $\left(\varphi_{\mathrm{Bn}}\right)$ due to the larger work function of $\mathrm{ZnO}$. In addition, the depletion region near the $\mathrm{ZnO}$ is much wider than that near ITO since the free charge carrier concentration of $\mathrm{ZnO}$ is much lower than ITO. When subjected to illumination, photo-generated separated electron-hole pairs move through the interface between $\mathrm{ZnO}$ and ITO and eventually reach the electrode and electrolyte to participate in electro-chemical oxidation-reduction reactions. Therefore, the heterojunction barrier $\varphi_{\mathrm{Bn}}$ between piezoelectric semiconductor and electrode becomes a significant obstacle for charge transfer. Additionally, when a piezoelectric semiconductor $\mathrm{ZnO}$ is subjected to a tensile strain, the energy bands near the electrolyte increase, where the valence band (VB) is closer to the oxidation potential $\left(E_{\mathrm{Ox}}\right)$. Thus, holes are sufficiently active to drive the oxidation process, and electrons on the conductor band (CB) drift to the ITO side due to the 
increase of the energy band near the electrolyte interface. Meanwhile, the energy bands of $\mathrm{ZnO}$ decrease near the ITO region, and $\varphi_{\mathrm{Bn}}$ decreases as a result that can benefit charge transfer. When the piezoelectric semiconductor $\mathrm{ZnO}$ is subjected to a compressive strain, the energy bands near the interface of $\mathrm{ZnO}$ and ITO increase, while those near the interface of $\mathrm{ZnO}$ and electrolyte decrease. As a result, there is an increase in $\varphi_{\mathrm{Bn}}$, so that the separation and transfer of the photo-generated electric charge carriers show a further restrain, which prevents the progress of the electro-chemical reactions.

\subsection{Electro-chemical Processes in Specific Applications}

In the previous section, we have discussed electro-chemical processes controlled by piezoelectricity. A detailed description and contrast in mechanisms for specific applications will be provided in this section. As mentioned in Sect. 2.1, electro-chemical processes for practical applications obey Faraday's law of electrolysis. The premise of whether or not a redox reaction can occur is the relationship between the induced piezoelectric output and the oxidation-reduction potentials of the target products. The possible electrochemical equations in detail for a variety of applications are given in Table 2.

For selective deposition, the characteristic oxidation-reduction potentials of a variety of metal salts lead to various electro-chemical reactions occurring on opposite facets of the piezoelectric particles. Typical selective deposition reactions take place on the surface of piezoelectric BTO in $\mathrm{AgNO}_{3}$ and $\mathrm{Pb}\left(\mathrm{C}_{2} \mathrm{H}_{3} \mathrm{O}_{2}\right)$ aqueous solutions, where the chemical equations are illustrated as follows [77]:

$\mathrm{Ag}^{+}+\mathrm{e}^{-} \rightarrow \mathrm{Ag}$

$\mathrm{Pb}^{2+}+2 \mathrm{H}_{2} \mathrm{O}+2 \mathrm{~h}^{+} \rightarrow \mathrm{PbO}_{2}+4 \mathrm{H}^{+}$.

For piezo-electro-chemical hydrogen evolution, different piezoelectric materials generate a specific voltage when subjected to applied force, and piezoelectric materials can theoretically drive electro-chemical hydrogen production when the piezoelectrically induced potential exceeds the oxidation potential of hydrogen ions $(1.23 \mathrm{~V})$, where the fundamental electro-chemical reactions of hydrogen production are as follows [69]:
Table 2 Reported electro-chemical reactions in a variety of piezoelectric applications

\begin{tabular}{ll}
\hline $\begin{array}{l}\text { Piezo-electro-chemical applica- } \\
\text { tions }\end{array}$ & Electro-chemical reactions \\
\hline Selective deposition & $\mathrm{Ag}^{+}+\mathrm{e}^{-} \rightarrow \mathrm{Ag}$ \\
& $\mathrm{Sn}^{2+}+2 \mathrm{e}^{-} \rightarrow \mathrm{Sn}$ \\
& $\mathrm{H}_{2} \mathrm{O}+2 \mathrm{~h}^{+} \rightarrow 1 / 2 \mathrm{O}_{2}+2 \mathrm{H}^{+}$ \\
& $\mathrm{Al}^{3+}+3 \mathrm{e}^{-} \rightarrow \mathrm{Al}$ \\
& $\mathrm{Zn}^{2+}+2 \mathrm{e}^{-} \rightarrow \mathrm{Zn}$ \\
& $\mathrm{Pb}^{2+}+2 \mathrm{H}_{2} \mathrm{O}+2 \mathrm{~h}^{+} \rightarrow \mathrm{PbO}_{2}+4 \mathrm{H}^{+}$ \\
& $\mathrm{PbO}^{+} 2 \mathrm{~h}^{+} \rightarrow \mathrm{Pb}^{2+}+1 / 2 \mathrm{O}_{2}$ \\
& $\mathrm{PbO}_{2}+2 \mathrm{~h}^{+} \rightarrow \mathrm{Pb}^{2+}+\mathrm{O}_{2}$ \\
& $3 \mathrm{NO}_{3}^{-}+4 \mathrm{H}^{+}+2 \mathrm{e}^{-} \rightarrow \mathrm{N}_{2} \mathrm{O}_{4}+2 \mathrm{H}_{2} \mathrm{O}$ \\
& $\mathrm{NO}_{3}^{-}+4 \mathrm{H}^{+}+3 \mathrm{e}^{-} \rightarrow \mathrm{NO}^{-} 2 \mathrm{H}_{2} \mathrm{O}$ \\
& $2 \mathrm{Cl}^{-}+2 \mathrm{~h}^{+} \rightarrow \mathrm{Cl}_{2}(\mathrm{~g})$ \\
& $\mathrm{Cl}^{-}+4 \mathrm{H}_{2} \mathrm{O}+8 \mathrm{~h}^{+} \rightarrow \mathrm{ClO}_{4}+8 \mathrm{H}^{+}$ \\
& $\mathrm{Cl}^{-}+\mathrm{H}_{2} \mathrm{O}+2 \mathrm{~h}^{+} \rightarrow \mathrm{HClO}^{+} \mathrm{H}^{+}$ \\
& $\mathrm{Cl}^{-}+2 \mathrm{H}_{2} \mathrm{O}+4 \mathrm{~h}^{+} \rightarrow \mathrm{HClO}_{2}+3 \mathrm{H}^{+}$ \\
& $\mathrm{Fe}^{2+}+2 \mathrm{e}^{-} \rightarrow \mathrm{Fe}^{-}$ \\
& $2 \mathrm{H}^{+}+2 \mathrm{e}^{-} \rightarrow \mathrm{H}_{2}$ \\
& $\mathrm{H}_{2} \mathrm{O}+2 \mathrm{~h}^{+} \rightarrow 2 \mathrm{H}^{+}+1 / 2 \mathrm{O}_{2}$ \\
& $\mathrm{e}^{-}+\mathrm{O}_{2} \rightarrow \cdot \mathrm{O}_{2}^{-}$ \\
& $\mathrm{h}^{+}+\mathrm{OH}^{-} \rightarrow \cdot \mathrm{OH}$ \\
& $\mathrm{LiCoO}_{2} \rightarrow \mathrm{Li}_{1-x} \mathrm{CoO}_{2}+x \mathrm{Li}^{+}+x \mathrm{e}^{-}$ \\
& $\mathrm{TiO}_{2}+x \mathrm{Li}^{+}+x \mathrm{e}^{-} \rightarrow \mathrm{Li}_{x} \mathrm{TiO}_{2}$ \\
\hline Hydrogen production & \\
\hline &
\end{tabular}

$2 \mathrm{H}^{+}+2 \mathrm{e}^{-} \rightarrow \mathrm{H}_{2}$

$\mathrm{H}_{2} \mathrm{O}+2 \mathrm{~h}^{+} \rightarrow 2 \mathrm{H}^{+}+1 / 2 \mathrm{O}_{2}$.

Here, the mass of produced hydrogen and oxygen is in proportion to the amount of generated electric charge, and a large amount of hydrogen production is preferred, where of great significance is the long lifetime of negative charges actively for hydrogen generation. In order to decrease the recombination of piezoelectrically induced charges and extend the lifetime of negative charges, sodium sulfite $\left(\mathrm{Na}_{2} \mathrm{SO}_{3}\right)$ is a common sacrificial agent which can scavenge positive charges effectively [117]. For piezo-electrochemical dye degradation, the generation of active radicals is suggested as the necessary species for further decomposing organic dye molecules, such as superoxide $\left(\cdot \mathrm{O}_{2}^{-}\right)$ and hydroxyl $(\cdot \mathrm{OH})$ radicals [118-120]. Brief procedures for piezo-electro-chemical wastewater treatment can be expressed by the following [69]:

$\mathrm{e}^{-}+\mathrm{O}_{2} \rightarrow \cdot \mathrm{O}_{2}^{-}$ 
$\mathrm{h}^{+}+\mathrm{OH}^{-} \rightarrow \cdot \mathrm{OH}$

$\cdot \mathrm{O}_{2}^{-}+\cdot \mathrm{OH}+$ dye $\rightarrow$ degradation products.

The degradation products generally include 2-naphthol, 2-hydroxy-1,4-naphthoquinone, and smaller aromatic intermediates $[87,121-123]$.
The electro-chemical processes in self-charging power cells exhibit a more complex behavior, which can be generally divided into several steps for charging reactions driven by a cyclic compressive strain. If we take a typical self-charging power cell device as an example, as shown in Fig. 4, when the power cell device is subjected to compressive strain, the piezoelectric PVDF separator builds

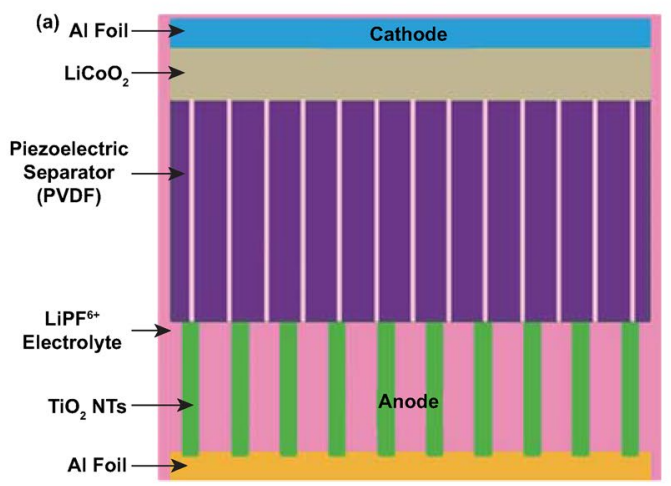

(b)
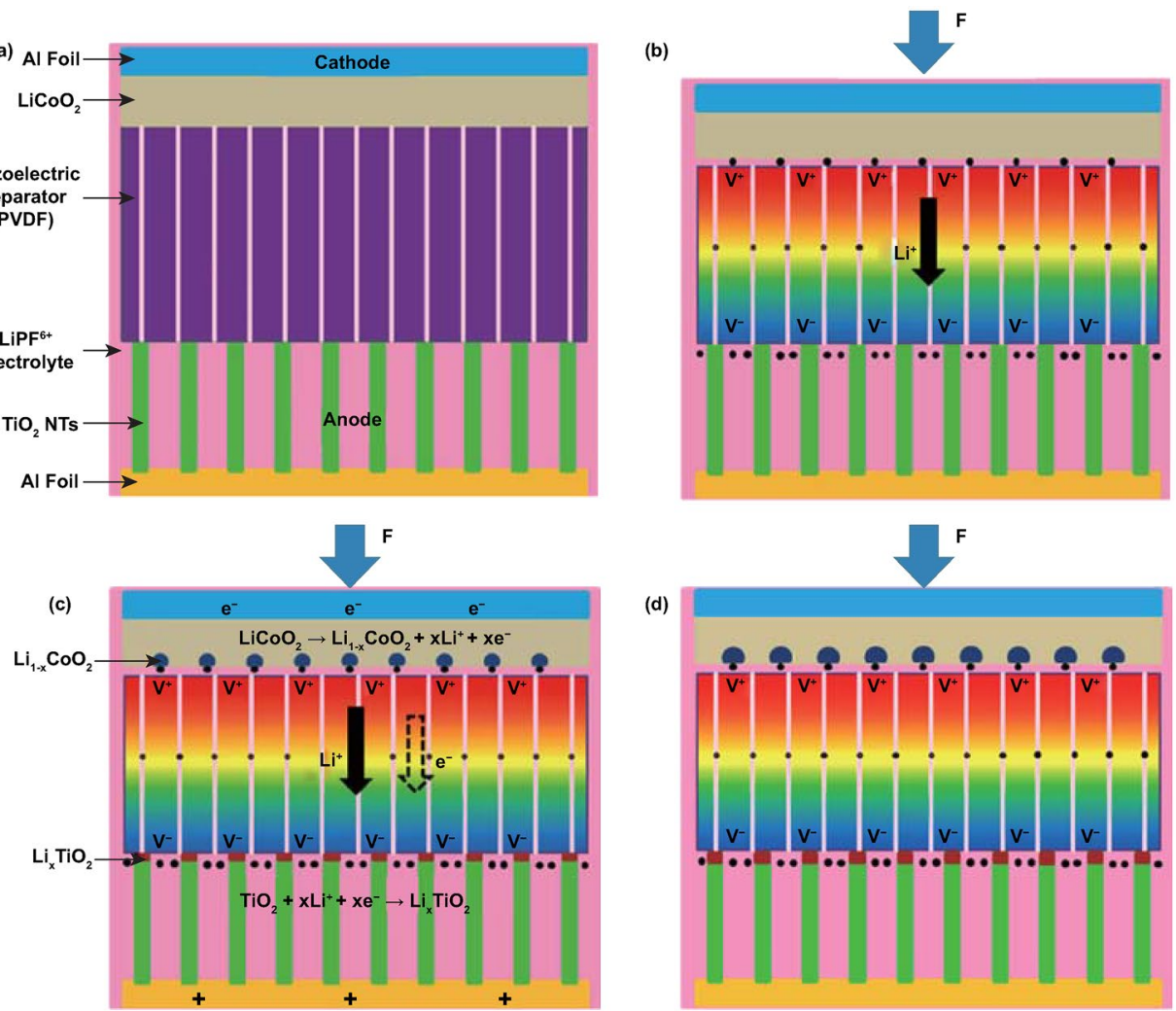

(e)

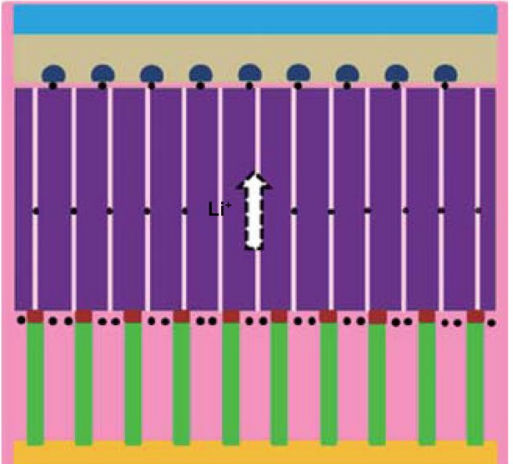

(f)

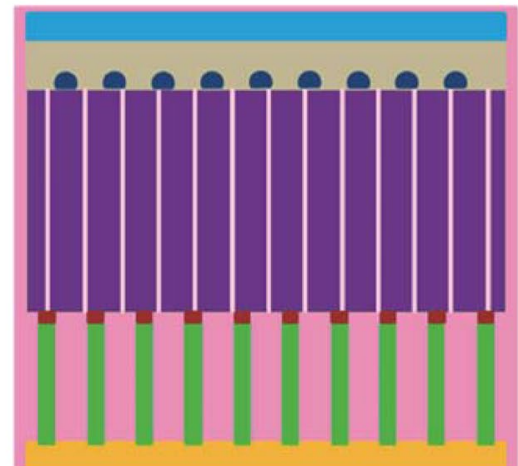

Fig. 4 a Schematic of the self-charging power cell in discharged state. b Under compressed stress, piezoelectric PVDF film can create a potential. c Under the piezoelectric field, Li ions are driven to migrate from the cathode toward the anode, which leads to the corresponding charging reactions at the electrodes. d Chemical equilibrium is rebuilt in the self-charging power cell. e When the compressive stress is released, the piezoelectric field across the piezo-separator disappears; in the meanwhile, the Li ions diffuse to the cathode side. $\mathbf{f}$ New chemical equilibrium is reached, and one typical cycle of self-charging reaction is accomplished. Reproduced with permission [44]. Copyright 2012, American Chemical Society 
positive and negative potentials at the cathode and anode sides, respectively. Li ions from the cathode move across the piezo-separator film driven by the built-in piezoelectric field. This process can be considered as the charging reactions for the special lithium-ion battery, where the electrochemical oxidation-reduction reactions occur at the cathode and anode sides as follows [44]:

$\mathrm{LiCoO}_{2} \rightarrow \mathrm{Li}_{1-x} \mathrm{CoO}_{2}+x \mathrm{Li}^{+}+x \mathrm{e}^{-}$

$\mathrm{TiO}_{2}+x \mathrm{Li}^{+}+x \mathrm{e}^{-} \rightarrow \mathrm{Li}_{x} \mathrm{TiO}_{2}$.

Meanwhile, free positive and negative charges dissipate, respectively, at the cathode and anode sides, until an electrostatic equilibrium status is rebuilt. When the compressive strain is released, partial Li ions diffuse back to the cathode, and the as-mentioned electro-chemical reactions process to the inverse sides. Thus, when a cyclic compressive strain is applied, the power cell can realize intermittent self-charging cycles. From the perspective of a chemical reaction, the greatest difference of self-charging power cells with other electro-chemical systems is that the reactions can be controlled to react toward the inverse directions when subjected to appropriate conditions.

In Sect. 2, we overview the reported mechanisms of coupling piezoelectric and electro-chemical effects. In the following section, specific piezoelectric materials applied in electro-chemical processes will be described in detail.

\section{Piezoelectric Materials in Electro-chemical Processes}

Since Jaffe discovered lead zirconate titanate ferroelectric ceramics in 1954 [124], lead-based piezoelectric materials including ceramics as well as single crystals have been fabricated that operate in a wide variety of transducer devices (SONAR, sensors, and actuators) and occupied an essential place in functional materials for the following three decades as a result of their high performance and stable piezoelectric properties. More recently, these materials have been used as particles for the hydrogen evolution reaction and wastewater treatment in electro-chemical applications [125-129]. However, these lead-based piezoelectric materials contain the element $\mathrm{Pb}$, which is one of the major heavy metal pollutants and can endanger human health [130-133]. Leadfree piezoelectric materials are being examined intensively as a green initiative [134-137], and due to the need for environmental protection and socially sustainable materials, research related to alternative lead-free materials has become a significant research activity in recent decades [130, 138, 139]. The general piezoelectric/ferroelectric perovskites $\left(\mathrm{ABO}_{3}\right.$-type) [140, 141], in particular barium titanate [142-145] and bismuth ferrite [146-149], have been utilized to process functional advanced devices [150-153]. In addition to $\mathrm{ABO}_{3}$-type ferroelectric materials, wurtzite and non-ferroelectric zinc oxide materials have been considered as advanced piezoelectric materials and have been prepared in a variety of dimensions and morphologies to convert mechanical vibration energy into electric charge for a range of applications $[18,25,47,69,154-156]$. During the last 10 years, remarkable piezoelectric properties have been observed in two-dimensional (2D) layered transition metal dichalcogenide-based materials with single-layered and odd-layered structures [72, 82, 157, 158], such as molybdenum disulfide [159-162], tungsten disulfide [163, 164] and molybdenum diselenide [165-169], which have received worldwide scientific attention for electronic device applications and nanoscale electromechanical systems. The piezoelectric effect in 2D layered materials is a consequence of the non-centrosymmetry of monolayers [72, 157, 158]. In addition to inorganic piezoelectric materials, organic piezoelectric materials such as polyvinylidene fluoride possess the ability to convert mechanical stress into electricity, and represent the most widely available piezoelectric polymer in functional materials and devices due to their physical characteristics of transparency and mechanical flexibility [45, 84, 90, 170-175]. In addition, specific biomaterials, such as collagen, exhibit piezoelectric properties which have been linked to the promotion of healing and reconstruction, due to the polar uniaxial orientation of molecular dipoles in the structure [10, 85, 176-178].

Above all, typical piezoelectric materials can be divided into groups of piezoelectric/ferroelectric perovskites [140-149], wurtzite zinc oxide materials [18, 27, 50, 72, 157-159], layered transition metal dichalcogenide piezoelectric materials [72, 82, 157-169], organic piezoelectric materials [45, 84, 90, 170-175], and piezoelectric biomaterials [10, 88, 179-181]. For piezo-electro-chemical processes, researchers have fabricated both single-component $[76,81]$ and polynary systems $[49,74,90]$, and piezoelectric nano-/micro-/bulk materials with a variety of shapes, sizes, and piezoelectric constants using a variety of approaches. 
Depending on the preparation method, the material size spans the nanoscale to macroscale and the synthesis methods include hydrothermal reactions [47, 75], sol-gel processes [77, 179], ball-milling methods [38, 49], high-temperature calcination [74], chemical precipitation [36], electrospinning [37], thermal evaporation [79], spin-coating [180, 181] and bioactive extraction [85]. Bulk polycrystalline ferroelectric materials require poling to exhibit a remnant polarization and piezoelectricity; however, a number of microscale and nanoscale materials formed by bottom-up manufacturing, whose sub-crystal grows along certain crystallographic face, exhibit piezoelectric effects without undergoing a poling process $[182,183]$.

Piezoelectric coefficient aside, each of materials with different morphologies has respective advantages. Piezoelectric materials with high aspect ratio are preferred to obtain optimum deformation under a mechanical load, which can realize a high piezoelectric output. In general, materials in fiber and sheet form possessing high aspect ratio are beneficial to induce high piezoelectric output. Besides, some morphologies such as flower and nanostructured surface own high specific surface area, which makes large contact area between piezoelectric materials and solution medium, and piezo-electro-chemical performance can be improved. In addition, bulk and particle materials have advantages in material preparation.

The range of materials used to control electro-chemical reactions is now discussed in detail.

\subsection{Piezoelectric/Ferroelectric Perovskites Morphologies}

Piezoelectric $\mathrm{Pb}\left(\mathrm{Mg}_{1 / 3} \mathrm{Nb}_{2 / 3}\right) \mathrm{O}_{3}-32 \mathrm{PbTiO}_{3}(\mathrm{PMN}-\mathrm{PT})$ single-crystal slab with the size of $24 \mathrm{~mm} \times 4 \mathrm{~mm} \times 0.25 \mathrm{~mm}$ has been used to form a piezoelectric cantilever and achieves excellent piezo-electro-chemical hydrogen production [65]. Sol-gel processed lead zirconate titanate (PZT) has been fabricated as particles with an average size in the range of $70-100 \mathrm{~nm}$ and films of $70 \mathrm{~nm}$ in thickness for selective deposition investigations of the photochemical reaction with a variety of metal salts, and the influence of $\mathrm{Zr} / \mathrm{Ti}$ ratio on the preferential growth of Ag onto their surfaces [77, 179]. Hydrothermally synthesized piezoelectric PZT fibers have been fabricated which achieved an excellent acid orange 7 dye degradation under the application of ultrasonic vibrations [67]. As shown in Fig. 5a, the as-prepared PZT fibers are several micrometers in length and $500 \mathrm{~nm}$ in diameter [67]. You et al. reported on hydrothermally synthesized bismuth ferrite (BFO) square sheets for harvesting mechanical vibration energy for wastewater treatment and hydrogen evolution [70, 71]. The BFO square micro-sheets are shown in Fig. 5b with an average size of $\sim 1 \mu \mathrm{m}$, whose size and shape are used to facilitate bending of the sheets and thereby obtain a strong piezoelectric effect since their dimensions are of the same magnitude as the diameter of the cavitation-induced microbubbles in solution [70]. Mushtaq and coworkers prepared $\mathrm{BFO}$ nanosheets and nanowires via hydrothermal reactions to decompose a rhodamine B dye solution under UV light irradiation and excitation by ultrasonic vibration [78]. The nanosheets exhibit an edge length of $2-3 \mu \mathrm{m}$ and a thickness of approximately $150 \mathrm{~nm}$, and the nanowires are $\sim 30 \mu \mathrm{m}$ in length and $200-700 \mathrm{~nm}$ in diameter [78]. Ferroelectric barium titanate (BTO) has been produced to form a variety of particle shapes [37, 49, 75, 86, 101], nanocubes [36], nanowires [101], microdendrites [32, 87] for dye degradation and dechlorination [36, 37, 75, 76, 87, 101], hydrogen evolution [32], selective deposition [74, 86], as well as Li-ion batteries [49]. Hydrothermally synthesized BTO microdendrites researched by Hong et al. displayed a dendritic morphology with $10 \mu \mathrm{m}$ primary branches and secondary branches with dimensions of a few micrometers, and achieved efficient direct water splitting to produce hydrogen and oxygen $[32,87]$. Wu et al. compared the piezo-catalytic dye degradation activities of hydrothermal BTO nanowires, hydrothermal BTO nanoparticles, and commercial BTO nanoparticles [150]. As shown in Fig. 5c, the BTO nanowires are predominately straight, smooth, and elongated with an average diameter of $100 \mathrm{~nm}$ and are several micrometers in length [101]. Hydrothermal and commercial BTO nanoparticles generally exhibit a quadrilateral shape and spherical shape with average sizes of 200 and $50 \mathrm{~nm}$, respectively [101]. Qian et al. reported BTO particles made by electrospinning with an average size of $<1 \mu \mathrm{m}$ were encapsulated in polydimethylsiloxane (PDMS) as a porous foam for wastewater treatment [37]. In addition, hydrothermal zinc stannate (ZTO) nanowires showed excellent catalytic performance, with dimensions from a few $100 \mathrm{~nm}$ to dozens of micron range [68, 89]. 

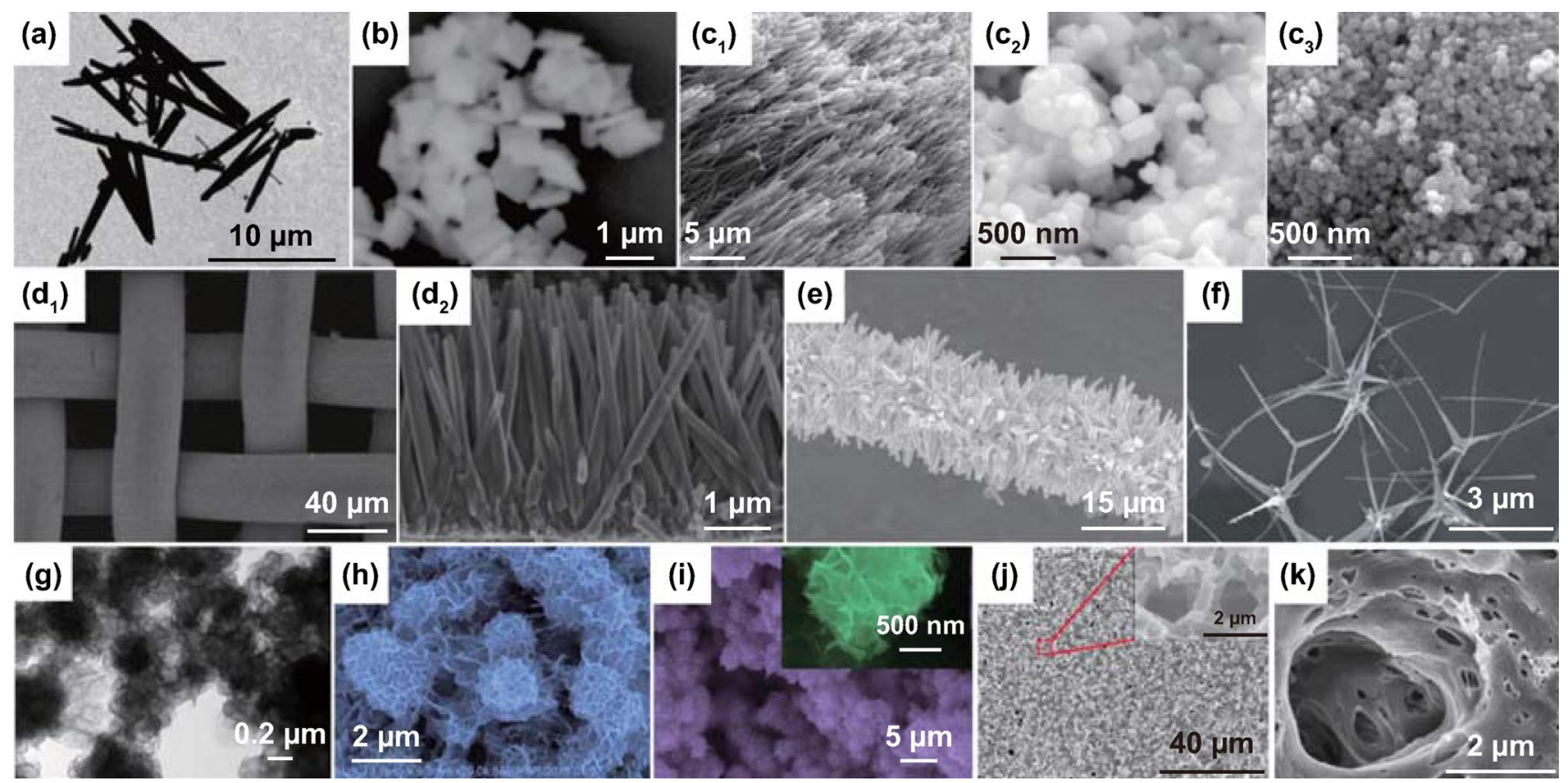

Fig. 5 a TEM of PZT fibers. Reproduced with permission [67]. Copyright 2014, AIP Publishing LLC. b SEM image of BFO square microsheets. Reproduced with permission [70]. Copyright 2017, Elsevier. c SEM images of hydrothermal BTO nanowires, hydrothermal BTO nanoparticles, and commercial BTO nanoparticles. Reproduced with permission [101]. Copyright 2018, Elsevier. d SEM images of bare ZnO nanowire arrays on stainless steel mesh. Reproduced with permission [80]. Copyright 2016, American Chemical Society. e SEM images of ZnO nanowires. Reproduced with permission [88]. Copyright 2015, Elsevier. f SEM image of $\mathrm{Ag}_{2} \mathrm{O} / \mathrm{T}-\mathrm{ZnO}$ nanostructures. Reproduced with permission [79]. Copyright 2016, Royal Society of Chemistry. g TEM image of $\mathrm{MoS}_{2}$ nanoflowers. Reproduced with permission [73]. Copyright 2017, Elsevier. h SEM image of $\mathrm{WS}_{2}$ nanoflowers. Reproduced with permission [82]. Copyright 2018, Elsevier. i SEM image of MoSe ${ }_{2}$ nanoflowers. Reproduced with permission [81]. Copyright 2017, Elsevier. j SEM image of PVDF mesoporous nanostructured film in a top view. Reproduced with permission [83]. Copyright 2014, Elsevier. k PVDF surface image. Reproduced with permission [84]. Copyright 2015, Elsevier. 1 Micrographs of propidium iodide fluorescent staining cells on cortical bone collagen. The nuclei of the cells are stained in red. The deformed internal side corresponds to the face subject to compression. The deformed external side corresponds to the face subject to tension. Reproduced with permission [85]. Copyright 2017, Trans Tech Publications

\subsection{Wurtzite Zinc Oxide Morphologies}

In general, wurtzite zinc oxide $(\mathrm{ZnO})$ nanofibers, nanowires or nanorods have been synthesized via simple hydrothermal methods under appropriate conditions [109]. Piezoelectrically induced water splitting and dye wastewater decolorization has been performed using pure $\mathrm{ZnO}$ fibers and nanorods with an average diameter of $0.4 \mu \mathrm{m}$ and $25 \mathrm{~nm}$ and length of 4-10 and $1.25 \mu \mathrm{m}$, respectively [32, 184]. In addition, $\mathrm{ZnO}$ nanowire arrays have been fabricated through a two-step hydrothermal processes, where $\mathrm{ZnO}$ seeds are initially deposited on a substrate and the nanowire arrays are then hydrothermally grow on it. Hong et al. aligned $\mathrm{ZnO}$ nanowire arrays and combined copper sulfide $(\mathrm{CuS})$ on the surface, which led to a high piezo-photocatalytic efficiency for the degradation of methylene blue solutions using mechanical and solar energy [80]. Figure 5d shows detailed images of bare $\mathrm{ZnO}$ nanowire arrays on a stainless steel mesh with a diameter of $25 \mu \mathrm{m}$, and the nanowire arrays are vertically aligned on the mesh with an average diameter of $150 \mathrm{~nm}$ and an average length of $4 \mu \mathrm{m}$ from a side view [80]. Xue et al. designed a tailored structure from seed-assisted hydrothermal $\mathrm{ZnO}$ nanowires that were vertically aligned on carbon fibers for decomposing methylene blue by coupling a piezoelectric with a semiconductor [88]. The $\mathrm{ZnO}$ nanowires attached on the carbon fibers are shown in Fig. 5e, which exhibit an average diameter and length of $500 \mathrm{~nm}$ and $6 \mu \mathrm{m}$, respectively [88]. Through thermal evaporation, tetrapod- $\mathrm{ZnO}$ nanostructures have been synthesized which consist of four needle-shaped legs with a $109^{\circ}$ angle between any two legs. Sun et al. achieved an ultrafast degradation of methylene blue solutions efficiently by coapplication of mechanical and ultraviolet energy on silver oxide $\left(\mathrm{Ag}_{2} \mathrm{O}\right)$ /tetrapod-ZnO ( $\left.\mathrm{T}-\mathrm{ZnO}\right)$ nanostructures [79]. 
The composite nanostructures were synthesized by the following method: First, the tetrapod- $\mathrm{ZnO}$ was mass produced by thermal evaporation, and then, $\mathrm{Ag}_{2} \mathrm{O}$ was loaded on the surface of the $\mathrm{T}-\mathrm{ZnO}$. Figure $5 \mathrm{f}$ shows that the $\mathrm{T}-\mathrm{ZnO}$ are uniformly loaded with $\mathrm{Ag}_{2} \mathrm{O}$ nanoparticles on the surface, and the composite nanostructures have a tetrapod structure with four 4- $\mu \mathrm{m}$ needle-shaped legs and an average diameter of $200 \mathrm{~nm}$ [79]. Qian and coauthors encapsulated T-ZnO into PDMS to address the challenge of secondary pollution and reusable limits for dye degradation; the T-ZnO nanomaterials had an average needle length of $\sim 10 \mu \mathrm{m}$ [37].

\subsection{Morphology of Layered Transition Metal Dichalcogenide Based Materials}

Single-layer and odd-layered transition metal dichalcogenide-based materials have been reported that demonstrate excellent piezoelectricity [72, 82, 157-168, 185]. Wu's group has published a number of research articles on the use of hydrothermally synthesized layered transition metal dichalcogenide family nanoflowers for electro-chemical processes $[72,73,81,82]$. An ultra-high piezo-catalytic degradation rate in the dark was achieved for single- and few-layered molybdenum disulfide $\left(\mathrm{MoS}_{2}\right)$ nanoflowers [72]. The same $\mathrm{MoS}_{2}$ nanoflowers were also encapsulated in a PDMS film to destroy rhodamine B dye, and the $\mathrm{MoS}_{2} /$ PDMS was combined with copper to produce a triboelectric nanogenerator (TENG) for wastewater mechanical energy harvesting [73]. PDMS/tungsten disulfide $\left(\mathrm{WS}_{2}\right)$ composite materials have also been investigated for piezo-catalytic rhodamine $\mathrm{B}$ degradation, and the prepared $\mathrm{WS}_{2}$ nanoflowers achieved an almost complete antibacterial performance for Escherichia coli (E. coli) [82]. Single-layer and few-layered molybdenum diselenide $\left(\mathrm{MoSe}_{2}\right)$ nanoflowers exhibited an ultra-high degradation rate to decolor rhodamine B by $90 \%$ within only $30 \mathrm{~s}$ [81]. Images of the typical morphologies of the range of nanoflowers that have been described above are shown in Fig. $5 g-i[73,81]$. While the size of the nanoflowers exhibits some variation, a common aspect is that all possess an abundant surface area, where the $\mathrm{MoS}_{2}, \mathrm{WS}_{2}$ and $\mathrm{MoSe}_{2}$ nanoflowers are in the range of $0.4-0.6,1-2$, and 2-3 $\mu \mathrm{m}$, respectively $[72,73,81,82]$.

\subsection{Morphology of Organic Piezoelectric Materials}

Transparent and flexible organic piezoelectric polyvinylidene fluoride (PVDF) has been investigated as the most widely available piezoelectric polymer for practical electro-chemical related energy conversion applications [48, 87, 126, 173-178], which can be produced via simple spin-coating methods [45, 84, 90]. The majority of applications for PVDF-based materials have been related to battery power cells. Soroushian and coauthors proposed a poly(vinylidene fluoride-co-hexafluoropropylene) PVDF-HFP, solid electrolyte self-healing structure with $4 \mathrm{~mm}$ thickness and $25 \mathrm{~mm}$ side dimension, which was able to redistribute the structural mass in response to dynamic loads [186]. Xue et al. replaced the polyethylene (PE) separator of the battery cell with a commercial PVDF film (a thickness of $\sim 110 \mu \mathrm{m}$ ) in lithium battery to drive the migration of Li ions to achieve a self-charging power cell [44]. Subsequently, this group combined a cupric oxide $(\mathrm{CuO})$ anode with PVDF to create a $\mathrm{CuO} / \mathrm{PVDF}$ nanocomposite anode with a thickness of $\sim 80 \mu \mathrm{m}$ and achieved stability and efficiency for the application of self-charging power cells [180]. Zhang and coworkers also designed a PVDF-PZT nanocomposite film with a thickness of $90 \mu \mathrm{m}$ that served as a piezo-separator in self-charging power cell [181]. Xing et al. and Kim et al. reported on porous piezoelectric PVDF films to enhance the properties of self-charging power cells, respectively $[83,84]$. The former processed the PVDF mesoporous nanostructured film using $\mathrm{ZnO}$ nanowire arrays as a template [83]. The mesopores of the PVDF share the same shape and size with hexagonal $\mathrm{ZnO}$ nanowire template, and the diameters of the pores ranged from 700 to $900 \mathrm{~nm}$, as shown in Fig. 5j [83]. In Kim's research, an image of the mesoporous PVDF is shown in Fig. 5k, where randomly distributed and highly interconnected pores are located within the PVDF [84]. Ramadoss et al. investigated PVDF-ZnO film that acted as a separator to manufacture a self-charging supercapacitor power cell [45]. Zhang et al. verified the feasibility of PVDF films for self-powered cathodic protection nanogenerators [90]. 


\subsection{Morphology of Piezoelectric Biomaterials}

Collagen, extracted from bone of animals, is of interest to promote the self-healing of bone due to the polar uniaxial orientation of molecular dipoles in the structure [10, 176, 177]. Karem et al. have described the electro-chemical influence of collagen piezoelectric effect in bone healing [85]. Cells on cortical bone collagen are stained by propidium iodide fluorescent, and the nuclei of the cells are red in color. The deformed internal and external sides correspond to the faces subject to compression and tension, respectively. [85]. In addition, piezoelectricity can also be found in different parts of living body, such as deoxyribonucleic acids (DNA), cartilage, tendon, dentin, ligaments, skin, as well as cell membranes, which plays a significant role in physiological phenomena for the living body [187-189]. However, reports on the combination of these piezoelectric biomaterials with electro-chemical processes remain limited to date, where they are focused only on the threshold of the hybrid piezo-electro-chemistry systems in piezoelectric biomaterials.

The morphologies of the variety of piezoelectric and ferroelectric materials have been described, which indicate the range of dimensions, shapes and porosity levels of the materials employed; these are summarized in Table 1. We will see later that such factors can strongly influence the surface area and resonant frequency of the particles in response to ultrasonic vibrations. The following section will overview the range of piezo-electro-chemical processes which have been explored.

\section{Piezo-Electro-chemical Processes and Practical Applications}

An electro-chemical reaction is regarded as a chemical reaction driven by an externally supplied electric circuit [28-30]. Generally, the reaction can be classified as an electro-chemical oxidation-reduction reaction if a chemical reaction is a result of an externally supplied current, and positive and negative electrical charges are transferred between atoms or molecules throughout the whole reaction [190, 191]. Piezoelectrically induced electric fields have been used as an external electric potential for electro-chemical processes [54-56]. In this section, we will examine recent research on piezo-electro-chemistry and consider their practical applications which include selective deposition [38, 77, 86], water splitting for hydrogen production [32, 65, 69], catalytic-related dye degradation and dechlorination $[76,79$, 90, 124, 125], self-charging power cells [44, 45, 49, 83], and others $[50,126]$.

\subsection{Selective Deposition}

The depolarization field is partially internally screened for a ferroelectric material [192], and the valence and conduction band edges near the material surface can be bent by polarization charges as well as surface states due to dangling bonds and defects, where the pinning of the Fermi level is influenced by the density of electric charges [193, 194]. As a result, the electronic states can be influenced by the polarization field along the ferroelectric material, which provides an opportunity to control the atomic deposition and the growth of new material on the surface of a material [38]. The polarization of the ferroelectric materials plays an important role in controlling the deposition reaction rate and the location of material growth [38, 74, 77, 86, 179].

Ferroelectric PZT films have been investigated to assist in photo-induced oxidation-reduction deposition [77, 179]. Under irradiation by a $400 \mathrm{~W} \mathrm{Hg}$ lamp, clear selective electro-chemical reactions could be observed on the surfaces of ferroelectric positive $\left(c^{+}\right)$and negative $\left(c^{-}\right)$domains, where the surface of the $c^{-}$domain was unaffected by the photoexcitation in stannous chloride $\left(\mathrm{SnCl}_{2}\right)$ solution, which is shown in Fig. 6a [179]. In addition, the films could be polarized by an atomic force microscope (AFM) under a potential of $14 \mathrm{~V}$ and the shape of the deposition structure changed as a result. A piezo-response force microscopy (PFM) image of poled patterns is shown in Fig. 6b, where bright squares and dark squares represent $c^{+}$domains and $c^{-}$domains, respectively, and the surrounding area represents an unpoled region [77]. Rohrer's group proposed to deposit titanium dioxide $\left(\mathrm{TiO}_{2}\right)$ films on the surface of ferroelectric BFO and BTO using pulsed laser deposition [38, 74]. Spatially, the patterns of products $\left(\mathrm{Ag}\right.$ and $\left.\mathrm{Pb}^{2+}\right)$ on the surface of $\mathrm{TiO}_{2}$ film reproduced those on the bare ferroelectric materials, which could be observed by AFM. As the thickness of $\mathrm{TiO}_{2}$ film increased, the orientation of ferroelectric dipoles had a diminished influence of selective electro-chemical reactions at the surface of the $\mathrm{TiO}_{2}$ film, where silver ions $\left(\mathrm{Ag}^{+}\right)$were reduced to silver atoms $(\mathrm{Ag})$ and bivalent lead ions $\left(\mathrm{Pb}^{2+}\right)$ 

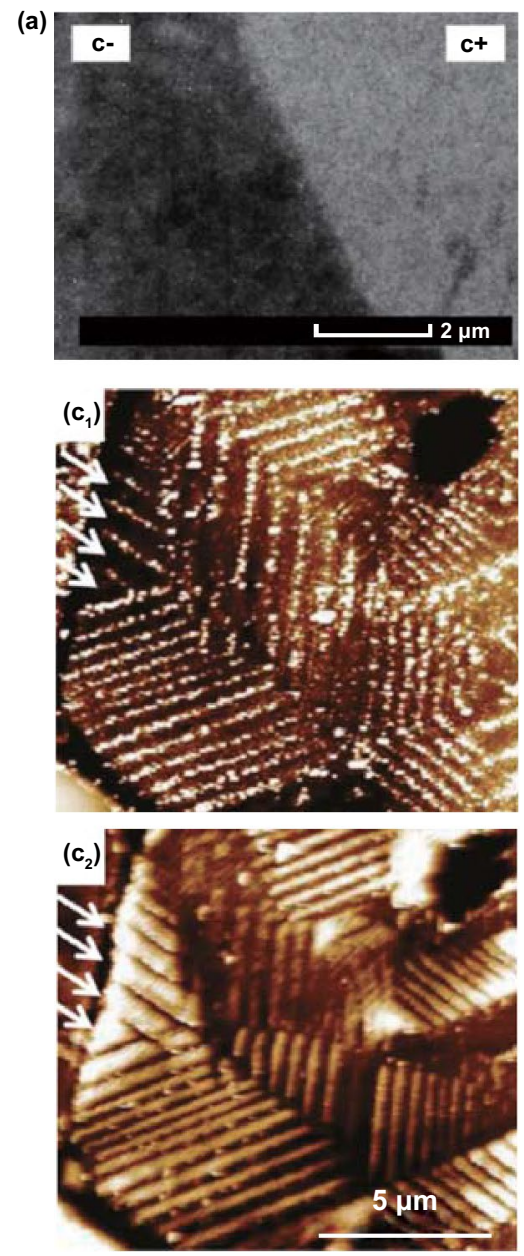

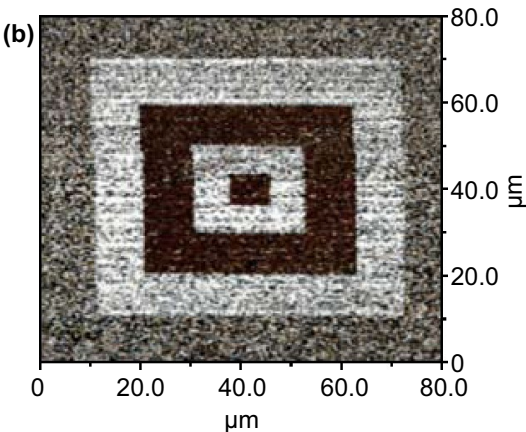

(e)

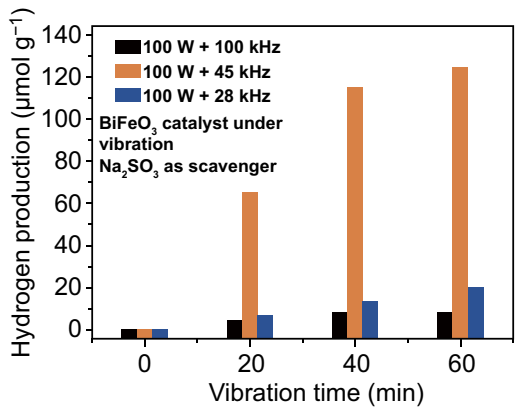

(e $\left.e_{2}\right) \widetilde{T}$

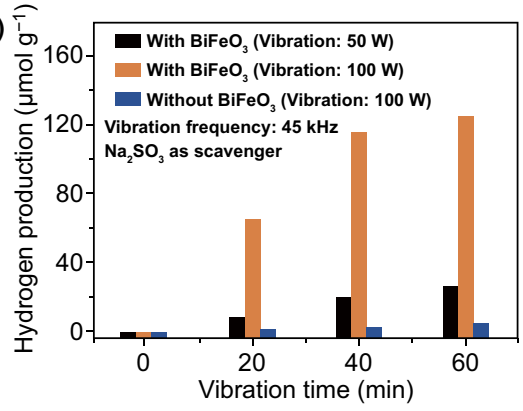

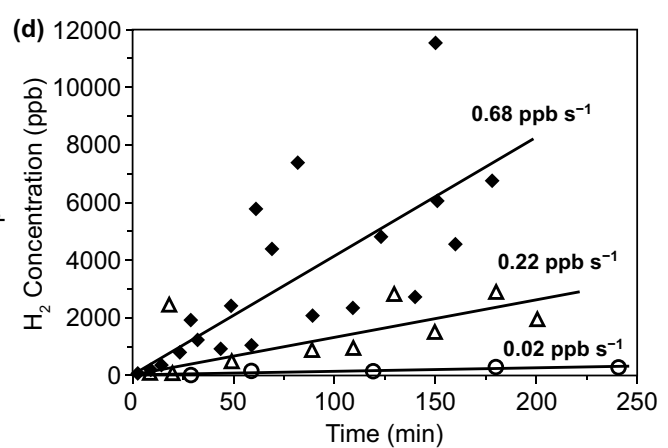

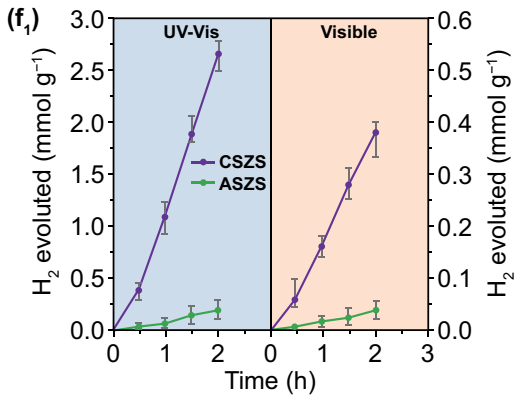

(f)

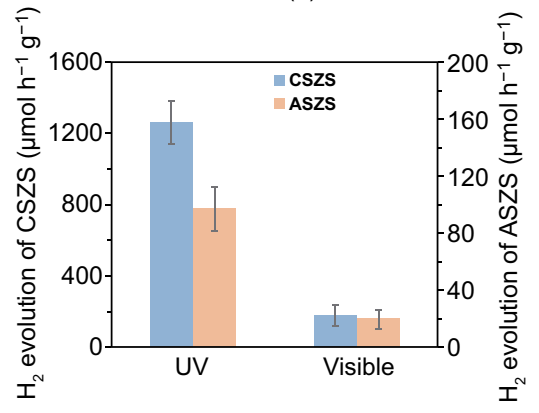

Fig. 6 a SEM image of $\mathrm{Sn}$ deposited on the $c^{+}$domain from $\mathrm{SnCl}_{2}$ solution. The surface of the $c^{-}$domain was unaffected by the photoexcitation. Reproduced with permission [179]. Copyright 2008, American Chemical Society. b A typical PFM image of the poled pattern. Brighter squares in the picture are positive domains and the dark squares are negative domains; surrounding region is an unpoled area. Reproduced with permission [77]. Copyright 2009, Elsevier. c Topographic AFM images of a 15-nm-thick $\mathrm{TiO}_{2}$ film surface after reaction with silver nitrate solution and after reaction in lead acetate solution. Reproduced with permission [74]. Copyright 2010, American Chemical Society. d $\mathrm{H}_{2}$ concentration measured as a function of oscillating time of a piezoelectric beam in deionized water at a frequency of $10 \mathrm{~Hz}$ (triangles) and $20 \mathrm{~Hz}$ (diamonds). A Si cantilever with identical configuration was used as a control (circles). Reproduced with permission [65]. Copyright 2008, Wiley-VCH. e The piezo-catalytic hydrogen production from water splitting under vibration by BFO nanosheets at different vibration frequencies, and with different mechanical powers. Reproduced with permission [71]. Copyright 2019, Wiley-VCH. f Rate coefficients of the BHS in degradation of $\mathrm{MO}$ and corresponding $\mathrm{H}_{2}$ evolution rates. Reproduced with permission [69]. Copyright 2015, American Chemical Society

were oxidized to tetravalent lead ions $\left(\mathrm{Pb}^{4+}\right)$ under ultraviolet illumination. There are multi-domain BTO substrates with a 15-nm-thick $\mathrm{TiO}_{2}$ coating after selective deposition in an aqueous silver nitrate $\left(\mathrm{AgNO}_{3}\right)$ solution and lead acetate $\left(\left(\mathrm{CH}_{3} \mathrm{COO}\right)_{2} \mathrm{~Pb}\right)$ solution, respectively, where the arrows on the upper left corner of the figures highlight the width of the reduced $\mathrm{Ag}$ and oxidized $\mathrm{Pb}$ stripes [74].

In general, a variety of orientations of spontaneous polarization are present in bulk ferroelectric materials, while nano-/micro-piezoelectric particles can exhibit more simplex dipole arrangement due to single polarization orientation throughout the whole crystal with the sub-crystals along a certain crystallographic face $[86,182,183]$. The occupied and unoccupied energy states at the interfaces between the material and its surroundings are influenced by the spontaneous polarization, which control the movement of electrical charge. In this case, piezo-electro-chemical selective deposition can have negative effects on precisely engineered nano-/microstructures. Giocondi et al. utilized the spontaneous polarization within $1-5-\mu \mathrm{m}$ BTO microparticles to drive 
photo-deposition reactions in $\mathrm{AgNO}_{3}$ and $\left(\mathrm{CH}_{3} \mathrm{COO}\right)_{2} \mathrm{~Pb}$ solutions [86]. The spatial distribution of deposited silver is related to the domain structure as well as the surface orientation. The relative reactivity of the faces increases in the order of $\{110\}<\{111\}<\{100\}$ [86]. In some cases, reduced silver could be exposed merely on the faces of $\{100\}$. These reactive regions were surrounded by unreactive regions in the boundaries of the face, which indicates a range of polarized domains were formed to minimize electrostatic energy.

Moreover, the above-mentioned selective deposition reactions involve semiconductive photovoltaic effects, since PZT, BTO, and BFO materials can be considered as piezoelectric/ferroelectric materials and semiconductors. The structure of the energy band can be significantly affected by the spontaneous polarization field across the semiconductors. For typical photo-electro-chemical deposition, the substances that can be deposited possess appropriate redox potentials, which must be less than the bandgap $\left(E_{\mathrm{g}}\right)$ of the semiconductor. Specifically, the photo-generated electrons and holes ideally arrive at the material surface with potentials determined by the energy of the conduction band $\left(E_{\mathrm{c}}\right)$ and the valence band $\left(E_{\mathrm{v}}\right)$ at the surface [195]. Generally, the ability of electrons and holes to drive electro-chemical reactions is dictated by the quasi-Fermi energy of the electrons $\left(E_{\mathrm{Fn}}\right)$ and holes $\left(E_{\mathrm{Fp}}\right)$ at the surface, and $E_{\mathrm{Fn}}$ must be at a more negative potential than the desired reduction reaction and $E_{\mathrm{Fp}}$ must be more positive than the oxidation reaction [196, 197]. However, there is a difference in piezoelectric/ ferroelectric materials since energy band tilting under an induced piezoelectric field can make the conduction band and valence band more positive or negative than the redox potentials, which determines whether the photo-electrochemical oxidation-reduction reactions take place or not [71].

To sum up, the polarization field induced by ferroelectric materials influences the electronic states, and the polarization field is a mostly important determiner to control the selective atomic deposition, where high piezoelectric constant of materials is preferred.

\subsection{Hydrogen Production}

Environmental pollution and the energy crisis are major challenges to humanity on the Earth; thus, pollution-free clean and renewable energy sources have gained increasing attention throughout the world [198, 199]. Hydrogen fuel contains abundant chemical energy and has become one of the most welcome environmentally friendly energy sources, since it possesses a high energy density and produces no greenhouse gases compared with traditional fossil fuels [200-203]. Therefore, hydrogen production has become a topic of intense interest over recent decades [200-203]. In general, hydrogen fuels can be harvested via the following approaches: coal gasification, partial oxidization, bacteria fermentation, electrolysis and water splitting [204, 205]. Piezo-electro-chemical water splitting is a recently examined approach to combine the piezoelectric properties and the electro-chemical redox reactions for hydrogen production.

Starr et al. investigated piezo-catalytic hydrogen production in a single-crystalline piezoelectric $68 \mathrm{~Pb}\left(\mathrm{Mg}_{1 / 3} \mathrm{Nb}_{2 / 3}\right)$ $\mathrm{O}_{3}-32 \mathrm{PbTiO}_{3}$ (PMN-PT) cantilever, where the piezoelectric cantilever was strained by a computer-controlled vibrator and linear actuator to control its high-frequency oscillation and strain state [65]. As shown in Fig. 6d, hydrogen production was related to the direct piezoelectric effect. Under different strained frequencies, $\mathrm{H}_{2}$ concentrations were measured as a function of oscillation time, with a constant piezoelectric potential of $20 \mathrm{~V}$ throughout the entire reaction. A linearized fit showed the rate of $\mathrm{H}_{2}$ concentration increased to $0.02,0.22$, and $0.68 \mathrm{ppb} \mathrm{s}^{-1}$ by oscillating at 0,10 , and $20 \mathrm{~Hz}$, respectively. Zhang et al. realized an indirect piezo-electro-chemical hydrogen generation in a device composed of a piezoelectric bimorph cantilever based on PZT-5 ceramics [66]. The hydrogen evolution rate is relatively low at $\sim 1.21 \mathrm{mmol} \mathrm{h}^{-1}$, and high ion concentration of $\mathrm{NaHSO}_{4}$ electrolyte aqueous solution benefits the piezo-electro-chemical water splitting reaction for hydrogen evolution. A high hydrogen generation rate of approximately $124.1 \mathrm{mmol} \mathrm{g}^{-1}$ was realized under $100 \mathrm{~W}$ mechanical vibration for BFO nanosheets within $1 \mathrm{~h}$ [71]. In Fig. 6e, the hydrogen production rates per unit mass of BFO nanosheets under $100 \mathrm{~W}$ vibration power are $20.4,124.1$, and $8.3 \mathrm{mmol} \mathrm{h}^{-1}$ at vibration frequencies of 28,45 , and $100 \mathrm{kHz}$, respectively. At a frequency of $45 \mathrm{kHz}$, the hydrogen evolution rate under a vibration power level of $50 \mathrm{~W}$ is lower than under a vibration power of $100 \mathrm{~W}$, which is shown in Fig. 6e. Additionally, hydrogen and oxygen production via direct water splitting was realized by vibrating piezoelectric $\mathrm{ZnO}$ microfibers and BTO microdendrites using ultrasonic waves. In the work of Hong, rapid hydrogen and oxygen 
evolution was achieved at an initial rate of $3.4 \times 10^{-3}$ and $1.7 \times 10^{-3} \mathrm{ppm} \mathrm{s}^{-1}$, respectively, using $\mathrm{ZnO}$ microfibers as the piezo-catalyst in the first period ( $0-40 \mathrm{~min})$, where the stoichiometric equivalence of the produced hydrogen and oxygen gases was $\mathrm{H}_{2} / \mathrm{O}_{2}=2: 1$ [32]. When the externally applied ultrasonic wave vibrations were stopped, the production of hydrogen and oxygen terminated immediately with a $\mathrm{H}_{2}$ generation rate of $<0.0001 \mathrm{ppm} \mathrm{s}^{-1}$. For piezoelectric BTO microdendrites, it was shown that an average hydrogen evolution rate is $1.25 \times 10^{-2}$ and $9.13 \times 10^{-3} \mathrm{ppm} \mathrm{s}^{-1}$ during the first and second piezoelectro-chemical reactions, respectively, where the first period of vibration was 0-50 min, the second period was 100-150 min, and the ultrasonic vibrations were turned off during 50-100 $\min$ [32].

Novel metal-semiconductor branched heterostructures (BHS) of hybrid $\mathrm{Cu} / \mathrm{CuS}-\mathrm{ZnO} / \mathrm{ZnS}$ (CSZS) and $\mathrm{Ag}$ / $\mathrm{Ag}_{2} \mathrm{~S}-\mathrm{ZnO} / \mathrm{ZnS}$ (ASZS) materials have been used to fabricate a hybrid cell to harvest multiple energy sources, namely mechanical and solar energy, for hydrogen production [69]. The hydrogen production performance of ASZS BHS and CSZS BHS under both UV-Vis and visible illumination is shown in Fig. 6f, where the hydrogen generation rates are 1250 and $182 \mu \mathrm{mol} \mathrm{h}^{-1} \mathrm{~g}^{-1}$ for the CSZS BHS and 98.8 and $20 \mu \mathrm{mol} \mathrm{h}^{-1} \mathrm{~g}^{-1}$ for the ASZS BHS, respectively, under UV-Vis illumination and visible illumination. The CSZS BHS exhibited the highest activity under UV-Vis illumination, due to sulfurized CSZS BHS possessing a higher absorbance across the wavelengths of 300 to $800 \mathrm{~nm}$. This approach was able to overcome the challenges in photocatalytic hydrogen production, such as inadequate power conversion, high recombination of photo-induced charges, and intermittent availability of solar illumination, due to visible light absorption, and high charge separation efficiency.

Results from hydrogen production procedures using the above-mentioned single or hybrid piezoelectric materials indicate that the challenges for generating hydrogen are to drive a potential, through the applied approaches of either single piezoelectrically induced or hybrid piezoelectric/photovoltaic coupling induced, in order to overcome the standard oxidation-reduction potential of water. This suggestion is discussed in more detail in Sect. 2, in relation to Faraday's law of electrolysis. In summary, methods to reduce environmental pollution are attracting increasing research interest, and the next section will introduce piezo-electro-chemical processes for environmental purification in wastewater treatment.

\subsection{Dye Degradation and Dechlorination}

Paper, dyeing, and textile industries produce a large amount of organic dye pollutant each year, which accelerates environmental pollution [206]. Dye degradation for wastewater treatment has attracted long-term and substantial attention for a variety of research fields, including environmental physics [207-209], chemistry [210-213], and biology [214-216]. Advanced chemical oxidation processes offer an environmentally friendly approach to decompose a range of dye molecules efficiently, and recently, scientists have placed significant effort in applying a piezoelectric built-in potential to drive electro-chemical wastewater treatment $[72,101]$.

Piezoelectric BTO nanoparticles and nanowires were synthesized to investigate the piezo-catalytic dye degradation in aqueous methyl orange solutions, and enhanced piezo-catalytic activity was exhibited in nanowires compared to nanoparticles due to their increased susceptibility to mechanical deformation [101]. The piezo-catalytic activity of BTO nanowires for degrading methyl orange dye solutions is shown in Fig. 7a, b. The UV-Vis absorption spectra of $5 \mathrm{mg} \mathrm{L}^{-1}$ methyl orange dye solution range from 350 to $650 \mathrm{~nm}$ with a peak at $460 \mathrm{~nm}$, where the intensity of the peak shows a sharp decrease with increasing piezocatalytic time. Within $160 \mathrm{~min}$, complete dye degradation could be achieved, as shown in the inset of Fig. 7a, where the color of the initial orange solution becomes transparent. The piezo-catalytic stability of the materials allows recycling of the BTO nanowires up to four times, while maintaining a high catalytic activity. An ultra-high degradation activity in single- and few-layered $\mathrm{MoS}_{2}$ nanoflowers was obtained in dark, where the degradation ratio of the rhodamine B solution was up to $93 \%$ within $60 \mathrm{~s}$ of the piezo-catalytic reaction [72]. In this work, the electro-chemical piezo-catalysis of the rhodamine $\mathrm{B}$ dye solutions in $\mathrm{MoS}_{2}$ nanoflowers, commercial $\mathrm{MoS}_{2}$, and $\mathrm{TiO}_{2}-\mathrm{P} 25$ has been evaluated in different conditions, as shown in Fig. 7c-f. The catalytic activities of commercial $\mathrm{MoS}_{2}$ and $\mathrm{TiO}_{2}-\mathrm{P} 25$ exhibit a relatively low performance, with or without the application of ultrasonic mechanical vibrations and light illumination. Interestingly, for single- and few-layered $\mathrm{MoS}_{2}$ nanoflowers, the piezocatalytic performance increases rapidly when the ultrasonic 

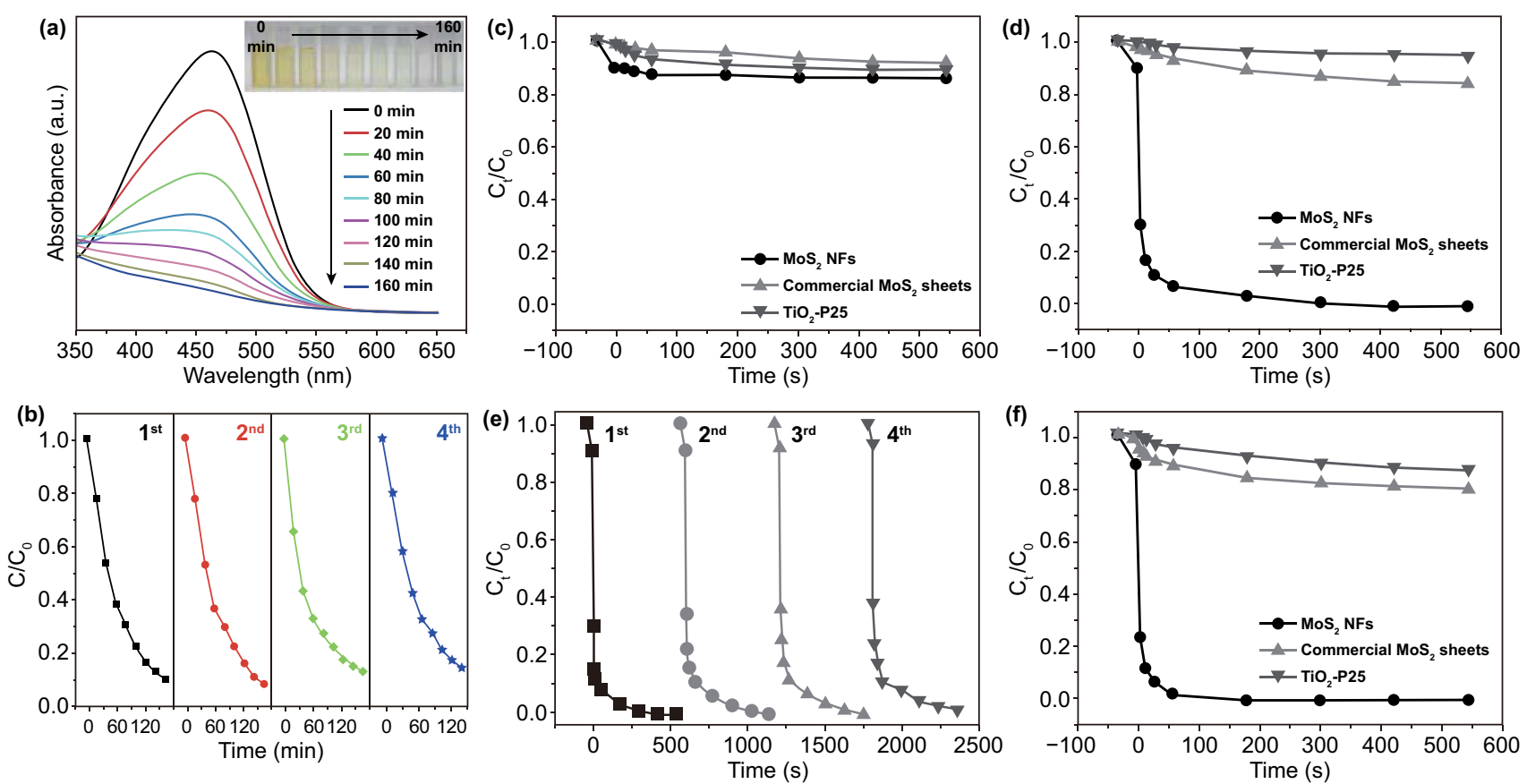

Fig. 7 a, b UV-Vis absorption spectra of the MO aqueous solutions sampled in BTO nanowires at set intervals. Inset: photograph of the MO solutions samples; plots of the relative intensity of the maximum absorption at $460 \mathrm{~nm}$ as a function of reaction time in four recycling processes.

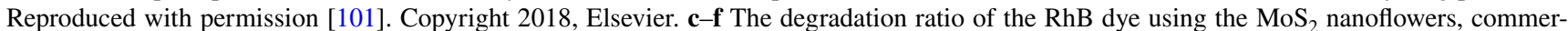
cial $\mathrm{MoS}_{2}$, and $\mathrm{TiO}_{2}-\mathrm{P} 25$, under different degradation conditions: $\mathbf{c}$ in the dark, $\mathbf{d}$ ultrasonic wave in the dark, $\mathbf{e}$ the repeatable degradation tests of the RhB dye using the $\mathrm{MoS}_{2}$ nanoflowers under ultrasonic-wave assistance in the dark, $\mathbf{f}$ degradation ratio of the RhB dye under ultrasonicwave assistance with the xenon lamp illumination using the $\mathrm{MoS}_{2}$ nanoflowers. Reproduced with permission [72]. Copyright 2017, Wiley-VCH

mechanical vibrations are applied during ultrasonic excitation in the dark. The degradation ratio reached $93 \%$ within $60 \mathrm{~s}$ and $100 \%$ within $300 \mathrm{~s}$. In general, light illumination improved piezo-catalysis and reduced the time for complete degradation to $180 \mathrm{~s}$. Thus, light plays an important role in catalytic dye degradation, which is generally well known for photocatalytic wastewater treatment, which has been widely researched [217-219]. Research and activities of piezo-potential-modulated photocatalysis have been widely reported, where the performance of typical photocatalysis can be extended to new approaches of piezo-photocatalysis, which features the simultaneous coupling of piezoelectricity, semiconduction, photocatalysis, and photoexcitation [68, 79, 89].

Under a combined excitation of ultrasonic mechanical vibration and $\mathrm{UV}$ irradiation, $\mathrm{Ag}_{2} \mathrm{O} / \mathrm{T}-\mathrm{ZnO}$ nanostructures with a mass of $2 \mathrm{~g} \mathrm{~L}^{-1}$ were able to completely degrade $5 \mathrm{mg} \mathrm{L}^{-1}$ methylene blue solution within $120 \mathrm{~s}$ [79]. The enhanced photocatalytic activity was thought to be mainly due to the piezoelectric field of the T- $\mathrm{ZnO}$ nanostructures and the build-in electric field of the $\mathrm{Ag}_{2} \mathrm{O} / \mathrm{T}-\mathrm{ZnO}$ heterojunctions, which can improve the separation of photo-generated positive and negative electric carriers and suppress their combination. Similarly, well-aligned LNtype single-crystalline ZTO nanowire arrays exploited synergistic piezo-photocatalysis to degrade aqueous methylene blue solutions efficiently $[68,89]$. It was suggested that synergistic piezo-photocatalysis was attributed to material band bending, sono-vibration, mass transfer enhancement, as well as abundant active reaction sites. Figure 8a shows the piezo-potential-modulated photocatalytic activities of different added catalysts under a variety of applied excitations including ultraviolet A (UVA) source illumination $(320-340 \mathrm{~nm}$ and $30 \mathrm{~W})$ and ultrasonic vibration $(40 \mathrm{kHz}$ and $0.2 \mathrm{~W}$ ), where ultrasonic vibration was applied with or without a 1.7-g transparent glass attached on ZTO nanowire arrays for piezo-photocatalytic measurement, and no additional pressure was applied to the reaction system for the contrastive photocatalytic measurement [68]. The self-degradation of the aqueous methylene blue solutions can be negligible, while the piezo-potential-modulated photocatalytic activity leads to an improved degradation 
$\left(a_{1}\right)$

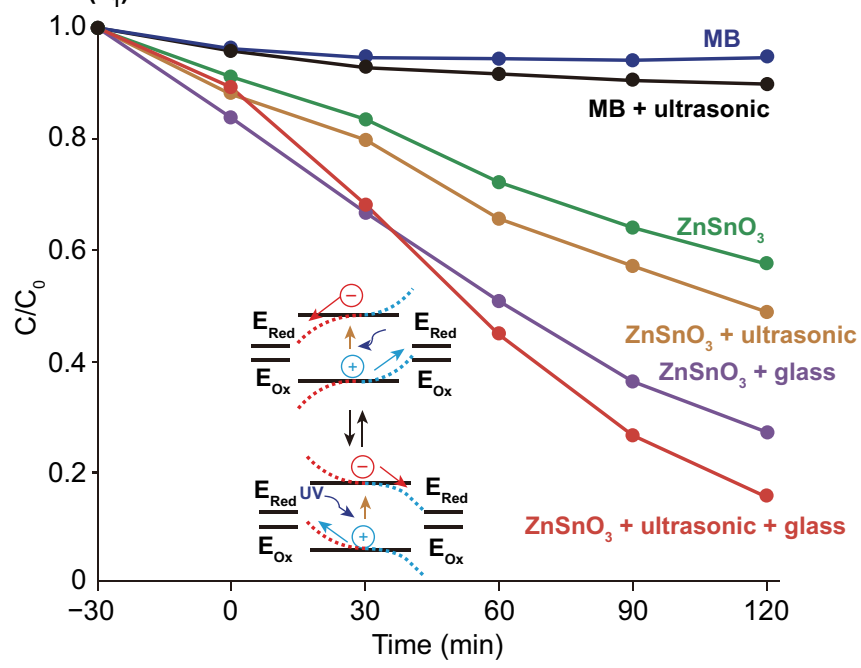

$\left(a_{3}\right)$

UVA-light

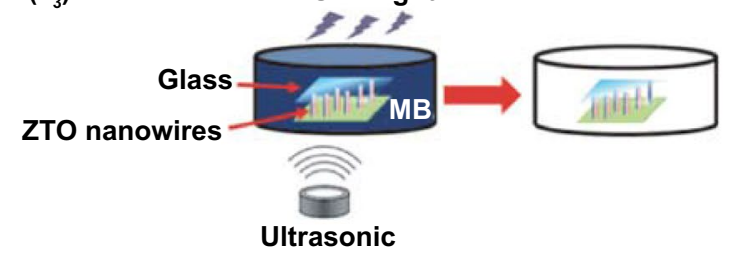

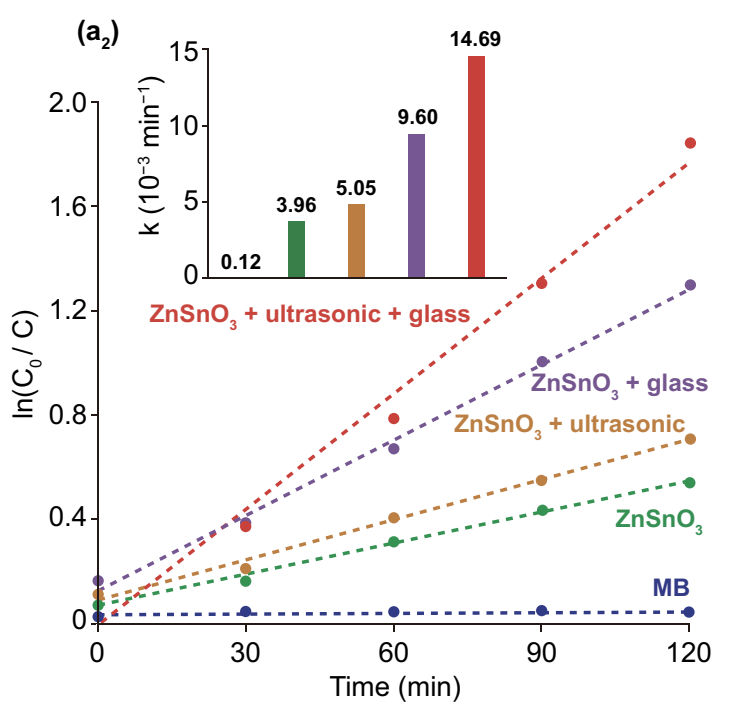

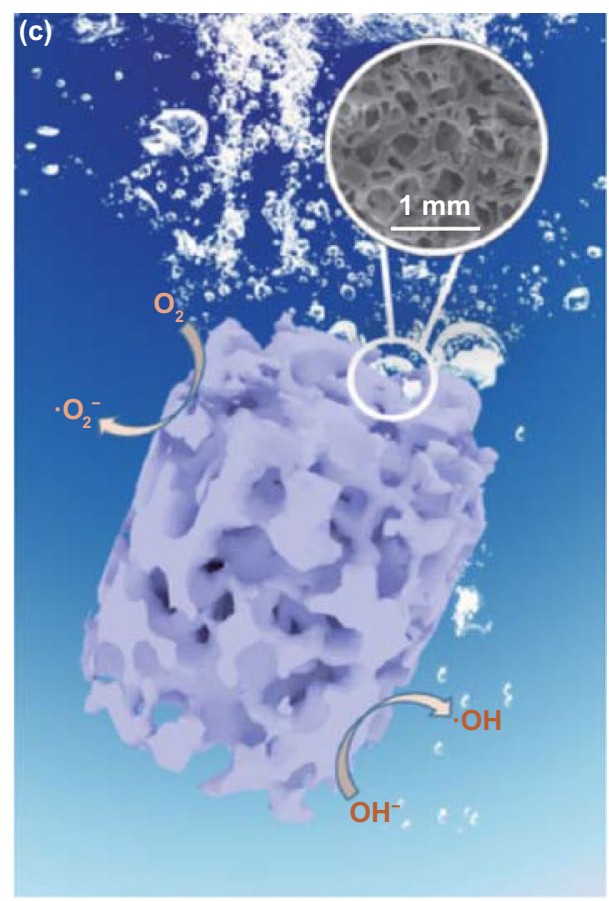

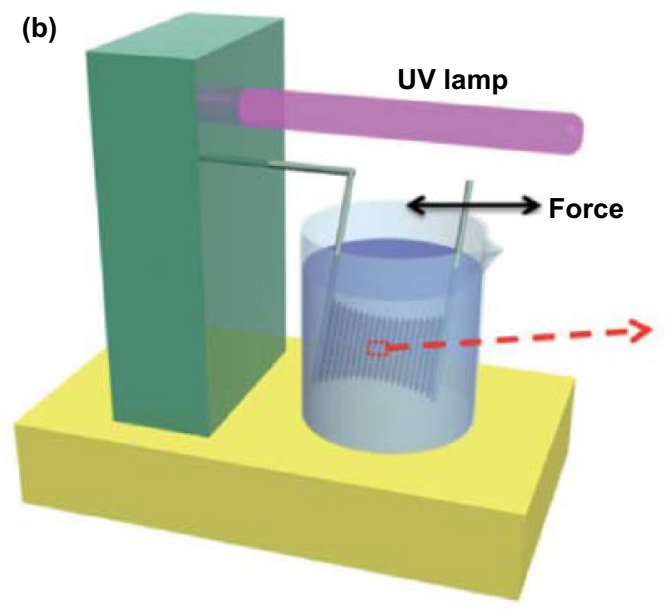

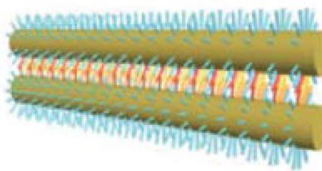

Fig. 8 a Photocatalytic results of ZTO nanowire arrays under various stresses. Reproduced with permission [89]. Copyright 2016, American Ceramic Society. b The degradation of MB solution by the piezo-photocatalytic activity of $\mathrm{ZnO}$ nanowires/C fibers under UV irradiation and periodically applied force. Reproduced with permission [88]. Copyright 2015, Elsevier. c Schematic of porous piezo-catalysis process in BTOPDMS porous foam. Reproduced with permission [37]. Copyright 2019, American Chemical Society

ratio of $75 \%$ within 120 min with both ultrasonic vibration and a transparent glass applied simultaneously. When vibrations or stress are applied to the system, the ZTO nanowires are bent which lead to electric potential variations across the nanowires that enhances the movement of the electric carriers and attenuates their recombination. The photodegradation kinetic behavior of ZTO under pressure from ultrasonic vibration and a transparent glass can be calculated as a degradation rate constant $(k)$ of $\sim 1.5 \times 10^{-2} \mathrm{~min}^{-1}$, which is approximately four times 
higher than that without any external pressure from glass or ultrasonic vibrations.

However, when piezoelectric micro-/nanocatalysts are in particulate form, they can flow into the water being treated to provide environmental challenges and secondary pollution. This can make it an expensive and time-consuming process and involve complex recycling procedures. To address the challenge of secondary pollution and reusable limits for particle based piezo-catalysis, approaches related to particle integration have been analyzed and achieved excellent piezo-catalytic activity. A two-step seed-assisted synthesized of hydrothermal $\mathrm{ZnO}$ nanowires led to vertically grown and tightly connected wires that were attached to polycrystalline carbon fibers, as reported by Xue and coworkers [88]. A device for both mechanical and solar energy harvesting to drive catalytic methylene blue dye degradation under UV irradiation was fabricated that was operated under a periodically applied force; this was achieved through weaving a $\mathrm{ZnO} / \mathrm{C}$ composite woven using multiple fibers, as shown in Fig. 8b. Additional work on piezoelectric material encapsulation has included a composite porous foam which comprised of piezoelectric materials and a PDMS polymer which was able to generate a strong oxidizing superoxide and hydroxyl species for organic rhodamine B dye degradation under the application of ultrasonic vibrations [37], as shown in Fig. 8c. Repeated decomposition reactions were achieved for up to 12 cycles, since the porous foam could be easily placed in the reaction system and removed from wastewater.

In addition, the degradation of 4-chlorophenol and dechlorination were achieved by the mechanical deformation of tetragonal BTO ( $t$-BTO) nano-/micrometer-sized particles [75]. The dechlorination efficiency of 4-chlorophenol in different catalysts is shown, and $\sim 35.2 \%$ of chlorines were removed from 4-chlorophenol in $t$-BTO within $120 \mathrm{~min}$. As the annealing temperature was increased, the dechlorination efficiency rapidly increases above $200^{\circ} \mathrm{C}$, due to the generation of $t$-BTO. Deposited Ag on $t$-BTO was also shown to improve the piezo-dechlorination activity.

For piezo-electro-chemical hydrogen production, dye degradation and dechlorination, the similarity of majority of these applications can be summarized that electro-chemical processes are driven by piezoelectric material under forced vibration in aqueous solution, where piezoelectric property, easy-to-bend shape, vibration frequency range, and nontoxicity of material are the notable factors for researchers.

\subsection{Self-charging Power Cells}

Energy generation and energy storage sources are often designed as two separate unit devices where the generators can convert different forms of energy sources into electricity for energy generation and power cells can store electrical energy as chemical energy for storage, which is released on demand [220-228]. Xue and the coworkers were the first to propose an integrated self-charging power cell that hybridized both energy generation and storage [44]. As shown in Fig. 9a, the exterior appearance of the integrated self-charging power cell is that of a stainless steel coin-type cell, and the major components within the cell comprise an anode with anatase $\mathrm{TiO}_{2}$ nanotubes aligned on $\mathrm{Ti}$ foil, a cathode with $\mathrm{LiCoO}_{2}$ /conductive carbon/binder mixtures on $\mathrm{Al}$ foil, and a separator formed by a polarized PVDF film. The above-mentioned structure was designed on the basis of the combination of piezoelectric effect and electro-chemistry, which can be used in practical applications of self-powered nano-/microsystems and personal electronic devices.

In further research, the components of the electrode and separator were modified to attain a high energy conversion, high piezo-electro-chemical charge/discharge performance and high stability. The hybrid structure of the electrode on the anode side was improved and obtained high stability and efficiency, by being fabricated using a $\mathrm{CuO} / \mathrm{PVDF}$ nanocomposite piezo-anode [180]. This type of piezo-anode structure benefited from an effective use of induced piezoelectric field by external mechanical deformation or vibration due to large interface area and intimate contact between the $\mathrm{CuO}$ and PVDF. Subsequently, the porous structure of the PVDF separation was used to achieve effective lithium ion transfer channels $[83,84]$, which could be attributed to a geometrical strain confinement effect. A PVDF-PZT nanocomposite film was proposed that acted as the piezoseparator to enhance the piezoelectric signals, since PZT was a more piezoelectrically active material [181]. Figure $9 \mathrm{~b}$ shows the self-charging power cell fabricated by hybrid $\mathrm{Al} /$ $\mathrm{LiCoO}_{2} / \mathrm{PVDF}-\mathrm{PZT} / \mathrm{MWCNT} / \mathrm{Cu}$, which was constructed as a sealed stainless steel 2016-coin-type cell with a diameter of $20 \mathrm{~mm}$ and was positioned underneath the touch buttons of a keyboard to harvest and store mechanical percussive forces. Generally, a unidirectional force was applied on the flexible devices to create additional forces in different directions and the induced strain along different directions can be effectively improved when pores are present in the 

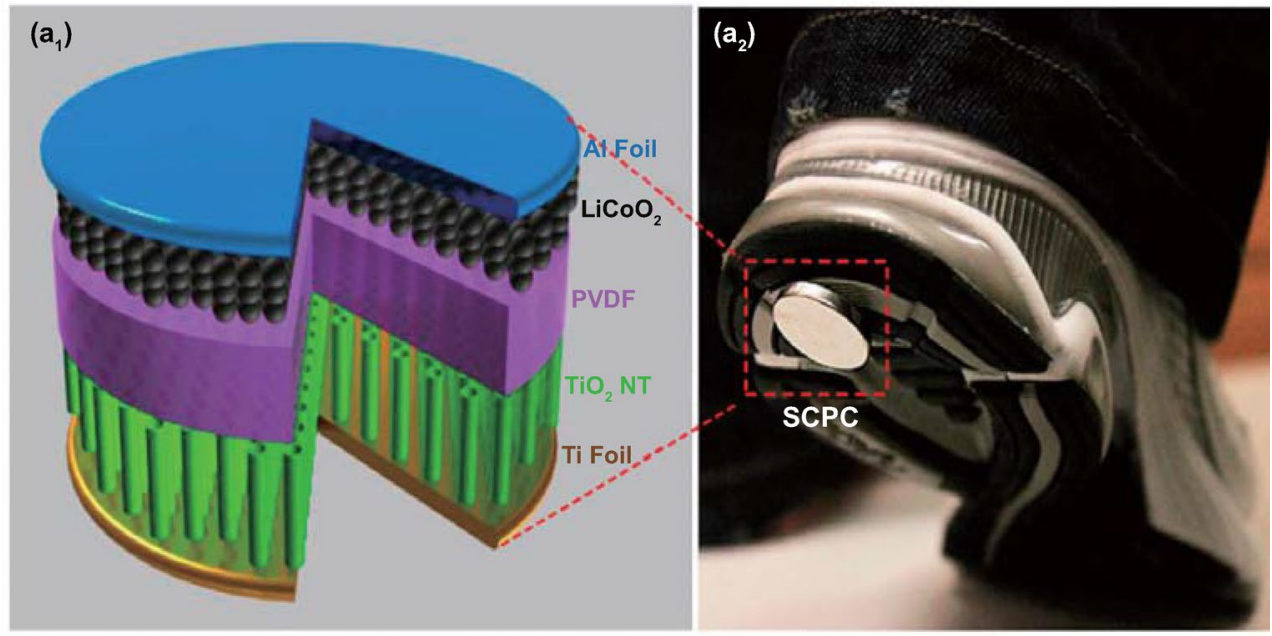

(b)

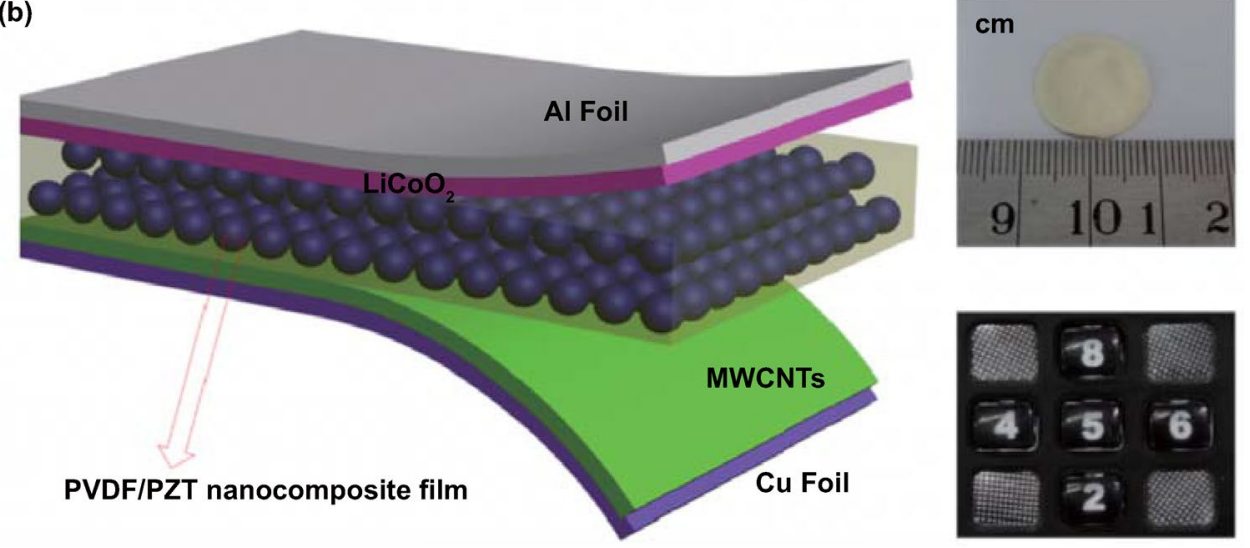

Fig. 9 a Schematic showing the design and structure of the self-charging power cell. This structure is sealed in stainless steel 2016-coin-type cells, as shown in the inset. On adhering a power cell to the bottom of a shoe, the compressive stress generated by walking can be converted and stored directly by SCPC. Reproduced with permission [44]. Copyright 2012, American Chemical Society. b Schematic structure of a SCPC with a PVDF-PZT nanocomposite film as a piezo-separator for charge storage. Photograph of PVDF-PZT nanocomposite film. Adhering an SCPC underneath the button of a calculator, the mechanical energy generated by pressing the button can be converted and directly stored by the SCPC. Reproduced with permission [181]. Copyright 2014, IOP Publishing Ltd

flexible materials [229]. In this case, the porous PVDF nanostructured film exhibited an enhanced piezoelectric output under an applied stress [83, 84]. The charge and discharge properties of highly porous piezoelectric PVDF membrane for a self-charging power cell are illustrated in Fig. 10 [84]. Under the application of a mechanical compression with an energy of $282 \mathrm{~mJ}$ and a frequency of $1 \mathrm{~Hz}$, the voltage increases from 1.2 to $1.4 \mathrm{~V}$ within $200 \mathrm{~s}$. Subsequently, the galvanostatically discharged reaction performs a constant voltage drop until $1.185 \mathrm{~V}$ with a current of $0.01 \mathrm{~mA}$, where $0.4 \mu \mathrm{Ah}$ is needed to return to the original potential of $1.2 \mathrm{~V}$. Finally, the self-charging power cell reaches an equilibrium level. Under mechanical energies of 141 and $282 \mathrm{~mJ}$ at a frequency of $1 \mathrm{~Hz}$ for $200 \mathrm{~s}$, the cell can be self-charged to 1335 and $1400 \mathrm{mV}$, respectively. The charge and discharge processes are stable under the same condition and even under the application of finger pressure, the power cell could be self-charged. After mechanically shocking for $3000 \mathrm{~s}$, the device exhibited no unexpected fluctuations, thereby indicating the stability of the piezo-separator in the self-charging power cell.

Supercapacitors are universally known as one of the most potential next-generation energy storage candidates because of their ultra-high power density, high 

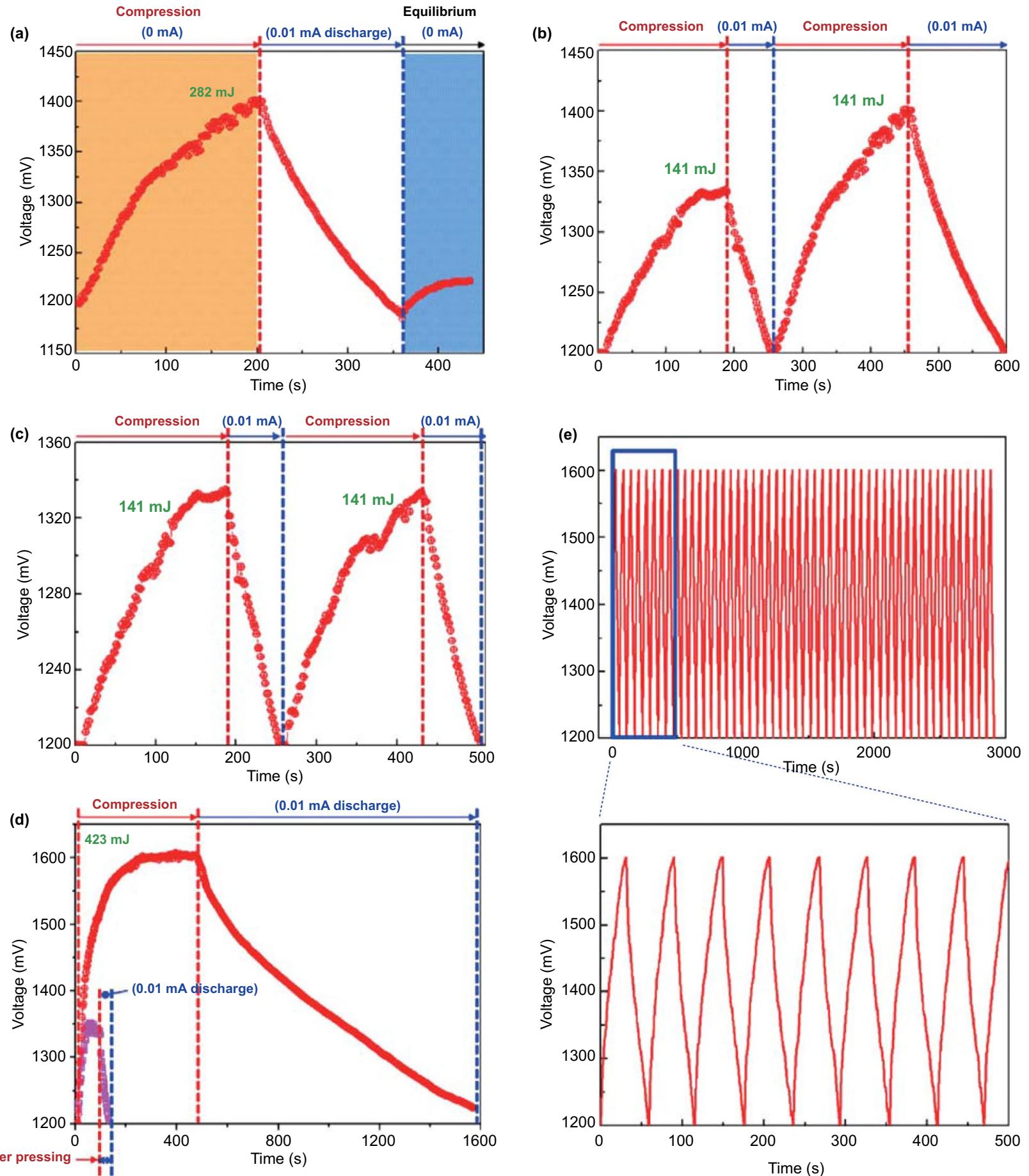

Fig. 10 a Typical self-charging curve comprised by compression, discharge and equilibrium regions. b Self-charging cycles with different applied forces. c Self-charging cycles with identical applied forces. d Comparison of self-charging performances via compressed by finger pressure and a higher mechanical force. e Galvanostatic charge/discharge profile. Reproduced with permission [84]. Copyright 2015, Elsevier

charge, and discharge rates, as well as long service life [230-233]. Ramadoss et al. investigated a self-charging supercapacitor power cell with PVDF-ZnO film as the separator and $\mathrm{MnO}_{2}$ nanowires as the positive and negative electrodes in a supercapacitor [45]. The cell exhibited a self-charging capability under palm impact, where 
the aluminum-foil-based and the fabric-based devices were charged 110 and $45 \mathrm{mV}$ within $300 \mathrm{~s}$, respectively. In addition, green LEDs could be illuminated when the power cell acted as a power source. The application of piezo-electro-chemical-related self-charging power cells offers a promising research direction for advanced functional self-powered small-scale devices.

Piezoelectric properties aside, materials that facilitate ion transfer and flexibility are ideal issues for piezo-electrochemical practical applications in self-charging power cells. (a)

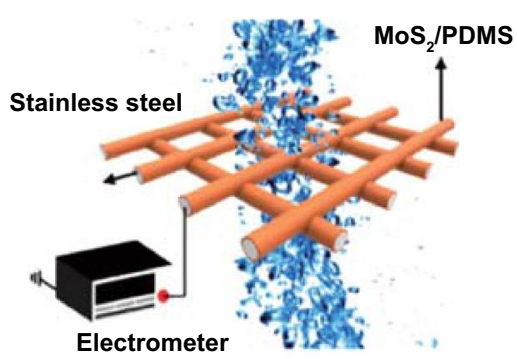

(d)
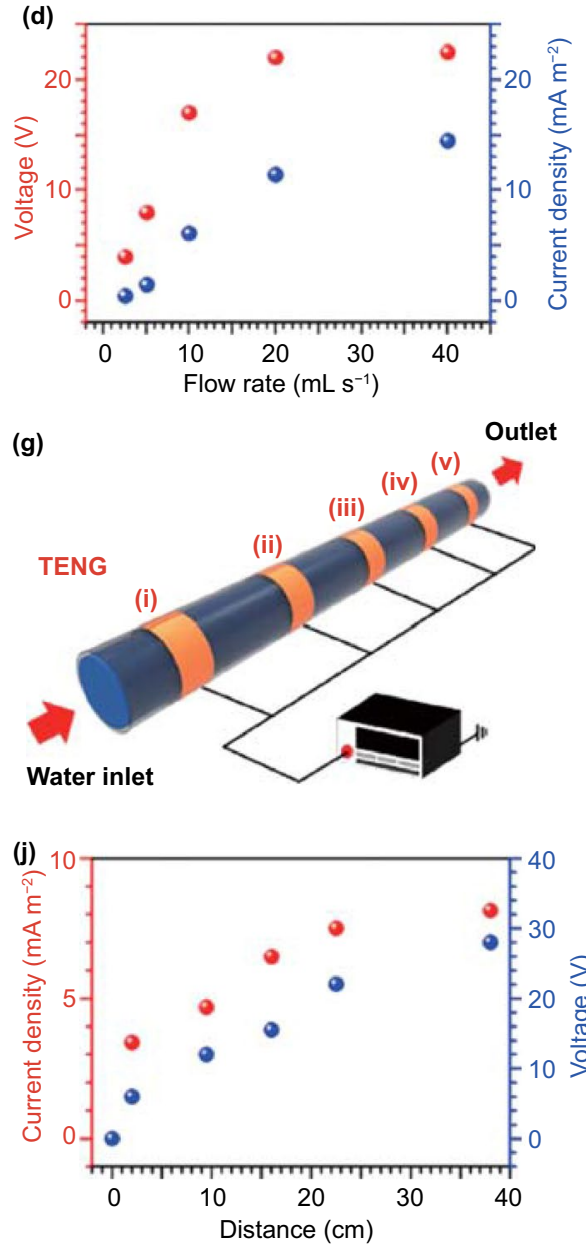

(b)
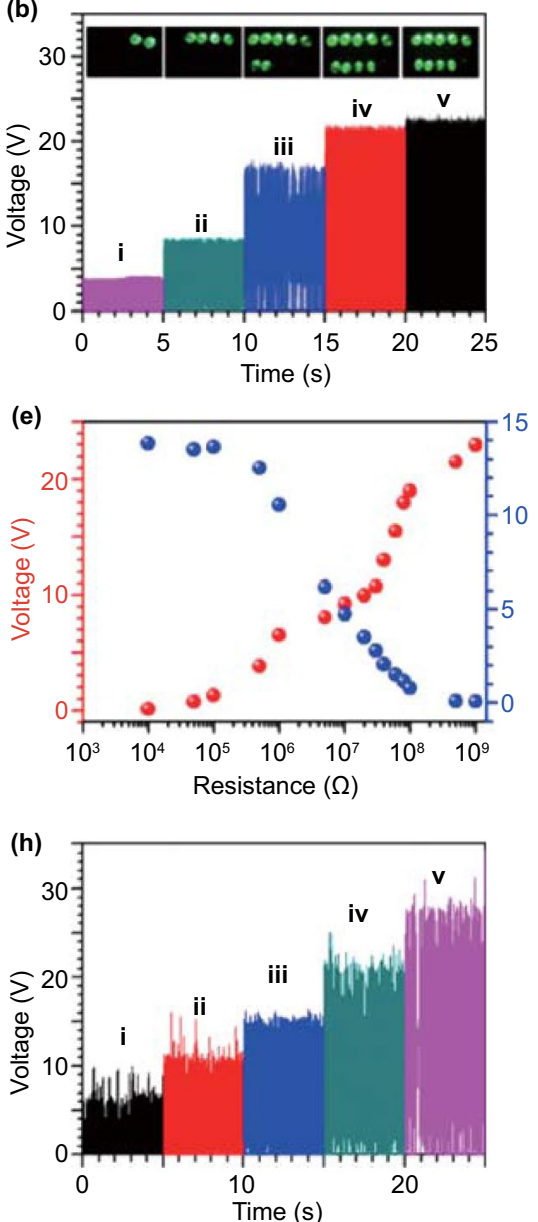

(k)

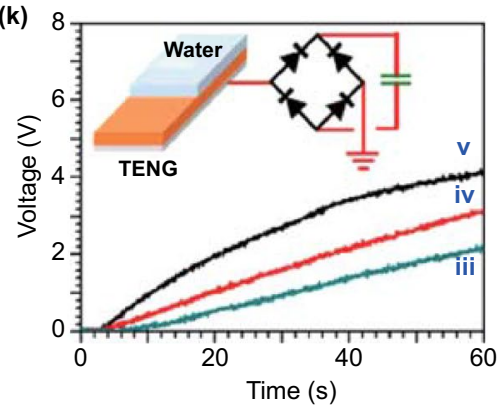

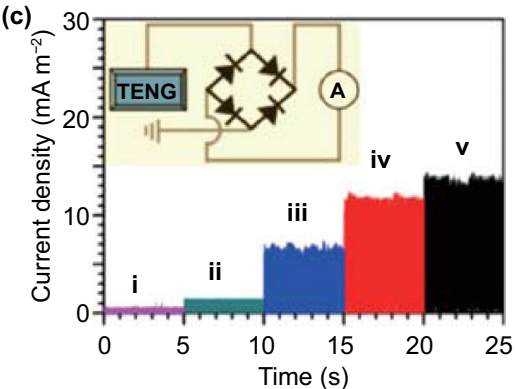
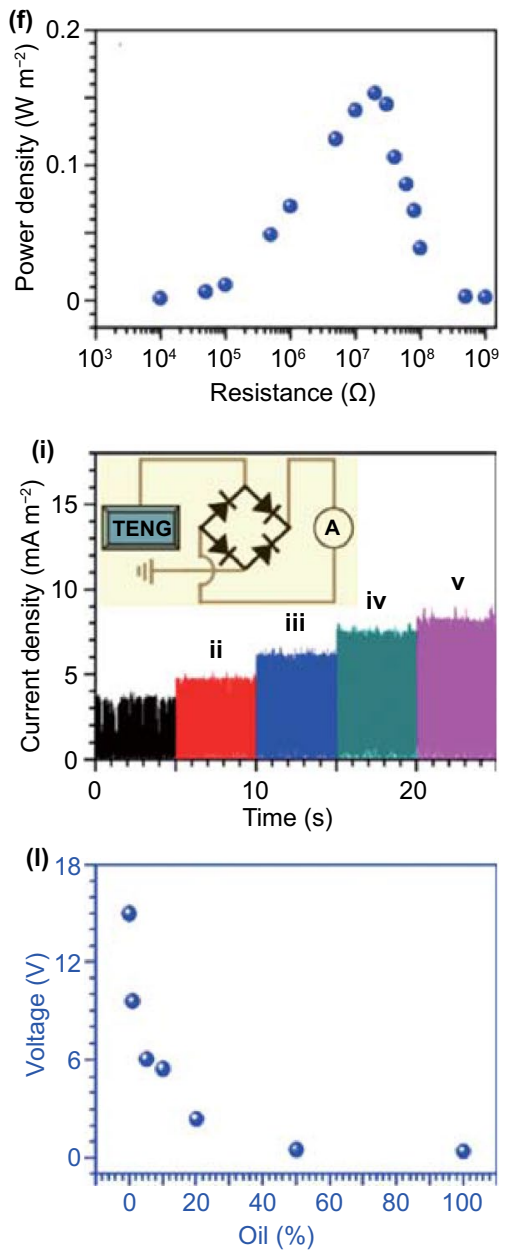

Fig. 11 a-f Illustration and performance of nanogenerator manufactured from a MoS 2 PDMS nanocomposite coating on a commercial stainless steel grid. g-l Illustration and performance of a thin water-TENG attached to different positions inside a polymer tube. Reproduced with permission [73]. Copyright 2017, Elsevier 


\subsection{Additional Piezoelectric Electro-chemical Applications}

In the previous section, we have discussed self-charging power cells, which combined a Li-ion battery structure and a nanogenerator for simultaneous generation and storage of energy sources. Individual nanogenerators have also been utilized in practical applications in electro-chemistry systems. Zhang et al. produced a flexible hybrid nanogenerator for cathodic protection without the need for any external power source, where the nanogenerator output protected the metal surface from chemical corrosion [90]. In Lin's work, a $\mathrm{MoS}_{2} / \mathrm{PDMS}$ composite nanogenerator with a different structure exhibited sensitive characteristics which depended on the water flow rate and position, as well as contamination detection in wastewater [73]; schematics of the devices and their performance are illustrated in Fig. 11. A nanogenerator was produced by coating a $\mathrm{MoS}_{2} / \mathrm{PDMS}$ composite (additive $\mathrm{MoS}_{2}$ amount of $5 \%$ in weight percentage) on a commercial stainless steel grid, as shown in Fig. 11a-f, with the composite nanogenerator being $5 \times 5 \mathrm{~cm}^{2}$, and the grid diameter and area of $200 \mu \mathrm{m}$ and $\sim 2 \mathrm{~cm}^{2}$, respectively. The nanogenerator was placed under a kitchen faucet, and the distance between the faucet and the nanogenerator was fixed at $\sim 30 \mathrm{~cm}$. It was observed that a faster water flow rate led to a higher output voltage and current density of the device. When the water flow rates were 2.5 and $20 \mathrm{~mL} \mathrm{~s}^{-1}$, the generated electric output $\sim 23$ and $\sim 4 \mathrm{~V}$ was able to drive two and nine LEDs, respectively. A nanogenerator was also produced by coating a $\mathrm{MoS}_{2} / \mathrm{PDMS}$ composite on a flexible substrate with a conducting layer, as shown in Fig. 11g-1. The output generated was at a maximum when the nanogenerator was the nearest to the water inlet. With an increase in the distance from the water inlet, both the output voltage and current density of the generator gradually decreased. In addition, the generated output was dependent on the oil content of the water, since any interaction between the nanogenerator and oil weakened the contact between the aqueous solution and the piezoelectric nanogenerator.

Biological systems have also been examined. The selfhealing phenomenon of organisms is a stable and balanced mechanism to achieve self-recovery and self-regulation [234-237]. Generally, osteoblasts control the reaction of bone healing and growth in living bodies [238]. Without osteoblasts present, Karem et al. reported that deformed collagen produced the deposition of hydroxyapatite (HA) via an electro-chemical process due to the piezoelectric effect, where the rate of deposition of HA was able to control bone healing and growth, which indicated the possibility to help with the self-healing of bones via harvesting biomechanical motion [85]. For bionic applications, selfhealing devices and structures have been fabricated to reestablish the structural mass under dynamic service loads excitation via imitating biological bone healing structures. Soroushian and coauthors proposed a PVDF-HFP solid electrolyte and self-healing structure, which was able to redistribute the structural mass in response to dynamic loads due to the piezoelectricity to convert mechanical energy into electrical energy [186].

\section{Conclusion}

This review has covered in detail current progress on the variety of piezoelectric materials for controlling electrochemical processes to inspire rising efforts in the emerging research field. Table 1 provides a summary of the piezoelectric material types, their characteristics, and piezo-electrochemical processes which cover a wide range of piezoelectric materials including piezoelectric perovskites, wurtzite zinc oxide, two-dimensional layered transition metal dichalcogenide family, organic piezoelectric materials, and biological materials. The material magnitude and morphology are varied for the creation of macro-/micro-/nanomaterials and include materials in bulk, fiber, sheet, flower, particle, and irregular form, which have been synthesized by different physical, chemical, or biological methods. The practical electro-chemical applications of these piezoelectric materials include selective deposition, hydrogen production, dye degradation, and self-charging power cells. The degree by which the piezoelectric materials and external conditions influence the electro-chemical system is of significant interest and has also been summarized. In order to achieve a high piezoelectric output, materials with high aspect ratio are preferred to obtain optimum deformation under a mechanical load. In addition, piezoelectric materials with a specific resonant frequency can be exploited to harvest mechanical vibrations ranging in different frequency bands for different practical applications. These factors provide a reliable guidance on the selection of piezoelectric materials for experimental designs. 
Today, energy generation and environmental pollution have become significant challenges for humanity. Piezoelectric materials in electro-chemical applications can play important roles in bringing new ideas and approaches to resolve issues from challenges of energy and environment. We have seen that specific piezoelectric domains can affect the electro-chemical selective deposition, where polarization structures can be controlled by an electric field. This research can lead to the potential in developing methods to coat materials with specific polarized piezoelectric materials that can be utilized in corrosion resistance. Furthermore, the strong ability of piezoelectric materials in cleaning wastewater could be a replacement for photo-cleaning and enable piezoelectric materials to be used for self-cleaning the surface of buildings. For energy harvesting, piezoelectric materials allow the conversion of environmental mechanical vibrations across a large range of frequencies into an electric energy source. Energy storage is the capture of electric energy produced that is available for use at a later time, and self-charging power cells that use a piezo-separator can realize a simultaneous approach to combining energy harvesting and storage, which can be applied in ocean wave vibration energy harvesting and storage for further because there are abundant water fluctuations in ocean. However, piezo-electro-chemical applications in laboratory work are far inferior to commercial market to benefit humans. First, energy conversion efficiency is always needed to improve in order to achieve maximum energy use and minimize waste at sources. Second, actually most materials and devices in laboratory perform great in ideal circumstances, but when these products come to real tests, they will be difficult to maintain a long lifetime. Third, a variety of samples manufactured with sophisticated equipment and costed costly manpower and material resources in order to pursue high performance; however, cost is an indispensable consideration in business models.

In addition, the potential for coupling multiple systems is of great interest and piezo-electro-chemistry has the potential to work together with photo-electro-chemistry, including piezoelectric affected photo-deposition, photocatalytic hydrogen production, and photodegradation. To achieve piezoelectric and photovoltaic coupling, ferroelectric semiconductors can exhibit piezoelectricity, pyroelectricity, ferroelectricity, as well as photovoltaic effects, which can achieve multiple coupling in a single material. On the basis of piezoelectric, pyroelectric photovoltaic, thermoelectric, triboelectric, and flexoelectric effects, the design for their efficient coupling could be analyzed for further. Finally, although piezo-electro-chemical applications have attracted a large amount of interest with a growing number of researches, patents, and publications, the business conversion of these potential applications is necessary.

Acknowledgements This work was supported by the National Key R\&D Project from Minister of Science and Technology in China (No. 2016YFA0202701), the National Natural Science Foundation of China (No. 51472055), External Cooperation Program of BIC, Chinese Academy of Sciences (No. 121411KYS820150028), the 2015 Annual Beijing Talents Fund (No. 2015000021223ZK32), Qingdao National Laboratory for Marine Science and Technology (No. 2017ASKJ01), the University of Chinese Academy of Sciences (Grant No. Y8540XX2D2), and the 'thousands talents' program for the pioneer researcher and his innovation team, China.

Open Access This article is licensed under a Creative Commons Attribution 4.0 International License, which permits use, sharing, adaptation, distribution and reproduction in any medium or format, as long as you give appropriate credit to the original author(s) and the source, provide a link to the Creative Commons licence, and indicate if changes were made. The images or other third party material in this article are included in the article's Creative Commons licence, unless indicated otherwise in a credit line to the material. If material is not included in the article's Creative Commons licence and your intended use is not permitted by statutory regulation or exceeds the permitted use, you will need to obtain permission directly from the copyright holder. To view a copy of this licence, visit http://creativecommons.org/licenses/by/4.0/.

\section{References}

1. P. Curie, J. Curie, Development, via compression, of electric polarization in hemihedral crystals with inclined faces. Bull. Soc. Minerol. Fr. 3, 90-93 (1880)

2. Z. Liang, C.F. Yan, S. Rtimi, J. Bandara, Piezoelectric materials for catalytic/photocatalytic removal of pollutants: recent advances and outlook. Appl. Catal. B 241, 256-269 (2019). https://doi.org/10.1016/j.apcatb.2018.09.028

3. M.B. Starr, X.D. Wang, Coupling of piezoelectric effect with electrochemical processes. Nano Energy 14, 296-311 (2015). https://doi.org/10.1016/j.nanoen.2015.01.035

4. R.S. Dahiya, A. Adami, C. Collini, L. Lorenzelli, POSFET tactile sensing arrays using CMOS technology. Sens. Actuat. A 202, 226-232 (2013). https://doi.org/10.1016/j. sna.2013.02.007

5. C.R. Bowen, H.A. Kim, P.M. Weaver, S. Dunn, Piezoelectric and ferroelectric materials and structures for energy harvesting applications. Energy Environ. Sci. 7, 25-44 (2014). https ://doi.org/10.1039/C3EE42454E

6. D. Damjanovic, Ferroelectric, dielectric and piezoelectric properties of ferroelectric thin films and 
ceramics. Rep. Prog. Phys. 61, 1267-1324 (1998). https:// doi.org/10.1088/0034-4885/61/9/002

7. J. Wu, Z. Wu, W.Q. Qian, Y.M. Jia, Y. Wang, H.S. Luo, lectric-field-treatment-induced enhancement of photoluminescence in $\mathrm{Er}^{3+}$-doped $\left(\mathrm{Ba}_{0.95} \mathrm{Sr}_{0.05}\right)\left(\mathrm{Zr}_{0.1} \mathrm{Ti}_{0.9}\right) \mathrm{O}_{3}$ piezoelectric ceramic. Mater. Lett. 184, 131-133 (2016). https://doi. org/10.1016/j.matlet.2016.07.061

8. P.P. Shi, Y.Y. Tang, P.F. Li, W.Q. Liao, Z.X. Wang, Q. Ye, R.G. Xiong, Symmetry breaking in molecular ferroelectrics. Chem. Soc. Rev. 45, 3811-3827 (2016). https://doi. org/10.1039/C5CS00308C

9. A.L. Kholkin, N.A. Pertsev, A.V. Goltsev, Piezoelectricity and crystal symmetry, in Piezoelectric and Acoustic Materials for Transducer Applications, ed. by A. Safari, E.K. Akdogan (Springer, Berlin, 2008), pp. 17-38. https://doi. org/10.1007/978-0-387-76540-2

10. A.A. Marino, R.O. Becker, Piezoelectric effect and growth control in bone. Nature 228, 473-474 (1970). https://doi. org/10.1038/228473a0

11. I. Katsouras, K. Asadi, M.Y. Li, T.B. van Driel, K.S. Kjaer et al., The negative piezoelectric effect of the ferroelectric polymer poly(vinylidene fluoride). Nat. Mater. 15, 78-84 (2016). https://doi.org/10.1038/nmat4423

12. P.S. Brody, Large polarization-dependent photovoltages in ceramic $\mathrm{BaTiO}_{3}+5 \mathrm{wt} \% \mathrm{CaTiO}_{3}$. Solid State Commun. 12, 673-676 (1973). https://doi.org/10.1016/00381098(73)90310-4

13. P.S. Brody, High-voltage photovoltaic effect in barium-titanate and lead titanate lead zirconate ceramics. J. Solid State Chem. 12, 193-200 (1975). https://doi. org/10.1016/0022-4596(75)90305-9

14. V.M. Fridkin, Review of recent work on the bulk photovoltaic effect in ferro and piezoelectrics. Ferroelectrics 53, 169-187 (1984). https://doi.org/10.1080/001501984082450 47

15. J.L. Giocondi, G.S. Rohrer, Spatially selective photochemical reduction of silver on the surface of ferroelectric barium titanate. Chem. Mater. 13, 241-242 (2001). https://doi. org/10.1021/cm000890h

16. J.L. Giocondi, G.S. Rohrer, Spatial separation of photochemical oxidation and reduction reactions on the surface of ferroelectric $\mathrm{BaTiO}_{3}$. J. Phys. Chem. B 105, 8275-8277 (2001). https://doi.org/10.1021/jp011804j

17. A. Bhardwaj, N.V. Burbure, A. Gamalski, G.S. Rohrer, Composition dependence of the photochemical reduction of Ag by $\mathrm{Ba}_{1-\mathrm{x}} \mathrm{Sr}_{\mathrm{x}} \mathrm{TiO}_{3}$. Chem. Mater. 22, 3527-3534 (2010). https://doi.org/10.1021/cm100718t

18. W. Wu, X. Wen, Z.L. Wang, Taxel-addressable matrix of vertical-nanowire piezotronic transistors for active and adaptive tactile imaging. Science 340, 952-957 (2013). https://doi.org/10.1126/science.1234855

19. Y. Zhang, M.Y. Xie, V. Adamaki, H. Khanbareh, C.R. Bowen, Control of electro-chemical processes using energy harvesting materials and devices. Chem. Soc. Rev. 46, 7757-7786 (2017). https://doi.org/10.1039/c7cs00387k
20. G. Sebald, D. Guyomar, A. Agbossou, On thermoelectric and pyroelectric energy harvesting. Smart Mater. Struct. 18(12), 125006-125007 (2009). https://doi. org/10.1088/0964-1726/18/12/125006

21. Z.Y. Fei, W.J. Zhao, T.A. Palomaki, B.S. Sun, M.K. Miller et al., Ferroelectric switching of a two-dimensional metal. Nature 560, 336-339 (2018). https://doi.org/10.1038/s4158 6-018-0336-3

22. W. Li, L.J. Ji, Perovskite ferroelectrics go metal free. Science 361, 132 (2018). https://doi.org/10.1126/science.aat5729

23. C.H. Ahn, K.M. Rabe, J.M. Triscone, Ferroelectricity at the nanoscale: local polarization in oxide thin films and heterostructures. Science 303, 488-491 (2004). https://doi. org/10.1126/science. 1092508

24. Y.M. You, W.Q. Liao, D.W. Zhao, H.Y. Ye, Y. Zhang et al., An organic-inorganic perovskite ferroelectric with large piezoelectric response. Science 357, 306-309 (2017). https:// doi.org/10.1126/science.aai8535

25. Z.L. Wang, J.H. Song, Piezoelectric nanogenerators based on zinc oxide nanowire arrays. Science 312, 242-246 (2006). https://doi.org/10.1126/science.1124005

26. S.C. Masmanidis, R.B. Karabalin, I. De Vlaminck, G. Borghs, M.R. Freeman, M.L. Roukes, Multifunctional nanomechanical systems via tunably coupled piezoelectric actuation. Science 317, 780-783 (2007). https://doi.org/10.1126/ science. 1144793

27. M.B. Starr, X.D. Wang, Fundamental analysis of piezocatalysis process on the surfaces of strained piezoelectric materials. Sci. Rep. 3, 2160 (2013). https://doi.org/10.1038/srep02160

28. A. Fujishima, K. Honda, Electrochemical photolysis of water at a semiconductor electrode. Nature 238, 37-38 (1972). https ://doi.org/10.1038/238037a0

29. D. Das, T.N. Veziroglu, Hydrogen production by biological processes: a survey of literature. Int. J. Hydrog. Energy 26, 13-28 (2001). https://doi.org/10.1016/s0360-3199(00)00058 $-6$

30. S.A. Grigoriev, V.I. Porembsky, V.N. Fateev, Pure hydrogen production by PEM electrolysis for hydrogen energy. Int. J. Hydrog. Energy 31, 171-175 (2006). https://doi. org/10.1016/j.ijhydene.2005.04.038

31. A. Mostafaeipour, M. Khayyami, A. Sedaghat, K. Mohammadi, S. Shamshirband, M.A. Sehati, E. Gorakifard, Evaluating the wind energy potential for hydrogen production: a case study. Int. J. Hydrog. Energy 41, 6200-6210 (2016). https:// doi.org/10.1016/j.ijhydene.2016.03.038

32. K.S. Hong, H.F. Xu, H. Konishi, X.C. Li, Direct water splitting through vibrating piezoelectric microfibers in water. J. Phys. Chem. Lett. 1, 997-1102 (2010). https://doi. org/10.1021/jz100027t

33. M.Z. Jacobson, G.M. Masters, Energy: exploiting wind versus coal. Science 293, 1438 (2001). https://doi.org/10.1126/ science. 1063376

34. W.D. Metz, Wind energy: large and small systems competing. Science 197, 971-973 (1977). https://doi.org/10.1126/scien ce.197.4307.971 
35. M. Qolipour, A. Mostafaeipour, O.M. Tousi, Techno-economic feasibility of a photovoltaic-wind power plant construction for electric and hydrogen production: a case study. Renew. Sustain. Energy Rev. 78, 113-123 (2017). https://doi. org/10.1016/j.rser.2017.04.088

36. H.D. Li, Y.H. Sang, S.J. Chang, X. Huang, Y. Zhang et al., Enhanced ferroelectric-nanocrystal-based hybrid photocatalysis by ultrasonic-wave-generated piezophototronic effect. Nano Lett. 15, 2372-2379 (2015). https://doi.org/10.1021/ $\mathrm{nl} 504630 \mathrm{j}$

37. W. Qian, K. Zhao, D. Zhang, C.R. Bowen, Y. Wang, Y. Yang, Piezoelectric material-polymer composite porous foam for efficient dye degradation via the piezo-catalytic effect. ACS Appl. Mater. Interfaces. 11, 27862-27869 (2019). https://doi. org/10.1021/acsami.9b07857

38. Y.L. Zhang, A.M. Schultz, P.A. Salvador, G.S. Rohrer, Spatially selective visible light photocatalytic activity of $\mathrm{TiO}_{2} /$ $\mathrm{BiFeO}_{3}$ heterostructures. J. Mater. Chem. 21, 4168-4174 (2011). https://doi.org/10.1039/c0jm04313c

39. V. Bermudez, F. Caccavale, C. Sada, F. Segato, E. Dieguez, Etching effect on periodic domain structures of lithium niobate crystals. J. Cryst. Growth 191, 589-593 (1998). https ://doi.org/10.1016/S0022-0248(98)00394-7

40. F. Kubel, H. Schmid, Growth, twinning and etch figures of ferroelectric ferroelastic dendritic $\mathrm{BiFeO} 3$ single domain crystals. J. Cryst. Growth 129, 515-524 (1993). https://doi. org/10.1016/0022-0248(93)90485-f

41. W.L. Holstein, Etching study of ferroelectric microdomains in $\mathrm{LiNbO}_{3}$ and $\mathrm{MgO}: \mathrm{LiNbO}_{3}$. J. Cryst. Growth 171, 477484 (1997). https://doi.org/10.1016/S0022-0248(96)00681 $-1$

42. O.Y. Gorobets, S.V. Gorobets, O.K. Dvoynenko, Correlation between the sizing features of domain structure and the etching figures of a steel cylinder. Metallofiz Nov. Tekh. 34, 1027-1034 (2012). https://doi.org/10.1063/1.1754147

43. C.L. Sones, S. Mailis, W.S. Brocklesby, R.W. Eason, J.R. Owen, Differential etch rates in z-cut LiNbO3 for variable HF/HNO3 concentrations. J. Mater. Chem. 12, 295-298 (2002). https://doi.org/10.1039/b106279b

44. X.Y. Xue, S.H. Wang, W.X. Guo, Y. Zhang, Z.L. Wang, Hybridizing energy conversion and storage in a mechanicalto-electrochemical process for self-charging power cell. Nano Lett. 12, 5048-5054 (2012). https://doi.org/10.1021/n1302 $879 \mathrm{t}$

45. A. Ramadoss, B. Saravanakumar, S.W. Lee, Y.S. Kim, S.J. Kim, Z.L. Wang, Piezoelectric-driven self-charging supercapacitor power cell. ACS Nano 9, 4337-4345 (2015). https:// doi.org/10.1021/acsnano.5b00759

46. R.B. Song, H.Y. Jin, X. Li, L.F. Fei, Y.D. Zhao et al., A rectification-free piezo-supercapacitor with a polyvinylidene fluoride separator and functionalized carbon cloth electrodes. J. Mater. Chem. A 3, 14963-14970 (2015). https:// doi.org/10.1039/c5ta03349g

47. F. Wang, C.M. Jiang, C.L. Tang, S. Bi, Q.H. Wang, D.F. Du, J.H. Song, High output nano-energy cell with piezoelectric nanogenerator and porous supercapacitor dual functions-a technique to provide sustaining power by harvesting intermittent mechanical energy from surroundings. Nano Energy 21, 209-216 (2016). https://doi.org/10.1016/j.nanoe n.2016.01.018

48. K. Parida, V. Bhavanasi, V. Kumar, J.X. Wang, P.S. Lee, Fast charging self-powered electric double layer capacitor. J. Power Sources 342, 70-78 (2017). https://doi.org/10.1016/j. jpowsour.2016.11.083

49. B.S. Lee, J. Yoon, C. Jung, D.Y. Kim, S.Y. Jeon et al., Silicon/ carbon nanotube/BaTiO3 nanocomposite anode: evidence for enhanced lithium-ion mobility induced by the local piezoelectric potential. ACS Nano 10, 2617-2627 (2016). https:// doi.org/10.1021/acsnano.5b07674

50. S. Kim, S.J. Choi, K.J. Zhao, H. Yang, G. Gobbi, S.L. Zhang, J. Li, Electrochemically driven mechanical energy harvesting. Nat. Commun. 7, 10146 (2016). https://doi. org/10.1038/ncomms 10146

51. S.B. Lang, S.A.M. Tofail, A.L. Kholkin, M. Wojtas, M. Gregor et al., Ferroelectric polarization in nanocrystalline hydroxyapatite thin films on silicon. Sci. Rep. 3, 2215 (2013). https://doi.org/10.1038/srep02215

52. F.R. Baxter, C.R. Bowen, I.G. Turner, A.C.E. Dent, Electrically active bioceramics: a review of interfacial responses. Ann. Biomed. Eng. 38, 2079-2092 (2010). https://doi. org/10.1007/s10439-010-9977-6

53. N. Touach, V.M. Ortiz-Martinez, M.J. Salar-Garcia, A. Benzaouak, F. Hernandez-Fernandez et al., On the use of ferroelectric material $\mathrm{LiNbO}_{3}$ as novel photocatalyst in wastewater-fed microbial fuel cells. Particuology 34, 147155 (2017). https://doi.org/10.1016/j.partic.2017.02.006

54. E. Jacques, M.H. Kjell, D. Zenkert, G. Lindbergh, Piezoelectrochemical effect in lithium-intercalated carbon fibres. Electrochem. Commun. 35, 65-67 (2013). https://doi. org/10.1016/j.elecom.2013.07.040

55. E. Jacques, G. Lindbergh, D. Zenkert, S. Leijonmarck, M.H. Kjell, Piezo-electrochemical energy harvesting with lithium-intercalating carbon fibers. ACS Appl. Mater. Interfaces. 7, 13898-13904 (2015). https://doi.org/10.1021/ acsami.5b02585

56. S. Ikeda, T. Takata, T. Kondo, G. Hitoki, M. Hara et al., Mechano-catalytic overall water splitting. Chem. Commun. 20, 2185-2186 (1998). https://doi.org/10.1039/A804549F

57. E. Asadian, M. Ghalkhani, S. Shahrokhian, Electrochemical sensing based on carbon nanoparticles: a review. Sens. Actuator B 293, 183-209 (2019). https://doi.org/10.1016/j. snb.2019.04.075

58. L. Rossner, M. Armbruster, Electrochemical energy conversion on intermetallic compounds: a review. ACS Catal. 9, 2018-2062 (2019). https://doi.org/10.1021/acscatal.8b045 66

59. V. Vogiazi, A. de la Cruz, S. Mishra, V. Shanov, W.R. Heineman, D.D. Dionysiou, A comprehensive review: development of electrochemical biosensors for detection of cyanotoxins in freshwater. ACS Sens. 4, 1151-1173 (2019). https://doi. org/10.1021/acssensors.9b00376 
60. J. Kim, R. Kumar, A.J. Bandodkar, J. Wang, Advanced materials for printed wearable electrochemical devices: a review. Adv. Electron. Mater. 3, 1600260 (2017). https://doi. org/10.1002/aelm.201600260

61. E. Fresta, R.D. Costa, Beyond traditional light-emitting electrochemical cells - a review of new device designs and emitters. J. Mater. Chem. C 5, 5643-5675 (2017). https://doi. org/10.1039/C7TC00202E

62. X.C. Tian, J. Jin, S.Q. Yuan, C.K. Chua, S.B. Tor, K. Zhou, Emerging 3D-printed electrochemical energy storage devices: a critical review. Adv. Energy Mater. 7, 100127 (2017). https ://doi.org/10.1002/aenm.201700127

63. P.K. Nayak, E.M. Erickson, F. Schipper, T.R. Penki, N. Munichandraiah et al., Review on challenges and recent advances in the electrochemical performance of high capacity Li- and Mn-rich cathode materials for li-ion batteries. Adv. Energy Mater. 8, 1702397 (2018). https://doi.org/10.1002/ aenm. 201702397

64. R.G. Saratale, G.D. Saratale, A. Pugazhendhi, G.Y. Zhen, G. Kumar, A. Kadier, P. Sivagurunathan, Microbiome involved in microbial electrochemical systems (MESs): a review. Chemosphere 177, 176-188 (2017). https://doi.org/10.1016/j. chemosphere.2017.02.143

65. M.B. Starr, J. Shi, X.D. Wang, Piezopotential-driven redox reactions at the surface of piezoelectric materials. Angew. Chem. Int. Ed. 51, 5962-5966 (2012). https://doi. org/10.1002/ange.201201424

66. J. Zhang, Z. Wu, Y.M. Jia, J.W. Kan, G.M. Cheng, Piezoelectric bimorph cantilever for vibration-producing-hydrogen. Sensors 13, 367-374 (2013). https://doi.org/10.3390/s1301 00367

67. H. Lin, Z. Wu, Y.M. Jia, W.J. Li, R.K. Zheng, H.S. Luo, Piezoelectrically induced mechano-catalytic effect for degradation of dye wastewater through vibrating $\mathrm{Pb}\left(\mathrm{Zr}_{0.52} \mathrm{Ti}_{0.48}\right)$ $\mathrm{O}_{3}$ fibers. Appl. Phys. Lett. 104, 162907 (2014). https://doi. org/10.1063/1.4873522

68. M.K. Lo, S.Y. Lee, K.S. Chang, Study of $\mathrm{ZnSnO}_{3}$-nanowire piezophotocatalyst using two-step hydrothermal synthesis. J. Phys. Chem. C 119, 5218-5224 (2015). https://doi. org/10.1021/acs.jpcc.5b00282

69. C.F. Tan, W.L. Ong, G.W. Ho, Self-biased hybrid piezoelectric-photoelectrochemical cell with photocatalytic functionalities. ACS Nano 9, 7661-7670 (2015). https://doi. org/10.1021/acsnano.5b03075

70. H.L. You, Y.M. Jia, Z. Wu, X.L. Xu, W.Q. Qian, Y.T. Xia, M. Ismail, Strong piezo-electrochemical effect of multiferroic $\mathrm{BiFeO}_{3}$ square micro-sheets for mechanocatalysis. Electrochem. Commun. 79, 55-58 (2017). https://doi.org/10.1016/j. elecom.2017.04.017

71. H.L. You, Z. Wu, L.H. Zhang, Y.R. Ying, Y. Liu et al., Harvesting the vibration energy of $\mathrm{BiFeO}_{3}$ nanosheets for hydrogen evolution. Angew. Chem. Int. Ed. 58, 11779-11784 (2019). https://doi.org/10.1002/anie.201906181

72. J.M. Wu, W.E. Chang, Y.T. Chang, C.K. Chang, Piezocatalytic effect on the enhancement of the ultra-high degradation activity in the dark by single- and few-layers $\mathrm{MoS}_{2}$ nanoflowers. Adv. Mater. 28, 3718-3725 (2016). https://doi. org/10.1002/adma.201505785

73. J.H. Lin, Y.H. Tsao, M.H. Wu, T.M. Chou, Z.H. Lin, J.M. $\mathrm{Wu}$, Single- and few-layers $\mathrm{MoS}_{2}$ nanocomposite as piezocatalyst in dark and self-powered active sensor. Nano Energy 31, 575-581 (2017). https://doi.org/10.1016/j.nanoe n.2016.12.013

74. N.V. Burbure, P.A. Salvador, G.S. Rohrer, Photochemical reactivity of titania films on $\mathrm{BaTiO}_{3}$ substrates: origin of spatial selectivity. Chem. Mater. 22, 5823-5830 (2010). https:// doi.org/10.1021/cm1018025

75. S.Y. Lan, J.X. Feng, Y. Xiong, S.H. Tian, S.W. Liu, L.J. Kong, Performance and mechanism of piezo-catalytic degradation of 4-chlorophenol: finding of effective piezo-dechlorination. Environ. Sci. Technol. 51, 6560-6569 (2017). https ://doi.org/10.1021/acs.est.6b06426

76. W. Lv, L.J. Kong, S.Y. Lan, J.X. Feng, Y. Xiong, S.H. Tian, Enhancement effect in the piezoelectric degradation of organic pollutants by piezo-Fenton process. J. Chem. Technol. Biotechnol. 92, 152-156 (2017). https://doi.org/10.1002/ jctb.4981

77. D. Tiwari, S. Dunn, Q. Zhang, Impact of $\mathrm{Zr} / \mathrm{Ti}$ ratio in the PZT on the photoreduction of silver nanoparticles. Mater. Res. Bull. 44, 1219-1224 (2009). https://doi.org/10.1016/j. materresbull.2009.01.016

78. F. Mushtaq, X. Chen, M. Hoop, H. Torlakcik, E. Pellicer et al., Piezoelectrically enhanced photocatalysis with $\mathrm{BiFeO}_{3}$ nanostructures for efficient water remediation. Science $\mathbf{4}$, 236-246 (2018). https://doi.org/10.1016/j.isci.2018.06.003

79. C. Sun, Y.M. Fu, Q. Wang, L.L. Xing, B.D. Liu, X.Y. Xue, Ultrafast piezo-photocatalytic degradation of organic pollutions by $\mathrm{Ag}_{2} \mathrm{O}$ /tetrapod- $\mathrm{ZnO}$ nanostructures under ultrasonic/ UV exposure. RSC Adv. 6, 87446-87453 (2016). https://doi. org/10.1039/C6RA13464E

80. D.Y. Hong, W.L. Zang, X. Guo, Y.M. Fu, H.X. He et al., High piezo-photocatalytic efficiency of $\mathrm{CuS} / \mathrm{ZnO}$ nanowires using both solar and mechanical energy for degrading organic dye. ACS Appl. Mater. Interfaces. 8, 21302-21314 (2016). https ://doi.org/10.1021/acsami.6b05252

81. M.H. Wu, J.T. Lee, Y.J. Chung, M. Srinivaas, J.M. Wu, Ultrahigh efficient degradation activity of single- and few-layered $\mathrm{MoSe}_{2}$ nanoflowers in dark by piezo-catalyst effect. Nano Energy 40, 369-375 (2017). https://doi.org/10.1016/j.nanoe n.2017.08.042

82. S. Masimukku, Y.C. Hu, Z.H. Lin, S.W. Chan, T.M. Chou, J.M. Wu, High efficient degradation of dye molecules by PDMS embedded abundant single-layer tungsten disulfide and their antibacterial performance. Nano Energy 46, 338346 (2018). https://doi.org/10.1016/j.nanoen.2018.02.008

83. L.L. Xing, Y.X. Nie, X.Y. Xue, Y. Zhang, PVDF mesoporous nanostructures as the piezo-separator for a self-charging power cell. Nano Energy 10, 44-52 (2014). https://doi. org/10.1016/j.nanoen.2014.09.004

84. Y.S. Kim, Y.N. Xie, X.N. Wen, S.H. Wang, S.J. Kim, H.K. Song, Z.L. Wang, Highly porous piezoelectric PVDF membrane as effective lithium ion transfer channels for enhanced 
self-charging power cell. Nano Energy 14, 77-86 (2015). https://doi.org/10.1016/j.nanoen.2015.01.006

85. K. Noris-Suarez, J. Lira-Olivares, A.M. Ferreira, A. Graterol, J.L. Feijoo, S.W. Lee, Electrochemical influence of collagen piezoelectric effect in bone healing. Mater. Sci. Forum 544545, 981-984 (2007). https://doi.org/10.4028/www.scientific .net/MSF.544-545.981

86. J.L. Giocondi, G.S. Rohrer, The influence of the dipolar field effect on the photochemical reactivity of $\mathrm{Sr}_{2} \mathrm{Nb}_{2} \mathrm{O}_{7}$ and $\mathrm{BaTiO}_{3}$ microcrystals. Top. Catal. 49, 18-23 (2008). https:// doi.org/10.1007/s11244-008-9067-2

87. K.S. Hong, H.F. Xu, H. Konishi, X.C. Li, Piezoelectrochemical effect: a new mechanism for azo dye decolorization in aqueous solution through vibrating piezoelectric microfibers. J. Phys. Chem. C 116, 13045-13051 (2012). https://doi. org/10.1021/jp211455z

88. X.Y. Xue, W.L. Zang, P. Deng, Q. Wang, L.L. Xing, Y. Zhang, Z.L. Wang, Piezo-potential enhanced photocatalytic degradation of organic dye using $\mathrm{ZnO}$ nanowires. Nano Energy 13, 414-422 (2015). https://doi.org/10.1016/j.nanoe n.2015.02.029

89. Y.T. Wang, K.S. Chang, Piezopotential-induced schottky behavior of $\mathrm{Zn}_{1-\mathrm{x}} \mathrm{SnO}_{3}$ nanowire arrays and piezophotocatalytic applications. J. Am. Ceram. Soc. 99, 2593-2600 (2016). https://doi.org/10.1111/jace.14264

90. H.L. Zhang, S.J. Zhang, G. Yao, Z.L. Huang, Y.H. Xie et al., Simultaneously harvesting thermal and mechanical energies based on flexible hybrid nanogenerator for self-powered cathodic protection. ACS Appl. Mater. Interfaces. 7, 28142 28147 (2015). https://doi.org/10.1021/acsami.5b10923

91. X.F. Bai, J. Wei, B.B. Tian, Y. Liu, T. Reiss et al., Size effect on optical and photocatalytic properties in $\mathrm{BiFeO}_{3}$ nanoparticles. J. Phys. Chem. C 120, 3595-3601 (2016). https://doi. org/10.1021/acs.jpcc.5b09945

92. T.J. Park, G.C. Papaefthymiou, A.J. Viescas, A.R. Moodenbaugh, S.S. Wong, Size-dependent magnetic properties of single-crystalline multiferroic $\mathrm{BiFeO}_{3}$ nanoparticles. Nano Lett. 7, 766-772 (2007). https://doi.org/10.1021/n1063039w

93. S. Li, Y.H. Lin, B.P. Zhang, Y. Wang, C.W. Nan, Controlled fabrication of $\mathrm{BiFeO}_{3}$ uniform microcrystals and their magnetic and photocatalytic behaviors. J. Phys. Chem. C 114, 2903-2908 (2010). https://doi.org/10.1021/jp910401u

94. H.D. Espinosa, R.A. Bernal, M. Minary-Jolandan, A review of mechanical and electromechanical properties of piezoelectric nanowires. Adv. Mater. 24, 4656-4675 (2012). https:// doi.org/10.1002/adma.201104810

95. S.K. Singh, H. Ishiwara, K. Maruyama, Room temperature ferroelectric properties of $\mathrm{Mn}$-substituted $\mathrm{BiFeO}_{3}$ thin films deposited on Pt electrodes using chemical solution deposition. Appl. Phys. Lett. 88, 262908-262910 (2006). https:// doi.org/10.1063/1.2218819

96. J.M. Park, S. Nakashima, M. Sohgawa, T. Kanashima, M. Okuyama, Ferroelectric and piezoelectric properties of polycrystalline $\mathrm{BiFeO}_{3}$ thin films prepared by pulsed laser deposition under magnetic field. Jpn. J. Appl. Phys. 51, 09 MD05 (2012). https://doi.org/10.1143/JJAP.51.09MD05
97. G. Mantini, Y.F. Gao, A. D’Amico, C. Falconi, Z.L. Wang, Equilibrium piezoelectric potential distribution in a deformed ZnO nanowire. Nano Res. 2, 624-629 (2009). https://doi. org/10.1007/s12274-009-9063-2

98. M.Y. Choi, D. Choi, M.J. Jin, I. Kim, S.H. Kim, J.Y. Choi et al., Mechanically powered transparent flexible chargegenerating nanodevices with piezoelectric $\mathrm{ZnO}$ nanorods. Adv. Mater. 21, 2185-2189 (2009). https://doi.org/10.1002/ adma.200803605

99. Z.Y. Gao, J. Zhou, Y.D. Gu, P. Fei, Y. Hao, G. Bao, Z.L. Wang, Effects of piezoelectric potential on the transport characteristics of metal- $\mathrm{ZnO}$ nanowire-metal field effect transistor. J. Appl. Phys. 106, 113707-113712 (2009). https://doi. org/10.1063/1.3125449

100. Y.W. Feng, L.L. Ling, Y.X. Wang, Z.M. Xu, F.L. Cao, H.X. Li, Z.F. Bian, Engineering spherical lead zirconate titanate to explore the essence of piezo-catalysis. Nano Energy 40, 481486 (2017). https://doi.org/10.1016/j.nanoen.2017.08.058

101. J. Wu, N. Qin, D.H. Bao, Effective enhancement of piezocatalytic activity of BaTiO3 nanowires under ultrasonic vibration. Nano Energy 45, 44-51 (2018). https://doi.org/10.1016/j. nanoen.2017.12.034

102. M.C. Junger, D. Feit, Sound, Structures, and Their Interaction, 2nd ed. (MIT Press, Cambridge, 1986). http://hdl.handl e.net/1721.1/1740

103. O.E. Gulin, V.I. Klyatskin, Generation of a low-frequency acoustical noise in the layered ocean by the surface sources. Nat. Phys. Sources Underw. Sound (1993). https://doi. org/10.1007/978-94-011-1626-8_19. Accessed 11 Aug 2019

104. J.A. Scrimger, D.J. Evans, W. Yee, Underwater noise due to rain-open ocean measurements. J. Acoust. Soc. Am. 85, 726-731 (1989). https://doi.org/10.1121/1.397598

105. Y.G. Adewuyi, Sonochemistry: environmental science and engineering applications. Ind. Eng. Chem. Res. 40, 46814715 (2001). https://doi.org/10.1021/ie0100961

106. N.H. Ince, G. Tezcanli, R.K. Belen, I.G. Apikyan, Ultrasound as a catalyzer of aqueous reaction systems: the state of the art and environmental applications. Appl. Catal. B 29, 167-176 (2001). https://doi.org/10.1016/s0926-3373(00)00224-1

107. G. Tezcanli-Guyer, N.H. Ince, Individual and combined effects of ultrasound, ozone and UV irradiation: a case study with textile dyes. Ultrasonics 42, 603-609 (2004). https://doi. org/10.1016/j.ultras.2004.01.096

108. Y.F. Li, Z.P. Liu, Particle size, shape and activity for photocatalysis on titania anatase nanoparticles in aqueous surroundings. J. Am. Chem. Soc. 133, 15743-15752 (2011). https:// doi.org/10.1021/ja206153v

109. H.L. You, Z. Wu, Y.M. Jia, X.L. Xu, Y.T. Xia, Z.C. Han, Y. Wang, High-efficiency and mechano-/photo-bi-catalysis of piezoelectric-ZnO@ photoelectric-TiO ${ }_{2}$ core-shell nanofibers for dye decomposition. Chemosphere 183, 528-535 (2017). https://doi.org/10.1016/j.chemosphere.2017.05.130

110. S.C. Rai, K. Wang, J.J. Chen, J.K. Marmon, M. Bhatt et al., Enhanced broad band photodetection through piezo-phototronic effect in $\mathrm{CdSe} / \mathrm{ZnTe}$ core/shell nanowire array. Adv. 
Electron. Mater. 1, 1400050 (2015). https://doi.org/10.1002/ aelm.201570009

111. C. Han, M.Q. Yang, N. Zhang, Y.J. Xu, Enhancing the visible light photocatalytic performance of ternary CdS-(graphenePd) nanocomposites via a facile interfacial mediator and cocatalyst strategy. J. Mater. Chem. A 2, 19156-19166 (2014). https://doi.org/10.1039/c4ta04151h

112. R.E. Brandt, M. Young, H.H. Park, A. Dameron, D. Chua et al., Band offsets of n-type electron-selective contacts on cuprous oxide $\left(\mathrm{Cu}_{2} \mathrm{O}\right)$ for photovoltaics. Appl. Phys. Lett. 105, 263901-263905 (2014). https://doi.org/10.1063/1.49051 80

113. L.J. Meng, A.F. Ma, P.L. Ying, Z.C. Feng, C. Li, Sputtered highly ordered $\mathrm{TiO}_{2}$ nanorod arrays and their applications as the electrode in dye-sensitized solar cells. J. Nanosci. Nanotechnol. 11, 929-934 (2011). https://doi.org/10.1166/ jnn.2011.3084

114. S. Banerjee, S.C. Pillai, P. Falaras, K.E. O'Shea, J.A. Byrne, D.D. Dionysiou, New insights into the mechanism of visible light photocatalysis. J. Phys. Chem. Lett. 5, 2543-2554 (2014). https://doi.org/10.1021/jz501030x

115. C.C. Chen, P.X. Lei, H.W. Ji, W.H. Ma, J.C. Zhao, H. Hidaka, N. Serpone, Photocatalysis by titanium dioxide and polyoxometalate/TiO2 cocatalysts. Intermediates and mechanistic study. Environ. Sci. Technol. 38, 329-337 (2004). https://doi. org/10.1021/es034384f

116. J. Shi, M.B. Starr, H. Xiang, Y. Hara, M.A. Anderson, J.H. Seo, Z.Q. Ma, X.D. Wang, Interface engineering by piezoelectric potential in $\mathrm{ZnO}$-based photoelectrochemical anode. Nano Lett. 11, 5587-5593 (2011). https://doi.org/10.1021/ $\mathrm{nl} 203729 \mathrm{j}$

117. L.W. Lu, M.L. Lv, G. Liu, X.X. Xu, Photocatalytic hydrogen production over solid solutions between $\mathrm{BiFeO}_{3}$ and $\mathrm{SrTiO}_{3}$. Appl. Surf. Sci. 391, 535-541 (2017). https://doi. org/10.1016/j.apsusc.2016.06.160

118. N. Daneshvar, D. Salari, A.R. Khataee, Photocatalytic degradation of azo dye acid red 14 in water on $\mathrm{ZnO}$ as an alternative catalyst to $\mathrm{TiO}_{2}$. J. Photochem. Photobiol., A 162, 317322 (2004). https://doi.org/10.1016/S1010-6030(03)00378-2

119. W.Q. Qian, Z. Wu, Y.M. Jia, Y.T. Hong, X.L. Xu et al., Thermo-electrochemical coupling for room temperature thermocatalysis in pyroelectric $\mathrm{ZnO}$ nanorods. Electrochem. Commun. 81, 124-127 (2017). https://doi.org/10.1016/j.eleco m.2017.06.017

120. I.K. Konstantinou, T.A. Albanis, $\mathrm{TiO}_{2}$-assisted photocatalytic degradation of azo dyes in aqueous solution: kinetic and mechanistic investigations: a review. Appl. Catal. B 49, 1-14 (2004). https://doi.org/10.1016/j.apcatb.2003.11.010

121. C. Galindo, P. Jacques, A. Kalt, Photooxidation of the phenylazonaphthol $\mathrm{AO}_{20}$ on $\mathrm{TIO}_{2}$ : kinetic and mechanistic investigations. Chemosphere 45, 997-1005 (2001). https:// doi.org/10.1016/S0045-6535(01)00118-7

122. J. Bandara, J.A. Mielczarski, J. Kiwi, Photosensitized degradation of azo dyes on $\mathrm{Fe}, \mathrm{Ti}$, and $\mathrm{Al}$ oxides. Mechanism of charge transfer during the degradation. Langmuir 15, 76807687 (1999). https://doi.org/10.1021/la990030j
123. M. Stylidi, D.I. Kondarides, X.E. Verykios, Pathways of solar light-induced photocatalytic degradation of azo dyes in aqueous $\mathrm{TiO}_{2}$ suspensions. Appl. Catal. B 40, 271-286 (2003). https://doi.org/10.1016/S0926-3373(02)00163-7

124. B. Jaffe, R.S. Roth, S. Marzullo, Piezoelectric properties of lead zirconate-lead titanate solid-solution ceramics. J. Appl. Phys. 25, 809-810 (1954). https://doi.org/10.1063/1.1721741

125. D. Damjanovic, Comments on origins of enhanced piezoelectric properties in ferroelectrics. IEEE Trans. Ultrason. Ferroelectr. 56, 1574-1585 (2009). https://doi.org/10.1109/ TUFFC.2009.1222

126. W.Q. Liao, D.W. Zhao, Y.Y. Tang, Y. Zhang, P.F. Li et al., A molecular perovskite solid solution with piezoelectricity stronger than lead zirconate titanate. Science 363, 1206-1210 (2019). https://doi.org/10.1126/science.aav3057

127. T.M. Borman, S.W. Ko, P. Mardilovich, S.E. Trolier-McKinstry, Development of crystallographic texture in chemical solution deposited lead zirconate titanate seed layers. J. Am. Ceram. Soc. 100, 4476-4482 (2017). https://doi.org/10.1111/ jace. 15019

128. M.D. Nguyen, E.P. Houwman, M. Dekkers, G. Rijnders, Strongly enhanced piezoelectric response in lead zirconate titanate films with vertically aligned columnar grains. ACS Appl. Mater. Interfaces. 9, 9849-9861 (2017). https://doi. org/10.1021/acsami.6b16470

129. A. Schatz, D. Pantel, T. Hanemann, Pulsed laser deposition of piezoelectric lead zirconate titanate thin films maintaining a post-CMOS compatible thermal budget. J. Appl. Phys. 122, 114502-114509 (2017). https://doi.org/10.1063/1.5000367

130. T.R. Shrout, S.J. Zhang, Lead-free piezoelectric ceramics: Alternatives for PZT? J. Electroceram. 19, 113-126 (2007). https://doi.org/10.1007/s10832-007-9047-0

131. K. Brajesh, K. Tanwar, M. Abebe, R. Ranjan, Relaxor ferroelectricity and electric-field-driven structural transformation in the giant lead-free piezoelectric $(\mathrm{Ba}, \mathrm{Ca})(\mathrm{Ti}, \mathrm{Zr}) \mathrm{O} 3$. Phys. Rev. B 92, 224112 (2015). https://doi.org/10.1103/PhysR evB.92.224112

132. R.F. Cheng, Z.J. Xu, R.Q. Chu, J.G. Hao, J. Du, G.R. Li, Structure and electrical properties of $\mathrm{Bi}_{1 / 2} \mathrm{Na}_{1 / 2} \mathrm{TiO}_{3}$-based lead-free piezoelectric ceramics. RSC Adv. 5, 41646-41652 (2015). https://doi.org/10.1039/C5RA03997E

133. K.N. Kim, J. Chun, S.A. Chae, C.W. Ahn, I.W. Kim et al., Silk fibroin-based biodegradable piezoelectric composite nanogenerators using lead-free ferroelectric nanoparticles. Nano Energy 14, 87-94 (2015). https://doi.org/10.1016/j. nanoen.2015.01.004

134. H.G. Wei, H. Wang, Y.J. Xia, D.P. Cui, Y.P. Shi et al., An overview of lead-free piezoelectric materials and devices. J. Mater. Chem. C 6, 12446-12467 (2018). https://doi. org/10.1039/C8TC04515A

135. J. Chen, S.K. Oh, H.Y. Zou, S. Shervin, W.J. Wang et al., High-output lead-free flexible piezoelectric generator using single-crystalline GaN thin film. ACS Appl. Mater. Interfaces. 10, 12839-12846 (2018). https://doi.org/10.1021/ acsami.8b01281 
136. A. Akbarzadeh, K. Brajesh, Y. Nahas, N. Kumar, S. Prokhorenko et al., Quantum-fluctuation-stabilized orthorhombic ferroelectric ground state in lead-free piezoelectric ( $\mathrm{Ba}$, Ca)(Zr, Ti)O 3 . Phys. Rev. B 98, 104101 (2018). https://doi. org/10.1103/PhysRevB.98.104101

137. Y.M. Wang, H.J. Wu, X. Qin, K. Yao, S.J. Pennycook, F.E.H. Tay, Outstanding piezoelectric performance in lead-free 0.95(K, Na)(Sb, Nb)O-3-0.05(Bi, Na, K)ZrO3 thick films with oriented nanophase coexistence. Adv. Electron. Mater. 5, 1800691 (2019). https://doi.org/10.1002/aelm.201800691

138. J. Rodel, W. Jo, K.T.P. Seifert, E.M. Anton, T. Granzow, D. Damjanovic, Perspective on the development of lead-free piezoceramics. J. Am. Ceram. Soc. 92, 1153-1177 (2009). https://doi.org/10.1111/j.1551-2916.2009.03061.x

139. D.K. Kushvaha, S.K. Rout, B. Tiwari, Structural, piezoelectric and highdensity energy storage properties of lead-free BNKT-BCZT solid solution. J. Alloys Compd. 782, 270-276 (2019). https://doi.org/10.1016/j.jallcom.2018.12.196

140. C. Moure, O. Pena, Recent advances in perovskites: processing and properties. Prog. Solid State Chem. 43, 123148 (2015). https://doi.org/10.1016/j.progsolidstchem .2015 .09 .001

141. S. Mathews, R. Ramesh, T. Venkatesan, J. Benedetto, Ferroelectric field effect transistor based on epitaxial perovskite heterostructures. Science 276, 238-240 (1997). https://doi. org/10.1126/science.276.5310.238

142. K.J. Choi, M. Biegalski, Y.L. Li, A. Sharan, J. Schubert, R. Uecker et al., Enhancement of ferroelectricity in strained $\mathrm{BaTiO}_{3}$ thin films. Science 306, 1005-1009 (2004). https:// doi.org/10.1126/science. 1103218

143. H. Zheng, J. Wang, S.E. Lofland, Z. Ma, L. Mohaddes-Ardabili et al., Multiferroic $\mathrm{BaTiO}_{3}-\mathrm{CoFe}_{2} \mathrm{O}_{4}$ nanostructures. Science 303, 661-663 (2004). https://doi.org/10.1126/scien ce. 1094207

144. G.H. Jonker, J.H. Vansanten, Properties of barium titanate in connection with its crystal structure. Science 109, 632-635 (1949). https://doi.org/10.1126/science.109.2843.632

145. H.F. Kay, R.G. Rhodes, Barium titanate crystals. Nature 160, 126-127 (1947). https://doi.org/10.1038/160126a0

146. J. Wang, J.B. Neaton, H. Zheng, V. Nagarajan, S.B. Ogale et al., Epitaxial $\mathrm{BiFeO}_{3}$ multiferroic thin film heterostructures. Science 299, 1719-1722 (2003). https://doi. org/10.1126/science.1080615

147. W. Eerenstein, F.D. Morrison, J. Dho, M.G. Blamire, J.F. Scott, N.D. Mathur, Comment on "Epitaxial $\mathrm{BiFeO}_{3}$ multiferroic thin film heterostructures". Science 307, 1203 (2005). https://doi.org/10.1126/science.1105422

148. J. Wang, A. Scholl, H. Zheng, S.B. Ogale, D. Viehland et al., Response to comment on "Epitaxial $\mathrm{BiFeO}_{3}$ multiferroic thin film heterostructures”. Science 307, 1203 (2005). https://doi. org/10.1126/science.1103959

149. R.J. Zeches, M.D. Rossell, J.X. Zhang, A.J. Hatt, Q. He et al., A strain-driven morphotropic phase boundary in $\mathrm{BiFeO}_{3}$. Science 326, 977-980 (2009). https://doi.org/10.1126/scien ce. 1177046
150. J.H. Sun, S.Y. Dong, Y.K. Wang, S.P. Sun, Preparation and photocatalytic property of a novel dumbbell-shaped $\mathrm{ZnO}$ microcrystal photocatalyst. J. Hazard. Mater. 172, 1520-1526 (2009). https://doi.org/10.1016/j.jhazmat.2009.08.022

151. Y.T. Xia, Y.M. Jia, W.Q. Qian, X.L. Xu, Z. Wu et al., Pyroelectrically induced pyro-electro-chemical catalytic activity of $\mathrm{BaTiO}_{3}$ nanofibers under room-temperature cold-hot cycle excitations. Metals 7(4), 122-130 (2017). https://doi. org/10.3390/met7040122

152. S.G. Yuan, Z.B. Yang, C. Xie, F. Yan, J.Y. Dai et al., Ferroelectric-driven performance enhancement of graphene field-effect transistors based on vertical tunneling heterostructures. Adv. Mater. 28, 10048-10054 (2016). https://doi. org/10.1002/adma.201601489

153. M.C. Wong, L. Chen, M.K. Tsang, Y. Zhang, J.H. Hao, Magnetic-induced luminescence from flexible composite laminates by coupling magnetic field to piezophotonic effect. Adv. Mater. 27, 4488-4495 (2015). https://doi.org/10.1002/ adma.201570203

154. J.P. Ma, J. Ren, Y.M. Jia, Z. Wu, L. Chen et al., High efficiency bi-harvesting light/vibration energy using piezoelectric zinc oxide nanorods for dye decomposition. Nano Energy 62, 376-383 (2019). https://doi.org/10.1016/j.nanoe n.2019.05.058

155. A. Khan, M.A. Abbasi, M. Hussain, Z.H. Ibupoto, J. Wissting, O. Nur, M. Willander, Piezoelectric nanogenerator based on zinc oxide nanorods grown on textile cotton fabric. Appl. Phys. Lett. 101, 193506-193509 (2012). https://doi. org/10.1063/1.4766921

156. A. Mahmud, A.A. Khan, P. Voss, T. Das, E. Abdel-Rahman, D. Ban, A high performance and consolidated piezoelectric energy harvester based on 1D/2D hybrid zinc oxide nanostructures. Adv. Mater. Interfaces 5, 1801167 (2018). https ://doi.org/10.1002/admi.201801167

157. Z.W. Wang, Z.M. Zhang, W. Liu, Z.L. Wang, Investigating fold structures of $2 \mathrm{D}$ materials by quantitative transmission electron microscopy. Micron 95, 16-22 (2017). https://doi. org/10.1016/j.micron.2017.01.001

158. K.A.N. Duerloo, M.T. Ong, E.J. Reed, Intrinsic piezoelectricity in two-dimensional materials. J. Phys. Chem. Lett. 3, 2871-2876 (2012). https://doi.org/10.1021/jz3012436

159. K.J. Huang, L. Wang, Y.J. Liu, H.B. Wang, Y.M. Liu, L.L. Wang, Synthesis of polyaniline/2-dimensional graphene analog $\mathrm{MoS}_{2}$ composites for high-performance supercapacitor. Electrochim. Acta 109, 587-594 (2013). https://doi. org/10.1016/j.electacta.2013.07.168

160. J. Mann, Q. Ma, P.M. Odenthal, M. Isarraraz, D. Le et al., 2-Dimensional transition metal dichalcogenides with tunable direct band gaps: $\mathrm{MoS}_{(1-\mathrm{x})} \mathrm{Se}_{2 \mathrm{x}}$ monolayers. Adv. Mater. 26, 1399-1404 (2014). https://doi.org/10.1002/adma.201304389

161. C.N.R. Rao, U. Maitra, U.V. Waghmare, Extraordinary attributes of 2-dimensional $\mathrm{MoS}_{2}$ nanosheets. Chem. Phys. Lett. 609, 172-183 (2014). https://doi.org/10.1016/j.cplet t.2014.06.003

162. S.L. Shi, Z.X. Sun, Y.H. Hu, Synthesis, stabilization and applications of 2-dimensional $1 \mathrm{~T}$ metallic $\mathrm{MoS}_{2}$. J. Mater. 
Chem. A 6, 23932-23977 (2018). https://doi.org/10.1039/ C8TA08152B

163. K. Nowakowski, R. van Bremen, H.J.W. Zandvliet, P. Bampoulis, Control of the metal/ $\mathrm{WS}_{2}$ contact properties using 2-dimensional buffer layers. Nanoscale 11, 5548-5556 (2019). https://doi.org/10.1039/C9NR00574A

164. X. Yu, C.G. Pei, W.S. Chen, L.G. Feng, 2 dimensional WS tailored nitrogen-doped carbon nanofiber as a highly pseudocapacitive anode material for lithium-ion battery. Electrochim. Acta 272, 119-126 (2018). https://doi.org/10.1016/j. electacta.2018.03.201

165. S.J. Xu, Z.Y. Lei, P.Y. Wu, Facile preparation of 3D $\mathrm{MoS}_{2} /$ $\mathrm{MoSe}_{2}$ nanosheet-graphene networks as efficient electrocatalysts for the hydrogen evolution reaction. J. Mater. Chem. A 3, 16337-16347 (2015). https://doi.org/10.1039/C5TA0 $2637 \mathrm{G}$

166. X.S. Chen, G.B. Liu, W. Zheng, W. Feng, W.W. Cao, W.P. $\mathrm{Hu}$, P.A. $\mathrm{Hu}$, Vertical 2D $\mathrm{MoO}_{2} / \mathrm{MoSe}_{2}$ core-shell nanosheet arrays as high-performance electrocatalysts for hydrogen evolution reaction. Adv. Funct. Mater. 26, 85378544 (2016). https://doi.org/10.1002/adfm.201603674

167. X.S. Geng, Y.Q. Yu, X.L. Zhou, C.D. Wang, K.W. Xu et al., Design and construction of ultra-thin $\mathrm{MoSe}_{2}$ nanosheetbased heterojunction for high-speed and low-noise photodetection. Nano Res. 9, 2641-2651 (2016). https://doi. org/10.1007/s12274-016-1151-5

168. H. Peng, C.D. Wei, K. Wang, T.Y. Meng, G.F. Ma, Z.Q. Lei, X. Gong, $\mathrm{Ni}_{0.85} \mathrm{Se} @ \mathrm{MoSe}_{2}$ nanosheet arrays as the electrode for high-performance supercapacitors. ACS Appl. Mater. Interfaces. 9, 17068-17076 (2017). https:// doi.org/10.1021/acsami.7b02776

169. L.Z. He, T.Q. Nie, X.J. Xia, T. Liu, Y.Y. Huang, X.J. Wang, T.F. Chen, Designing bioinspired 2D $\mathrm{MoSe}_{2}$ nanosheet for efficient photothermal-triggered cancer immunotherapy with reprogramming tumor-associated macrophages. Adv. Funct. Mater. 29, 1901240 (2019). https://doi.org/10.1002/ adfm.201901240

170. V. Cauda, S. Stassi, K. Bejtka, G. Canayese, Nanoconfinement: an effective way to enhance PVDF piezoelectric properties. ACS Appl. Mater. Interfaces. 5, 6430-6437 (2013). https://doi.org/10.1021/am4016878

171. Z.Y. Pi, J.W. Zhang, C.Y. Wen, Z.B. Zhang, D.P. $\mathrm{Wu}$, Flexible piezoelectric nanogenerator made of poly(vinylidenefluoride-co-trifluoroethylene) (PVDFTrFE) thin film. Nano Energy 7, 33-41 (2014). https://doi. org/10.1016/j.nanoen.2014.04.016

172. N.R. Alluri, B. Saravanakumar, S.J. Kim, Flexible, hybrid piezoelectric film $\left(\mathrm{BaTi}_{(1-\mathrm{x})} \mathrm{Zr}_{\mathrm{x}} \mathrm{O}_{3}\right) / \mathrm{PVDF}$ nanogenerator as a self-powered fluid velocity sensor. ACS Appl. Mater. Interfaces. 7, 9831-9840 (2015). https://doi.org/10.1021/acsam i. 5 b01760

173. S.K. Karan, D. Mandal, B.B. Khatua, Self-powered flexible Fe-doped RGO/PVDF nanocomposite: an excellent material for a piezoelectric energy harvester. Nanoscale 7, 1065510666 (2015). https://doi.org/10.1039/c5nr02067k
174. G. Tian, W.L. Deng, Y.Y. Gao, D. Xiong, C. Yan et al., Rich lamellar crystal baklava-structured PZT/PVDF piezoelectric sensor toward individual table tennis training. Nano Energy 59, 574-581 (2019). https://doi.org/10.1016/j.nanoe n.2019.03.013

175. Q.Q. Li, W.Y. Ke, T.X. Chang, Z.J. Hu, A molecular ferroelectrics induced electroactive $\beta$-phase in solution processed PVDF films for flexible piezoelectric sensors. J. Mater. Chem. C 7, 1532-1543 (2019). https://doi.org/10.1039/ C8TC05090B

176. L. Knott, A.J. Bailey, Collagen cross-links in mineralizing tissues: a review of their chemistry, function, and clinical relevance. Bone 22, 181-187 (1998). https://doi.org/10.1016/ s8756-3282(97)00279-2

177. C.C. Silva, C.G.A. Lima, A.G. Pinheiro, J.C. Goes, S.D. Figueiro, A.S.B. Sombra, On the piezoelectricity of collagen-chitosan film. Phys. Chem. Chem. Phys. 3, 4154-4157 (2001). https://doi.org/10.1039/b100189m

178. S.K. Ghosh, D. Mandal, Sustainable energy generation from piezoelectric biomaterial for noninvasive physiological signal monitoring. ACS Sustain. Chem. Eng 5, 8836-8843 (2017). https://doi.org/10.1021/acssuschemeng.7b01617

179. P.M. Jones, D.E. Gallardo, S. Dunn, Photochemical investigation of a polarizable semiconductor, lead-zirconate-titanate. Chem. Mater. 20, 5901-5906 (2008). https://doi.org/10.1021/ cm8015116

180. X.Y. Xue, P. Deng, S. Yuan, Y.X. Nie, B. He, L.L. Xing, Y. Zhang, CuO/PVDF nanocomposite anode for a piezo-driven self-charging lithium battery. Energy Environ. Sci. 6, 26152620 (2013). https://doi.org/10.1039/C3EE41648H

181. Y. Zhang, Y.J. Zhang, X.Y. Xue, C.X. Cui, B. He et al., PVDF-PZT nanocomposite film based self-charging power cell. Nanotechnology 25, 2615-2620 (2014). https://doi. org/10.1088/0957-4484/25/10/105401

182. Z.Y. Wang, J. Hu, M.F. Yu, One-dimensional ferroelectric monodomain formation in single crystalline $\mathrm{BaTiO}_{3}$ nanowire. Appl. Phys. Lett. 89, 263119-263121 (2006). https://doi. org/10.1063/1.2425047

183. D. Yu, M.L. Zhao, C.L. Wang, L.H. Wang, W.B. Su et al., Enhanced piezoelectricity in plastically deformed nearly amorphous $\mathrm{Bi}_{12} \mathrm{TiO}_{20}-\mathrm{BaTiO}_{3}$ nanocomposites. Appl. Phys. Lett. 109, 032904-032908 (2016). https://doi. org/10.1063/1.4959248

184. X.L. Xu, Y.M. Jia, L.B. Xiao, Z. Wu, Strong vibrationcatalysis of $\mathrm{ZnO}$ nanorods for dye wastewater decolorization via piezo-electro-chemical coupling. Chemosphere 193, 1143-1148 (2018). https://doi.org/10.1016/j.chemospher e.2017.11.116

185. S.M. Guralnick, Contexts of faraday electrochemical laws. Isis 70, 59-75 (1979). https://doi.org/10.2307/230878

186. P. Soroushian, R.U.D. Nassar, A.M. Balachandra, Piezodriven self-healing by electrochemical phenomena. J. Intell. Mater. Syst. Struct. 24, 441-453 (2013). https://doi. org/10.1177/1045389X12461081

187. C. Ribeiro, V. Sencadas, D.M. Correia, S. Lanceros-Mendez, Piezoelectric polymers as biomaterials for tissue engineering 
applications. Colloid Surface B 136, 46-55 (2015). https:// doi.org/10.1016/j.colsurfb.2015.08.043

188. M.H. Shamos, L.S. Lavine, Piezoelectricity as a fundamental property of biological tissues. Nature 213, 267-269 (1967). https://doi.org/10.1038/213267a0

189. H. Athenstaedt, Pyroelectric and piezoelectric behaviour of human dental hard tissues. Arch. Oral Biol. 16, 495-501 (1971). https://doi.org/10.1016/0003-9969(71)90194-4

190. J. Hofkens, M.B.J. Roeffaers, Electrochemistry: photocatalysts in close-up. Nature 530, 36-37 (2016). https://doi. org/10.1038/530036a

191. J.W. Richards, The continuous advance of electrochemistry. Science 19, 0905-0912 (1904). https://doi.org/10.1126/scien ce.19.494.905

192. V.M. Fridkin, Photoferroelectrics (Springer, Berlin, 1979). https://doi.org/10.1007/978-3-642-81351-1

193. A.J. Bard, A.B. Bocarsly, F.R.F. Fan, E.G. Walton, M.S. Wrighton, The concept of Fermi level pinning at semiconductor-liquid junctions-consequences for energy-conversion efficiency and selection of useful solution redox couples in solar devices. J. Am. Chem. Soc. 102, 3671-3677 (1980). https://doi.org/10.1021/ja00531a001

194. S. Dunn, D. Tiwari, P.M. Jones, D.E. Gallardo, Insights into the relationship between inherent materials properties of PZT and photochemistry for the development of nanostructured. J. Mater. Chem. 17, 4460-4463 (2007). https:// doi.org/10.1039/b710894j

195. W.A. Smith, I.D. Sharp, N.C. Strandwitz, J. Bisquert, Interfacial band-edge energetics for solar fuels production. Energy Environ. Sci. 8, 2851-2862 (2015). https://doi. org/10.1039/C5EE01822F

196. P. Salvador, Semiconductors' photoelectrochemistry: a kinetic and thermodynamic analysis in the light of equilibrium and nonequilibrium models. J. Phys. Chem. B 105, 6128-6141 (2001). https://doi.org/10.1021/jp0033869

197. M.S. Wrighton, A.B. Ellis, P.T. Wolczanski, D.L. Morse, H.B. Abrahamson, D.S. Ginley, Strontium titanate photoelectrodes. Efficient photoassisted electrolysis of water at zero applied potential. J. Am. Chem. Soc. 98, 2774-2779 (1976). https://doi.org/10.1002/chin.197631008

198. L. Green Jr., Energy needs versus environmental pollution: a reconciliation? Science 156, 1448-1450 (1967). https:// doi.org/10.1126/science.156.3781.1448

199. D. Berg, R.G. Hickman, A. Kovats, Energy without pollution. Science 170, 17-18 (1970). https://doi.org/10.1126/ science. 170.3953 .17

200. J.A. Turner, Sustainable hydrogen production. Science $\mathbf{3 0 5}$, 972-974 (2004). https://doi.org/10.1126/science.1103197

201. S. Park, W.J. Chang, C.W. Lee, S. Park, H.Y. Ahn, K.T. Nam, Photocatalytic hydrogen generation from hydriodic acid using methylammonium lead iodide in dynamic equilibrium with aqueous solution. Nat. Energy 2, 16185 (2017). https://doi.org/10.1038/nenergy.2016.185

202. P. Zhang, Y.J. Guo, J.B. Chen, Y.R. Zhao, J. Chang, H. Junge, M. Beller, Y. Li, Streamlined hydrogen production from biomass. Nat. Catal. 1, 332-338 (2018). https://doi. org/10.1038/s41929-018-0062-0

203. A. Sartbaeva, V.L. Kuznetsov, S.A. Wells, P.P. Edwards, Hydrogen nexus in a sustainable energy future. Energy Environ. Sci. 1, 79-85 (2008). https://doi.org/10.1039/ b810104n

204. L. Lin, W. Zhou, R. Gao, S. Yao, X. Zhang et al., Low-temperature hydrogen production from water and methanol using Pt/alpha-MoC catalysts. Nature 544, 80-83 (2017). https:// doi.org/10.1038/nature21672

205. Q. Hu, D.Y. Kim, W. Yang, L. Yang, Y. Meng, L. Zhang, H.K. Mao, $\mathrm{FeO}_{2}$ and $\mathrm{FeOOH}$ under deep lower-mantle conditions and Earth's oxygen-hydrogen cycles. Nature 534, 241-244 (2016). https://doi.org/10.1038/nature18018

206. H. Lachheb, E. Puzenat, A. Houas, M. Ksibi, E. Elaloui, C. Guillard, J.M. Herrmann, Photocatalytic degradation of various types of dyes (Alizarin S, Crocein Orange G, Methyl Red, Congo Red, Methylene Blue) in water by UV-irradiated titania. Appl. Catal. B 39, 75-90 (2002). https://doi.org/10.1016/ S0926-3373(02)00078-4

207. P.D. Petrolekas, G. Maggenakis, Kinetic studies of the liquid-phase adsorption of a reactive dye onto activated lignite. Ind. Eng. Chem. Res. 46, 1326-1332 (2007). https://doi. org/10.1021/ie061222u

208. Q. Li, Q.Y. Yue, Y. Su, B.Y. Gao, J. Li, Two-step kinetic study on the adsorption and desorption of reactive dyes at cationic polymer/bentonite. J. Hazard. Mater. 165, 1170-1178 (2009). https://doi.org/10.1016/j.jhazmat.2008.10.110

209. J. Li, J. Cai, L. Zhong, H. Wang, H. Cheng, Q. Ma, Adsorption of reactive dyes onto chitosan/montmorillonite intercalated composite: multi-response optimization, kinetic, isotherm and thermodynamic study. Water Sci. Technol. 77, 2598-2612 (2018). https://doi.org/10.2166/wst.2018.221

210. H.M. Khan, M. Anwar, G. Ahmad, Effect of temperature and light on the response of an aqueous coumarin dosimeter. J. Radioanal. Nucl. Chem. Lett. 200, 521-527 (1995). https:// doi.org/10.1007/BF02162501

211. F. Gao, X.Y. Chen, K.B. Yin, S. Dong, Z.F. Ren et al., Visible-light photocatalytic properties of weak magnetic $\mathrm{BiFeO}_{3}$ nanoparticles. Adv. Mater. 19, 2889-2892 (2007). https://doi. org/10.1002/adma.200602377

212. A.B. Prevot, C. Baiocchi, M.C. Brussino, E. Pramauro, P. Savarino et al., Photocatalytic degradation of acid blue 80 in aqueous solutions containing $\mathrm{TiO}_{2}$ suspensions. Environ. Sci. Technol. 35, 971-976 (2001). https://doi.org/10.1021/es000 $162 \mathrm{v}$

213. A. Houas, H. Lachheb, M. Ksibi, E. Elaloui, C. Guillard, J.M. Herrmann, Photocatalytic degradation pathway of methylene blue in water. Appl. Catal. B 31, 145-157 (2001). https://doi. org/10.1016/S0926-3373(00)00276-9

214. S.S. Patil, V.M. Shinde, Biodegradation studies of aniline and nitrobenzene in aniline plant wastewater by gas chromatography. Environ. Sci. Technol. 22, 1160-1165 (1988). https:// doi.org/10.1021/es00175a005

215. I. Arslan, I.A. Balcioglu, Degradation of commercial reactive dyestuffs by heterogenous and homogenous advanced 
oxidation processes: a comparative study. Dyes Pigments 43, 95-108 (1999). https://doi.org/10.1016/S0143 -7208(99)00048-0

216. A.T. Moore, A. Vira, S. Fogel, Biodegradation of trans1,2-dichloroethylene by methane-utilizing bacteria in an aquifer simulator. Environ. Sci. Technol. 23, 403-406 (1989). https://doi.org/10.1021/es00181a003

217. E. Borgarello, J. Kiwi, E. Pelizzetti, M. Visca, M. Gratzel, Photochemical cleavage of water by photocatalysis. Nature 289, 158-160 (1981). https://doi.org/10.1038/289158a0

218. R. Asahi, T. Morikawa, T. Ohwaki, K. Aoki, Y. Taga, Visible-light photocatalysis in nitrogen-doped titanium oxides. Science 293, 269-271 (2001). https://doi.org/10.1126/scien ce. 1061051

219. Y. Peng, K.K. Wang, T. Liu, J. Xu, B. Xu, Synthesis of onedimensional $\mathrm{Bi}_{2} \mathrm{O}_{3}-\mathrm{Bi}_{2} \mathrm{O}_{2.33}$ heterojunctions with high interface quality for enhanced visible light photocatalysis in degradation of high-concentration phenol and MO dyes. Appl. Catal. B 203, 946-954 (2017). https://doi.org/10.1016/j.apcat b.2016.11.011

220. R.S. Yang, Y. Qin, L.M. Dai, Z.L. Wang, Power generation with laterally packaged piezoelectric fine wires. Nat. Nanotechnol. 4, 34-39 (2009). https://doi.org/10.1038/nnano .2008 .314

221. Y.F. Hu, Y. Zhang, C. Xu, L. Lin, R.L. Snyder, Z.L. Wang, Self-powered system with wireless data transmission. Nano Lett. 11, 2572-2577 (2011). https://doi.org/10.1021/nl201 $505 \mathrm{c}$

222. C.E. Chang, V.H. Tran, J.B. Wang, Y.K. Fuh, L.W. Lin, Direct-write piezoelectric polymeric nanogenerator with high energy conversion efficiency. Nano Lett. 10, 726-731 (2010). https://doi.org/10.1021/n19040719

223. C.K. Chan, H.L. Peng, G. Liu, K. McIlwrath, X.F. Zhang, R.A. Huggins, Y. Cui, High-performance lithium battery anodes using silicon nanowires. Nat. Nanotechnol. 3, 31-35 (2008). https://doi.org/10.1038/nnano.2007.411

224. Y. Idota, T. Kubota, A. Matsufuji, Y. Maekawa, T. Miyasaka, Tin-based amorphous oxide: a high-capacity lithiumion-storage material. Science 276, 1395-1397 (1997). https ://doi.org/10.1126/science.276.5317.1395

225. J.M. Tarascon, M. Armand, Issues and challenges facing rechargeable lithium batteries. Nature 414, 359-367 (2001). https://doi.org/10.1038/35104644

226. P. Poizot, S. Laruelle, S. Grugeon, L. Dupont, J.M. Tarascon, Nano-sized transition-metaloxides as negative-electrode materials for lithium-ion batteries. Nature 407, 496-499 (2000). https://doi.org/10.1038/35035045
227. P.G. Bruce, B. Scrosati, J.M. Tarascon, Nanomaterials for rechargeable lithium batteries. Angew. Chem. Int. Ed. 47, 2930-2946 (2008). https://doi.org/10.1002/anie.200702505

228. G. Armstrong, A.R. Armstrong, P.G. Bruce, P. Reale, B. Scrosati, $\mathrm{TiO}_{2}(\mathrm{~B})$ nanowires as an improved anode material for lithium-ion batteries containing $\mathrm{LiFePO}_{4}$ or $\mathrm{LiNi}_{0.5} \mathrm{Mn}_{1.5} \mathrm{O}_{4}$ cathodes and a polymer electrolyte. Adv. Mater. 18, 25972600 (2006). https://doi.org/10.1002/adma.200601232

229. Y.C. Mao, P. Zhao, G. McConohy, H. Yang, Y.X. Tong, X.D. Wang, Sponge-like piezoelectric polymer films for scalable and integratable nanogenerators and self-powered electronic systems. Adv. Energy Mater. 4, 1301624 (2014). https://doi. org/10.1002/aenm.201301624

230. P. Simon, Y. Gogotsi, B. Dunn, Where do batteries end and supercapacitors begin? Science 343, 1210-1211 (2014). https ://doi.org/10.1126/science.1249625

231. P. Huang, C. Lethien, S. Pinaud, K. Brousse, R. Laloo et al., On-chip and freestanding elastic carbon films for microsupercapacitors. Science 351, 691-695 (2016). https://doi. org/10.1126/science.aad3345

232. T.F. Qin, S.L. Peng, J.X. Hao, Y.X. Wen, Z.L. Wang et al., Flexible and wearable all-solid-state supercapacitors with ultrahigh energy density based on a carbon fiber fabric electrode. Adv. Energy Mater. 7, 1700409 (2017). https://doi. org/10.1002/aenm.201700409

233. C.Y. Cao, Y.H. Zhou, S. Ubnoske, J.F. Zang, Y.T. Cao et al., Highly stretchable supercapacitors via crumpled vertically aligned carbon nanotube forests. Adv. Energy Mater. 9, 1900618 (2019). https://doi.org/10.1002/aenm.201900618

234. P. Cordier, F. Tournilhac, C. Soulie-Ziakovic, L. Leibler, Self-healing and thermoreversible rubber from supramolecular assembly. Nature 451, 977-980 (2008). https://doi. org/10.1038/nature06669

235. L. Zhang, J.B. Bailey, R.H. Subramanian, A. Groisman, F.A. Tezcan, Hyperexpandable, self-healing macromolecular crystals with integrated polymer networks. Nature 557, 86-91 (2018). https://doi.org/10.1038/s41586-018-0057-7

236. E. Acome, S.K. Mitchell, T.G. Morrissey, M.B. Emmett, C. Benjamin et al., Hydraulically amplified self-healing electrostatic actuators with muscle-like performance. Science 359, 61-65 (2018). https://doi.org/10.1126/science.aao6139

237. B.S. Sumerlin, Next-generation self-healing materials. Science 362, 150-151 (2018). https://doi.org/10.1126/scien ce.aau6453

238. D.M. Goldenberg, H.J. Hansen, Electric enhancement of bone healing. Science 175, 1118-1120 (1972). https://doi. org/10.1126/science. 175.4026 .1118 